\title{
Insecticide resistance and resistance mechanisms in bed bugs, Cimex spp. (Hemiptera: Cimicidae)
}

\author{
Kai Dang ${ }^{1}$, Stephen L. Doggett ${ }^{2}$, G. Veera Singham³ and Chow-Yang Lee ${ }^{1 *}$
}

\begin{abstract}
The worldwide resurgence of bed bugs [both Cimex lectularius L. and Cimex hemipterus (F.)] over the past two decades is believed in large part to be due to the development of insecticide resistance. The transcriptomic and genomic studies since 2010, as well as morphological, biochemical and behavioral studies, have helped insecticide resistance research on bed bugs. Multiple resistance mechanisms, including penetration resistance through thickening or remodelling of the cuticle, metabolic resistance by increased activities of detoxification enzymes (e.g. cytochrome P450 monooxygenases and esterases), and knockdown resistance by kdr mutations, have been experimentally identified as conferring insecticide resistance in bed bugs. Other candidate resistance mechanisms, including behavioral resistance, some types of physiological resistance (e.g. increasing activities of esterases by point mutations, glutathione S-transferase, target site insensitivity including altered AChEs, GABA receptor insensitivity and altered nAChRs), symbiont-mediated resistance and other potential, yet undiscovered mechanisms may exist. This article reviews recent studies of resistance mechanisms and the genes governing insecticide resistance, potential candidate resistance mechanisms, and methods of monitoring insecticide resistance in bed bugs. This article provides an insight into the knowledge essential for the development of both insecticide resistance management (IRM) and integrated pest management (IPM) strategies for successful bed bug management.
\end{abstract}

Keywords: Bed bug, Cimex lectularius, Cimex hemipterus, Insecticide resistance, Mechanism, Molecular basis, Resistance monitoring

\section{Background}

Chemical control remains the most important and widely used strategy against most insect pests around the world. However, studies have shown that multiple resistance mechanisms in insects confer resistance to a range of insecticide classes [1-7]. Recently, researchers have used new techniques and advances in genomic research (e.g. transcriptomic sequencing and whole-genome sequencing) to identify the mechanisms that govern insecticide resistance in bed bugs (Table 1). Previous bioassay, genetic, morphological, biochemical and behavioral studies, also have made significant progress in the understanding of bed bug insecticide resistance mechanisms such as penetration resistance, metabolic resistance and knockdown resistance.

\footnotetext{
* Correspondence: chowyang@usm.my; chowyang@mac.com

'Urban Entomology Laboratory, Vector Control Research Unit, School of

Biological Sciences, Universiti Sains Malaysia, 11800 Penang, Malaysia

Full list of author information is available at the end of the article
}

This review focuses on resistance to different insecticide classes and the underlying mechanisms in bed bugs. Other potential candidate resistance mechanisms in bed bugs are also reviewed.

\section{Bed bugs}

The common bed bug Cimex lectularius L. and the tropical bed bug C. hemipterus (F.) (Hemiptera: Cimicidae) are two cryptic and nocturnal ectoparasites that have adapted to feed on human blood $[8,9]$. Cimex lectularius is most prevalent in temperate regions, whereas $C$. hemipterus is found mainly in tropical and subtropical regions $[8,10]$. However, there is overlap in the regions where both species can be found, such as Thailand [11, 12], Africa [13, 14], Australia [15-17] and more recently in Florida, USA [18]. Approximately $70 \%$ of people who are bitten by C. lectularius experience allergic reactions ranging from mild to severe, including itchiness, erythematous rash, or urticaria 
Table 1 Progress in morphological, behavioral, biochemical, bioassay, and genetic characterization of insecticide resistance mechanisms in bed bugs (Cimex spp.)

\begin{tabular}{|c|c|c|c|c|c|c|}
\hline Year & Characterization & Targets & Methods & Accession number ${ }^{a}$ & Resistance mechanisms & Reference \\
\hline \multicolumn{7}{|c|}{ C. lectularius } \\
\hline 2009 & Behavioral & - & Bioassay: SC & - & Behavioral resistance & [89] \\
\hline $\begin{array}{l}\text { 2009; } \\
2015 ; 2016\end{array}$ & Bioassay & $\begin{array}{l}\text { P450s; } \\
\text { esterases }\end{array}$ & $\begin{array}{l}\text { Bioassay }(\mathrm{SC} / \mathrm{T}) \\
\text { plus synergists } \\
\text { (e.g. } \mathrm{PBO}, \mathrm{PBH}, \mathrm{EN} 16 / 5-1)\end{array}$ & & $\begin{array}{l}\text { Metabolic resistance: P450s, } \\
\text { esterases }\end{array}$ & $\begin{array}{l}{[127,128,} \\
136]\end{array}$ \\
\hline $\begin{array}{l}2008 ; \\
2011 ; \\
2016\end{array}$ & Biochemical & $\begin{array}{l}\text { P450s; GSTs; } \\
\text { esterases }\end{array}$ & Biochemical assays & - & $\begin{array}{l}\text { Metabolic resistance: P450s, } \\
\text { GSTs and esterases }\end{array}$ & $\begin{array}{l}{[64,113,} \\
156]\end{array}$ \\
\hline 2016 & Morphological & Cuticle & SEM & - & Penetration resistance & [95] \\
\hline 2008 & Genetic & VGSC & $\begin{array}{l}\text { Cloning and sequencing } \\
\text { (RACE) }\end{array}$ & FJ031996; FJ031997 & Target site insensitivity: $k d r$ & [156] \\
\hline 2011 & Genetic & Transcriptome & $\begin{array}{l}454 \text { pyrosequencing } \\
\text { (Roche } 454 \text { GS FLX } \\
\text { Titanium platform) }\end{array}$ & SRA024509 & Metabolic resistance: P450s & [104] \\
\hline 2011 & Genetic & Transcriptome & $\begin{array}{l}\text { High-throughput } \\
\text { sequencing } \\
\text { (Roche } 454 \\
\text { Titanium platform) }\end{array}$ & SRA043735 & $\begin{array}{l}\text { Metabolic resistance: P450s, } \\
\text { GSTs and esterases; Target site } \\
\text { insensitivity: } k d r\end{array}$ & [113] \\
\hline 2012 & Genetic & RNA-seq & $\begin{array}{l}\text { Illumina high-throughput } \\
\text { sequencing (GAll platform) }\end{array}$ & GSE31823 & $\begin{array}{l}\text { Metabolic resistance: P450s, } \\
\text { GSTs, ABC-transporters, ester- } \\
\text { ases; Penetration resistance; } \\
\text { Target site insensitivity: } k d r\end{array}$ & [92] \\
\hline 2012 & Genetic & CICPR & $\begin{array}{l}\text { Cloning and sequencing } \\
\text { (RACE) }\end{array}$ & JQ178363 & Metabolic resistance: P450s & [122] \\
\hline 2012 & Genetic & $\begin{array}{l}\text { CIAChE1; } \\
\text { CIAChE2; } \\
\text { CISChE }\end{array}$ & $\begin{array}{l}\text { Cloning and sequencing } \\
\text { (RACE) }\end{array}$ & $\begin{array}{l}\text { JN563927; } \\
\text { GU597837;GU597838;GU597839 }\end{array}$ & - & [168] \\
\hline 2013 & Genetic & CPRR & Data from NCBI & - & Penetration resistance & [94] \\
\hline 2013 & Genetic & Transcriptome & $\begin{array}{l}454 \text { pyrosequencing } \\
\text { (Roche } 454 \text { GS FLX } \\
\text { Titanium platform) }\end{array}$ & - & $\begin{array}{l}\text { Metabolic resistance: P450s, } \\
\text { esterases, ABC-transporters; } \\
\text { Penetration resistance; Target } \\
\text { site insensitivity: } k d r\end{array}$ & [90] \\
\hline 2016 & Genetic & Genome & $\begin{array}{l}\text { Illumina high-throughput } \\
\text { sequencing } \\
\text { (Illumina HiSeq2000s) }\end{array}$ & SRS580017 & $\begin{array}{l}\text { Metabolic resistance: P450s, } \\
\text { esterases, ABC-transporters, } \\
\text { GSTs; Penetration resistance; } \\
\text { Target site insensitivity: } k d r\end{array}$ & [197] \\
\hline 2016 & Genetic & $\begin{array}{l}\text { Genome; } \\
\text { RNA-seq }\end{array}$ & $\begin{array}{l}\text { Illumina high-throughput } \\
\text { sequencing }\end{array}$ & SRS749263; SRR1790655 & $\begin{array}{l}\text { Target site insensitivity: } k d r, \\
\text { putative GABA receptors; } \\
\text { Metabolic resistance:P450s, } \\
\text { GSTs, esterases }\end{array}$ & [93] \\
\hline \multicolumn{7}{|c|}{ C. hemipterus } \\
\hline 2011 & Bioassay & P450s & Bioassay (SC) plus PBO & - & Metabolic resistance: P450s & [129] \\
\hline 2007 & Biochemical & $\begin{array}{l}\text { P450s; GSTs; } \\
\text { Esterases }\end{array}$ & Biochemical assays & - & $\begin{array}{l}\text { Metabolic resistance: GSTs, } \\
\text { and esterases }\end{array}$ & [56] \\
\hline 2015 & Genetic & VGSC(Part) & Sanger sequencing & - & Target site insensitivity: $k d r$ & [17] \\
\hline
\end{tabular}

Abbreviations: EN16/5-1 6-[2-(2-butoxyethoxy) ethoxymethyl]-5-propyl-2, 3-dihydrobenzofuranby [127], PBH 3-Phenoxybenzyl hexanoate, a surrogate substrate for carboxylesterases and oxidases [136], SC surface contact, $T$ topical application, SEM scanning electron microscope, CICPR Cimex lectularius NADPH-cytochrome P450 reductase [122], CPRR cuticular protein with the rebers and riddiford consensus [94], CIAChE1, CIAChE2 two C. lectularius acetylcholinesterases, CISChE C. lectularius salivary gland-specific cholinesterase-like protein [168], RACE rapid amplification of CDNA ends, ABC-transporters ATP-binding cassette (ABC) transporters ${ }^{a}$ Data from GenBank at NCBI (National Center for Biotechnology Information)

[19-22], although fewer people react on initial exposure. For $C$. hemipterus, the percentage of the population that produces a clinical reaction is unknown, with described skin reactions including the formation of papular lesions with associated itch, which resolve around $1 \mathrm{~h}$ after the bite [23]. In addition, scratching may lead to secondary bacterial infections such as cellulitis, impetigo, ecthyma, and lymphangites $[10,21]$. Only a small number of people may 
have no visible effect after repeated bed bug bites, and this lack of response may depend on previous exposure, although some people never develop a reaction despite multiple bites over time [24, 25]. Controlled laboratory studies have shown that bed bugs are capable of transmitting Trypanosoma cruzi (the etiological agent of Chagas disease) and Bartonella quintana (the etiological agent of trench fever) [26, 27]. However, to date there is no evidence to support the premise that bed bugs transmit these or other pathogens to humans in their natural habitat $[10,19,21,27]$.

Bed bugs have a long association with humans and were widespread and common world wide before World War II [9]. Soon thereafter, modern insecticides such as the organochlorine dichloro-diphenyl trichloroethane (DDT) were discovered and became a fast and an inexpensive method to control insect pests, including bed bugs. As a consequence, bed bugs gradually became uncommon, especially in economically developed countries, in the latter half of the twentieth century $[9,21,28]$. Unfortunately, over the last 15-20 years bed bugs have made a resurgence around the world with multiple reports of their comeback in the published literature, and popular main stream and social media (Table 2). Recent bed bug infestations have been reported from hotels, motels, homes and apartment complexes, cinemas, offices, retail outlets, public transportation, commercial flights, schools, and healthcare facilities (including neonatal units) [21, 28, 29]. Several factors, such as an increase in local and international travel, frequent exchange of second-hand items, poor pest management and insecticide resistance, have been suspected to be amongst the factors contributing to the global resurgence of bed bugs. Nevertheless, insecticide resistance has largely been incriminated as the main reason for the comeback of these nuisance pests [30].

\section{Insecticide resistance in bed bugs}

Insecticide resistance is defined by the Insecticide Resistance Action Committee (IRAC) [31] as 'a heritable change in the sensitivity of a pest population that is reflected in the repeated failure of a product to achieve the expected level of control when used according to the label recommendation for that pest species'. In other words, it is an inherited ability of a population to survive a lethal concentration of an insecticide product that would normally kill a wild population. This is due to alleles that confer appropriate resistance factors, which subsequently increase in frequency in response to insecticide selection pressure. However, insecticide resistance is not to be confused with insecticide tolerance. Unlike insecticide resistance, the latter is the natural ability to withstand insecticide action, and is not the result of genetic changes caused by the insecticide selection pressure [32].

\section{DDT resistance}

DDT was a long-lasting, relatively inexpensive and unrestricted chemical that was used worldwide as an insecticide to control disease-carrying mosquitoes, flies, and lice during and after the World War II [33]. Beginning in 1942, DDT was heavily used to control bed bug infestations in military barracks [9]. The first case of control failure of DDT against C. lectularius was reported in 1947 from the barracks of the Naval Receiving Station in Pearl Harbor, Hawaii [34]. It is noteworthy that bed bugs may have started developing resistance to DDT within 5 years after the product was first used, and the rapid pace of resistance was probably due to the excessive and continuous use of the insecticide. By the 1950s, bed bug resistance to DDT was widespread (Table 3) [35-40]. During this period, cross-resistance to pyrethrins was also observed in both $C$. lectularius (from Israel) and C. hemipterus (from Tanzania) [35]. Although there is abundant literature demonstrating that bed bugs had developed marked resistance to DDT, bed bug infestations decreased dramatically and were effectively reduced to very low levels from the 1950 s to the late 1970s in many developed countries. The repetitive and widespread use of DDT and subsequent insecticides (e.g. malathion, chlorpyrifos, and propoxur) had led to the significant decrease of bed bug infestations worldwide [9]. However, bed bug infestations were still a major problem in some developing countries, such as Sierra Leone [14], South Africa and rural Africa [13, 41, 42], as well as problematic in the poultry industry in many countries $[8,28,43,44]$.

\section{Pyrethroid resistance}

Pyrethroids, the synthetic analogues of pyrethrin in pyrethrum, an extract of Chrysanthemum cinerariaefolium flower, are a class of highly effective and extremely efficient neurotoxic insecticides [45, 46]. However, with the worldwide resurgence of bed bugs over the last two decades, resistance to pyrethroids (Table 4) has been documented in many parts of the world for both C. lectularius $[16,30,47-54]$ and $C$. hemipterus $[12,16,17,55,56]$.

\section{Neonicotinoid resistance}

Imidacloprid, a neonicotinoid was introduced into the market in 1991 [57]. The neonicotinoids are now widely used against a wide variety of chewing and sucking pests [58], including the bed bugs [59-63]. Over the last few years, neonicotinoids have been combined with pyrethroids in formulated products, such as Temprid ${ }^{\circ} \mathrm{SC}$ (beta-cyfluthrin + imidacloprid), Transport ${ }^{\oplus}$ Mikron (bifenthrin + acetamiprid) and Tandem ${ }^{\circ}$ (lambda-cyhalothrin + thiamethoxam) $[10,60,63]$, and with diatomaceous earth (e.g. Alpine Dust Insecticide, with dinotefuran) [64] for the control of bed bugs. However, in a recent study, C. lectularius collected from human dwellings in Cincinnati and Michigan, USA 
Table 2 Reports of bed bug (Cimex spp.) resurgence from around the world since the beginning of the 21 th century

\begin{tabular}{|c|c|c|c|}
\hline Continent & Country & Species & Reference \\
\hline \multirow[t]{15}{*}{ Asia } & One of the Arabian Gulf States & Cimex spp. ${ }^{a}$ & [205] \\
\hline & Bangladesh & C. hemipterus & [206] \\
\hline & China (Mainland) & C. lectularius, C. hemipterus & {$[207,208]$} \\
\hline & Taiwan & C. hemipterus & [209] \\
\hline & India & C. lectularius, C. hemipterus & {$[29,205]$} \\
\hline & Iran & C. lectularius & [210] \\
\hline & Israel & C. lectularius, C. hemipterus & {$[211,212]$} \\
\hline & Japan & C. lectularius & [213] \\
\hline & Kuwait & C. lectularius & [214] \\
\hline & Malaysia & C. hemipterus & {$[129,215-217]$} \\
\hline & Pakistan & C. lectularius & [218] \\
\hline & Singapore & C. hemipterus & [215] \\
\hline & South Korea & C. lectularius & [219] \\
\hline & Sri Lanka & C. hemipterus & [56] \\
\hline & Thailand & C. lectularius, C. hemipterus & {$[12,220]$} \\
\hline \multirow[t]{8}{*}{ Africa } & Ethiopia & Cimex spp..$^{a}$ & [221] \\
\hline & Kenya & C. hemipterus & [17] \\
\hline & Nigeria & C. lectularius, C. hemipterus & {$[222,223]$} \\
\hline & Rwanda & C. hemipterus & [224] \\
\hline & Sierra Leone & C. lectularius, C. hemipterus & [14] \\
\hline & South Africa & C. lectularius, C. hemipterus & [13] \\
\hline & Tanzania & C. lectularius, C. hemipterus & {$[55,225]$} \\
\hline & Uganda & Cimex spp. ${ }^{a}$ & [226] \\
\hline \multirow[t]{11}{*}{ Americas } & Argentina & C. lectularius & [227] \\
\hline & Brazil & C. lectularius, C. hemipterus & [228-230] \\
\hline & Canada & C. lectularius & {$[231,232]$} \\
\hline & Chile & C. lectularius & [227] \\
\hline & Colombia & C. lectularius & [233] \\
\hline & Cuba & C. hemipterus & [209] \\
\hline & Mexico & Cimex spp. ${ }^{a}$ & [28] \\
\hline & Panama & C. hemipterus & [209] \\
\hline & Peru & C. lectularius & [234] \\
\hline & USA & C. lectularius, C. hemipterus & {$[18,48,157,209,235,236]$} \\
\hline & Venezuela & C. lectularius, C. hemipterus & {$[209,237]$} \\
\hline \multirow[t]{10}{*}{ Europe } & Austria & C. lectularius & [238] \\
\hline & Czech Republic & C. lectularius & {$[205,238]$} \\
\hline & Denmark & C. lectularius & [239] \\
\hline & France & C. lectularius & {$[158,240,241]$} \\
\hline & Germany & C. lectularius & {$[159,242-244]$} \\
\hline & Hungary & C. lectularius & [245] \\
\hline & Italy & C. lectularius & {$[246,247]$} \\
\hline & Norway & C. lectularius & [238] \\
\hline & Poland & C. lectularius & [238] \\
\hline & Spain & C. lectularius & [238] \\
\hline
\end{tabular}


Table 2 Reports of bed bug (Cimex spp.) resurgence from around the world since the beginning of the 21th century (Continued)

\begin{tabular}{|c|c|c|c|}
\hline & Russia & C. lectularius & {$[248,249]$} \\
\hline & Sweden & C. lectularius & [238] \\
\hline & Slovakia & C. lectularius & [238] \\
\hline & Switzerland & C. lectularius & {$[238,250]$} \\
\hline & UK & C. lectularius & {$[205,251]$} \\
\hline \multirow[t]{2}{*}{ Oceania } & Australia & C. lectularius, C. hemipterus & {$[15-17,54,252,253]$} \\
\hline & New Zealand & C. lectularius & [254] \\
\hline
\end{tabular}

${ }^{a}$ Cimex spp., no indication of the species identification in the report

have shown moderate to high levels of tolerance/resistance to various neonicotinoids [64]. Romero \& Anderson [64] reported that resistance to neonicotinoids may likely be conferred by the increased enzymatic activities found in these populations. These findings indicate that tolerance or even resistance to neonicotinoids is now present in field bed bug populations.

\section{Pyrrole efficacy}

Besides the conventional insecticides (e.g. pyrethroids, OPs, and carbamates), newer insecticide such as chlorfenapyr from the pyrrole class have also been evaluated [65, 66]. Pyrroles are a class of pro-insecticides that are activated by cytochrome P450 monooxygenases (P450s) to its more active metabolite [67]. Unlike neurotoxic insecticides (e.g. pyrethroids), pyrroles are mitochondrial electron transport inhibitors (METI) which disrupt the conversion of adenosine diphosphate (ADP) to adenosine triphosphate (ATP) (oxidative phosphorylation) in mitochondria of cells. This process results in loss of energy production, which leads to cell dysfunction and subsequent death of the organism [67]. Due to their novel mode of action, pyrroles (e.g. chlorfenapyr) are currently registered in more than 19 countries for the control of various insect and mite pests [68], especially against pyrethroid-resistant insect pests, including bed bugs $[65,66,69,70]$. Nevertheless, there are increasing number of reports of insects and mites becoming resistant or crossresistant to pyrroles [71-74], mainly due to metabolic resistance (e.g. P450s and esterases) [72, 75].

Despite no cases of resistance to chlorfenapyr has been reported in the bed bug so far, this compound has shown varying performance against bed bugs. While chlorfenapyr $\left(\right.$ Phantom $\left.^{\circ}\right)$ was extremely slow-acting in laboratory residual bioassays [48], direct application of the product on the walls of infested apartments resulted in a $61 \%$ reduction in bed bug numbers in just 3 days [76]. Romero et al. [65] reported that chlorfenapyr is a non-repellent insecticide with long residual activity against $C$. lectularius based on laboratory studies. On the contrary, other researchers have found poor performance of this product even with laboratory susceptible bed bugs $[21,66]$. In a field evaluation [69], Phantom ${ }^{\bullet}$ was widely sprayed throughout 15 apartments monthly for 5 months. The authors only achieved control in 12 units despite including a range of non-chemical means, yet three units remained infested. It is not possible to determine if this lack of complete control was due to poor product efficacy (and possible resistance) or due to bed bugs being reintroduced.

\section{Resistance to other insecticides}

Besides resistance to DDT, by the 1950 s both bed bug species also had developed resistance to other chlorinated hydrocarbon compounds (OCs) [e.g. gamma-HCH (1957), methoxychlor (1958), dieldrin (1958), aldrin (1958), and endrin (1958)] (Table 3) [35], organophosphates (OPs) (e.g. malathion) (1971) [77], and carbaryl (carbamate) (1972) [78]. Following the resurgence in the new millennia, resistance to OCs [56], OPs [12, 53, 56] and carbamates [12, 44, 49, 52] were also reported in bed bugs (Table 4). All these classes of insecticides have largely been banned for indoor use against bed bugs with exception to selected countries in Asia, Africa, and some countries in Latin America.

\section{Mechanisms of resistance}

Insecticide resistance can be divided into two major types: behavioral resistance and physiological resistance $[1,79]$. In behavioral resistance, the insect populations may develop the ability to avoid or reduce lethal insecticide exposure [79]. In contrast, physiological resistance refers to physiological modification mechanisms, including reduced cuticular penetration, increased metabolic detoxification, and decreased target site sensitivity. Behavioral and physiological resistance often coexist in insect pests $[79,80]$ and both forms could be involved with bed bug resistance (Table 5, Fig. 1). Herein the resistance mechanisms that have been reported in the bed bug are discussed, as well as candidate resistance mechanisms that are yet to be confirmed. So far, only penetration resistance, metabolic resistance (namely P450 and esterase), and target site insensitivity (namely $k d r$-type) have been found to confer resistance in bed bugs. Other resistance mechanisms that are yet to be detected in bed bugs are behavioral resistance, glutathione S-transferase (GST), altered acetylcholinesterase (AChE), insensitive $\gamma$-aminobutyric acid (GABA) receptor, altered nAChRs, and symbiont-mediated insecticide 
Table 3 Reports of resistance to chlorinated hydrocarbons in bed bugs (Cimex spp.) by the 1970s

\begin{tabular}{|c|c|c|c|c|}
\hline Species & Year & Chlorinated hydrocarbon & Location & Reference \\
\hline \multirow{29}{*}{ C. lectularius } & 1947 & DDT & USA (Hawaii) & [34] \\
\hline & 1949 & DDT & Greece & {$[255-257]$} \\
\hline & 1952 & DDT & USA (Ohio, Illinois, Indiana, Utah) & {$[36]$} \\
\hline & 1953 & DDT & Belgian Congo & {$[258]$} \\
\hline & 1953 & DDT & Israel & {$[259,260]$} \\
\hline & 1953 & DDT & Japan, Italy & {$[36]$} \\
\hline & 1954 & $\mathrm{HCH}$, dieldrin & Italy & {$[36]$} \\
\hline & 1955 & DDT & USA (Colorado, Pennsylvania, Texas) & {$[36]$} \\
\hline & 1956 & $\mathrm{HCH}$, dieldrin & Israel & {$[36]$} \\
\hline & 1956 & DDT & French Guiana & [261] \\
\hline & 1956 & DDT & Iran & [262] \\
\hline & 1957 & $\mathrm{Y}-\mathrm{HCH}$ & Israel & [263] \\
\hline & 1957 & DDT & Trinidad, Turkey & {$[36]$} \\
\hline & 1957 & DDT, chlordane, dieldrin & Italy & [264] \\
\hline & 1958 & $\begin{array}{l}\text { Dieldrin, } \mathrm{y}-\mathrm{HCH} \text {, aldrin, endrin, isodrin, a-chlordane, } \\
\beta \text {-chlordane, methoxychlor, perthane, prolan }\end{array}$ & Israel & [35] \\
\hline & 1958 & DDT & Lebanon & [265] \\
\hline & 1958 & DDT & $\begin{array}{l}\text { Japan, Korea, USA (Ohio, and two US } \\
\text { naval vessels) }\end{array}$ & {$[266]$} \\
\hline & 1959 & DDT & Hungary, Poland & {$[36,40,267]$} \\
\hline & 1960 & $\mathrm{HCH}$, dieldrin & Indonesia, Zambia, Rhodesia, Borneo & {$[37]$} \\
\hline & 1960 & DDT & Borneo, Indonesia, Colombia & {$[36,40]$} \\
\hline & 1960 & DDT & Zimbabwe & {$[268]$} \\
\hline & 1961 & DDT, $\mathrm{HCH}$, dieldrin & South India & {$[36]$} \\
\hline & 1962 & $\mathrm{Y}-\mathrm{HCH}$ & India & [269] \\
\hline & 1962 & DDT, $\mathrm{HCH}$, dieldrin & South Africa & {$[37,270]$} \\
\hline & 1963 & DDT dieldrin & Gaza & [271] \\
\hline & 1967 & DDT, $\mathrm{HCH}$, dieldrin & Egypt & {$[37,272]$} \\
\hline & 1971 & $\mathrm{Y}-\mathrm{HCH}$ & Zambia, Italy, Borneo & [40] \\
\hline & 1972 & DDT & Papua-New Guinea & {$[273]$} \\
\hline & 1976 & DDT, dieldrin & Almost everywhere & {$[38]$} \\
\hline \multirow[t]{14}{*}{ C. hemipterus } & 1955 & DDT & West India & {$[36]$} \\
\hline & 1956 & $\mathrm{HCH}$, dieldrin & West India & {$[36]$} \\
\hline & 1956 & DDT & Taiwan & [274] \\
\hline & 1956 & DDT & India (Bombay State) & {$[275]$} \\
\hline & 1957 & $\mathrm{HCH}$, dieldrin & Tanzania, Kenya, Upper Volta & {$[37]$} \\
\hline & 1957 & DDT & Hong Kong, Singapore & [264] \\
\hline & 1957 & DDT & Kenya & {$[36]$} \\
\hline & 1957 & Dieldrin & Ivory Coast & [35] \\
\hline & 1958 & Dieldrin & Tanganyika & {$[276]$} \\
\hline & 1958 & DDT & Mombasa, Somalia, Gambia, Hong Kong & {$[35]$} \\
\hline & 1958 & Dieldrin & Mombasa, Gambia & {$[35]$} \\
\hline & 1958 & $\gamma-\mathrm{HCH}$ & Mombasa, Somalia, Gambia & {$[35]$} \\
\hline & 1958 & Methoxychlor & Mombasa, Somalia & {$[35]$} \\
\hline & 1959 & DDT & Poland & {$[267]$} \\
\hline
\end{tabular}


Table 3 Reports of resistance to chlorinated hydrocarbons in bed bugs (Cimex spp.) by the 1970s (Continued)

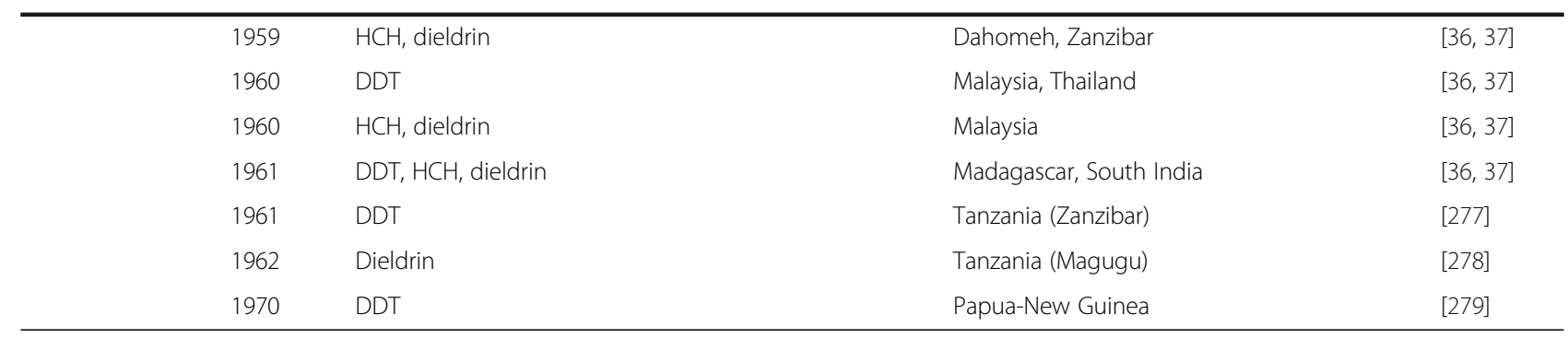

Abbreviations: $\mathrm{HCH}$ hexachlorocyclohexane, $\mathrm{\gamma}-\mathrm{HCH}$ gamma-hexachlorocyclohexane, also known as lindane, gammaxene, gammallin and sometimes incorrectly called benzene hexachloride (BHC)

resistance. The role of ATP-binding cassette (ABC) transporters in upregulation of toxicant removal from the target site will be discussed. For the ease of the flow of discussion, we shall discuss according to types of the resistance mechanisms (behavioural, metabolic, target site insensitivity, etc.) and will highlight resistance mechanisms that are yet to be detected in bed bugs as candidate mechanisms.

\section{Behavioral resistance (candidate resistance mechanism)}

Behavioral resistance can be divided into two broad categories: (i) stimulus-dependent behaviors (e.g. irritability and repellency), and (ii) stimulus-independent behavior (e.g. exophily, outside resting) [1, 79, 81]. Stimulus-dependent behaviors require sensory stimulation of the insect to detect a toxin-treated surface before acquiring a lethal dose, by which an avoidance response is elicted by the toxicant [79]. Such behaviors have been observed in a number of insect pests. The best known example is bait aversion to glucose in the German cockroach, Blattella germanica (L.), which was selected through field exposure to commercial cockroach baits [82-85]. Conversely, stimulus-independent behavior refers to insect behavior that prevents them from exposure to the toxicant [1]. These behaviors do not require sensory stimulation by the toxicant for avoidance to happen [79]. One example is 'exophily', which refers to the changes of behavior in anopheline mosquitoes from their regular habit of biting indoor, to biting outdoors [86]. This behavior decreases the prevalence of indoor mosquitoes, and hence reduces the potential for mosquitoes from contacting indoor insecticide applications [87, 88].

Although behavioral resistance has been documented in many insect pest groups, it has never been properly studied and confirmed in bed bugs. There were several studies that reported some behavioural observations in bed bugs in the presence of insecticides. One recent study showed that insecticide-susceptible and insecticide-resistant C. lectularius may either avoid resting on deltamethrintreated filter paper, or increased their movement upon direct contact with sublethal doses of deltamethrin [89]. This possibly suggested excito-repellency, a form of behavioral resistance. In another study however, Moore \& Miller
[48] found that insecticide-susceptible and insecticideresistant strains of $C$. lectularius did not avoid surfaces treated with lambda-cyhalothrin. Cimex lectularius also showed no avoidance behavior when exposed to chlorfenapyr $[48,65,89]$. Bed bugs are highly cryptic and often hide in dark areas and in cracks and crevices. This unique behavioral characteristic may protect them from contacting insecticide on treated surfaces, or being found during the inspection process $[8,10,90]$.

\section{Physiological resistance}

In contrast to behavioral resistance, many studies have identified physiological resistance mechanisms in bed bugs (Table 1). Mamidala et al. [91, 92] recently found that metabolic detoxification, cuticular proteins, and knockdown resistance $(k d r)$ mutations were associated with insecticide resistance in C. lectularius. Similarly, Zhu et al. [90] reported that there were $k d r$ mutations and/or differentially expressed genes including metabolic genes (P450s, esterases, $\mathrm{ABC}$ transporters, and cuticular protein genes associated with insecticide resistance (pyrethroid resistance) in C. lectularius. Overall, three major physiological resistance mechanisms have been investigated in association with bed bug resistance to insecticides, namely penetration resistance, metabolic resistance, and target site insensitivity.

\section{Penetration resistance}

Contact insecticides must pass through the insect cuticle before reaching the target site [5]. Therefore, the cuticle serves as the first line of defence against insecticides [90, 93]. Resistant insects develop cuticular barriers by evolving a thicker cuticle or by altering the cuticular structure to reduce the penetration rate of insecticides into the insect body $[94,95]$. Penetration resistance may provide protection to the insects against different classes of insecticides $[96,97]$. Penetration resistance also works in combination with other resistance mechanism(s), as it has been hypothesized that decreased cuticular penetration could help to 'buy more time' for detoxifying enzymes to metabolize the insecticide or to allow the insect to excrete the insecticide before it reaches its target $[90,98]$. Penetration resistance has been reported in various insect 
Table 4 Published reports of insecticide resistance and product efficacy in modern bed bugs (Cimex spp.), post 2000

\begin{tabular}{|c|c|c|c|c|c|c|}
\hline Year & Insecticide & Method & Location/Strain & $\begin{array}{l}\text { Susceptibility/ } \\
\text { efficacy }\end{array}$ & $\begin{array}{l}\text { Resistance } \\
\text { ratio }\end{array}$ & Reference \\
\hline \multicolumn{7}{|c|}{ C. lectularius } \\
\hline 2006 & a-cypermethrin ${ }^{a}$ & SC & UK (3 field strains) & Resistant & - & [47] \\
\hline 2006 & Bendiocarb ${ }^{b}$ & SC & UK (3 field strains) & Resistant & - & [47] \\
\hline 2006 & Deltamethrin $^{a}$ & SC & USA (Arlington, VA) & Resistant & $>300$ & [48] \\
\hline 2006 & Chlorfenapyr ${ }^{g}$ & SC & Susceptible Harlan strain & Less effective & & [48] \\
\hline 2007 & Deltamethrin $^{a}$ & SC & USA: Cincinnati, OH(CIN1, CIN2, CIN3); Lexington, KY (LEX1) & Resistant & $>12,765$ & [30] \\
\hline 2007 & $\lambda$-cyhalothrin ${ }^{\mathrm{a}}$ & SC & USA (Cincinnati, OH[CIN1]) & Resistant & $>6123$ & [30] \\
\hline 2007 & Deltamethrin $^{a}$ & SC & USA (Los Angeles, CA [LA2]; Kissimmee, FL[KIS1]; Vienna, VA[VIN1]) & Resistant & - & [30] \\
\hline 2007 & Deltamethrin $^{a}$ & SC & USA (Los Angeles, CA [LA1]) & Susceptible & & [30] \\
\hline 2008 & Deltamethrin $^{a}$ & $\mathrm{SC}$ & USA (New York City, NY [NY-BB]) & Resistant & $>250$ & [156] \\
\hline 2008 & Bifenthrin ${ }^{\mathrm{a}}$ & SC & USA (Arkansas: Washington, Carroll, Lafayette) & Susceptible & & [44] \\
\hline 2008 & $\lambda$-cyhalothrin ${ }^{a}$ & SC & USA (Arkansas: Washington, Carroll, Lafayette) & Susceptible & & [44] \\
\hline 2008 & Permethrin $^{a}$ & SC & USA (Arkansas: Washington, Carroll, Lafayette) & Susceptible & & [44] \\
\hline 2008 & Carbary $\left.\right|^{\mathrm{b}}$ & SC & USA (Arkansas: Washington, Carroll, Lafayette) & Susceptible & & [44] \\
\hline 2008 & Imidacloprid $^{c}$ & SC & USA (Arkansas: Washington, Carroll, Lafayette) & Susceptible & & [44] \\
\hline 2008 & Fipronil $^{d}$ & SC & USA (Arkansas: Washington, Carroll, Lafayette) & Susceptible & & [44] \\
\hline 2008 & Diazinon $^{e}$ & SC & USA (Arkansas: Washington, Lafayette) & Susceptible & & [44] \\
\hline 2008 & Diazinon $^{e}$ & SC & USA (Arkansas: Carroll) & Resistant & - & [44] \\
\hline 2008 & Dichlorvos ${ }^{\mathrm{e}}$ & SC & USA (Arkansas: Washington, Carroll, Lafayette) & Resistant & - & [44] \\
\hline 2008 & Spinosad $^{f}$ & SC & USA (Arkansas: Washington, Carroll, Lafayette) & Resistant & - & [44] \\
\hline 2008 & Chlorfenapyr ${ }^{g}$ & SC & USA (Arkansas: Washington, Carroll, Lafayette) & Less effective & & [44] \\
\hline 2008 & $\mathrm{DDT} T^{\mathrm{h}}$ & SC & USA (Arkansas: Washington, Carroll, Lafayette) & Resistant & - & [44] \\
\hline 2008 & Chlorfenapyr ${ }^{9}$ & SC & USA (Cincinnati, OH) & Less effective & & [69] \\
\hline 2009 & Pirimphos-methyle & $\mathrm{T}$ & Australia (Sydney strain) & Susceptible & 2.6 & {$[49,52]$} \\
\hline 2009 & Imidacloprid ${ }^{c}$ & $\mathrm{~T}$ & Australia (Sydney strain) & Susceptible & 2.6 & {$[49,52]$} \\
\hline 2009 & Bendiocarb $b^{b}$ & T & Australia (Sydney strain) & Resistant & 250 & {$[49,52]$} \\
\hline 2009 & Deltamethrin $^{a}$ & $\mathrm{~T}$ & Australia (Sydney strain) & Resistant & 370,000 & {$[49,52]$} \\
\hline 2009 & Permethrin $^{a}$ & $\mathrm{~T}$ & Australia (Sydney strain) & Resistant & $1,235,000$ & {$[49,52]$} \\
\hline 2009 & Diazinon ${ }^{\mathrm{e}}$ & $\mathrm{T} / \mathrm{SC}$ & Australia (Sydney strain) & Effective & & {$[50,51]$} \\
\hline 2009 & Pyrethrins $^{\mathrm{a}}$ & $\mathrm{T} / \mathrm{SC}$ & Australia (Sydney strain) & Resistant & - & {$[50,51]$} \\
\hline 2009 & $\beta$-cyfluthrin ${ }^{a}$ & $\mathrm{~T} / \mathrm{SC}$ & Australia (Sydney strain) & Resistant & - & {$[50,51]$} \\
\hline 2009 & Tetramethrin ${ }^{a}$ & $\mathrm{~T} / \mathrm{SC}$ & Australia (Sydney strain) & Resistant & - & {$[50,51]$} \\
\hline 2009 & Deltamethrin $^{a}$ & SC & USA (Cincinnati, OH [CIN-1]) & Resistant & $>2588$ & {$[128]$} \\
\hline 2009 & Deltamethrin $^{a}$ & SC & USA (Worcester, MA[WOR-1]) & Resistant & $>2588$ & [128] \\
\hline 2010 & Deltamethrin $^{a}$ & SC & USA (New York City, NY) & Resistant & $>9375$ & [162] \\
\hline 2010 & $\lambda$-cyhalothrin ${ }^{a}$ & SC & USA (New York City, NY) & Resistant & 6990 & {$[162]$} \\
\hline 2010 & Chlorfenapyr ${ }^{g}$ & SC & USA (Cincinnati, OH [CIN-1]) & Effective & - & [65] \\
\hline 2010 & Chlorfenapyr ${ }^{9}$ & SC & USA (Worcester, MA[WOR-1]) & Effective & - & {$[65]$} \\
\hline 2010 & Phenothrin $^{\mathrm{a}}$ & $\mathrm{SC} / \mathrm{T}$ & Japan (four field strains) & Resistant & - & {$[280]$} \\
\hline 2010 & Permetrhin $^{a}$ & $\mathrm{SC} / \mathrm{T}$ & Japan (four field strains) & Resistant & - & [280] \\
\hline 2010 & Dichlorvos $^{\mathrm{e}}$ & $\mathrm{SC} / \mathrm{T}$ & Japan (four field strains) & Susceptible & & {$[280]$} \\
\hline 2010 & Fenitrothion ${ }^{\mathrm{e}}$ & $\mathrm{SC} / \mathrm{T}$ & Japan (four field strains) & Susceptible & & {$[280]$} \\
\hline 2010 & Propoxur ${ }^{b}$ & $\mathrm{SC} / \mathrm{T}$ & Japan (four field strains) & Susceptible & & [280] \\
\hline
\end{tabular}


Table 4 Published reports of insecticide resistance and product efficacy in modern bed bugs (Cimex spp.), post 2000 (Continued)

\begin{tabular}{|c|c|c|c|c|c|c|}
\hline 2010 & Deltamethrin $^{a}$ & SC & $\begin{array}{l}\text { USA (Cincinnati, OH; Lexington, KY; Troy, Ml; Dover, NJ; Frankfort, KY; } \\
\text { Kalamazoo, Ml; Worcester, MA; Smithtown, Plainview, New York, NY) }\end{array}$ & Resistant & - & [157] \\
\hline 2011 & Deltamethrin $^{a}$ & IT & USA (Richmond, VA) & Resistant & 5167 & [113] \\
\hline 2011 & $\beta$-cyfuthrin ${ }^{a}$ & IT & USA (Richmond, VA) & Resistant & 111 & [113] \\
\hline 2011 & Deltamethrin $^{a}$ & SC & USA (Richmond, VA) & Resistant & 390.5 & [281] \\
\hline 2011 & Deltamethrin $^{a}$ & SC & USA (Cincinnati, OH) & Resistant & $>340$ & [281] \\
\hline 2011 & Deltamethrin $^{a}$ & SC & USA (Arlington, VA: Kramer) & Resistant & 339.6 & [282] \\
\hline 2011 & Permethrin ${ }^{a}$ & SC & USA (Arlington, VA: Kramer) & Resistant & $>115.1$ & [282] \\
\hline 2011 & Deltamethrin $^{a}$ & SC & USA (Richmond, VA) & Resistant & 390.5 & [282] \\
\hline 2011 & Permethrin $^{a}$ & SC & USA (Richmond, VA) & Resistant & $>291.7$ & [282] \\
\hline 2011 & $\mathrm{DDT} T^{\mathrm{h}}$ & SC & Thailand (Chiang Mai) & Resistant & - & [12] \\
\hline 2011 & Dieldrin ${ }^{h}$ & SC & Thailand (Chiang Mai) & Resistant & - & [12] \\
\hline 2011 & Bendiocarb $^{b}$ & SC & Thailand (Chiang Mai) & Resistant & - & [12] \\
\hline 2011 & Propoxur $^{b}$ & SC & Thailand (Chiang Mai) & Resistant & - & [12] \\
\hline 2011 & Malathion ${ }^{\mathrm{e}}$ & SC & Thailand (Chiang Mai) & Resistant & - & [12] \\
\hline 2011 & Fenitrothion ${ }^{\mathrm{e}}$ & SC & Thailand (Chiang Mai) & Resistant & - & [12] \\
\hline 2011 & Cyfluthrin $^{a}$ & SC & Thailand (Chiang Mai) & Resistant & - & [12] \\
\hline 2011 & Deltamethrin ${ }^{a}$ & SC & Thailand (Chiang Mai) & Resistant & - & [12] \\
\hline 2011 & Permethrin $^{a}$ & SC & Thailand (Chiang Mai) & Resistant & - & [12] \\
\hline 2011 & $\beta$-cyhalothrin ${ }^{a}$ & SC & Thailand (Chiang Mai) & Resistant & - & [12] \\
\hline 2011 & Etofenprox ${ }^{a}$ & SC & Thailand (Chiang Mai) & Resistant & - & [12] \\
\hline 2011 & Diazinon $^{\mathrm{e}}$ & Spray & Thailand (Chiang Mai) & Less effective & - & [12] \\
\hline 2011 & Fenobucarb ${ }^{\mathrm{b}}$ & Spray & Thailand (Chiang Mai) & Less effective & - & [12] \\
\hline 2011 & Esfenvalerate $^{a}$ & Spray & Thailand (Chiang Mai) & Less effective & - & [12] \\
\hline 2011 & Cypermethrin $^{a}$ & Spray & Thailand (Chiang Mai) & Less effective & - & [12] \\
\hline 2011 & Bifenthrin $^{a}$ & Spray & Thailand (Chiang Mai) & Less effective & - & [12] \\
\hline 2011 & Chlorfenapyr ${ }^{9}$ & Spray & Thailand (Chiang Mai) & Less effective & - & [12] \\
\hline 2011 & Fipronil $^{d}$ & Spray & Thailand (Chiang Mai) & Less effective & - & [12] \\
\hline 2011 & Imidacloprid $^{c}$ & Spray & Thailand (Chiang Mai) & Efficient & - & [12] \\
\hline 2011 & Permethrin ${ }^{a}$ & $\mathrm{~T}, \mathrm{SC}$ & Denmark & Resistant & - & [53] \\
\hline 2011 & Deltamethrin $^{a}$ & SC & Denmark & Resistant & - & [53] \\
\hline 2011 & Chlorpyrifos $^{e}$ & $\mathrm{~T}, \mathrm{SC}$ & Denmark & Effective & - & [53] \\
\hline 2012 & Deltamethrin $^{\mathrm{a}}$ & SC & USA (Columbus, OH) & Resistant & - & [92] \\
\hline 2012 & Pyrethrins $^{a}$ & T & USA(New Haven, CT) & Resistant & - & [283] \\
\hline 2012 & Cyfluthrin $^{\mathrm{a}}$ & T & USA(New Haven, CT) & Resistant & - & [283] \\
\hline 2012 & $\lambda$-cyhalothrin ${ }^{\mathrm{a}}$ & T & USA(New Haven, CT) & Resistant & - & [283] \\
\hline 2012 & cis-cypermethrin ${ }^{a}$ & T & USA(New Haven, CT) & Resistant & - & [283] \\
\hline 2012 & Deltamethrin $^{a}$ & T & USA(New Haven, CT) & Resistant & - & [283] \\
\hline 2012 & Deltamethrin ${ }^{a}$ & T & USA (Cincinnati, OH [CIN-1], Plainview, NY [NY-1]) & Resistant & - & [122] \\
\hline 2012 & Neopynamine $^{a}$ & SC & France (Paris) & Resistant & - & [158] \\
\hline 2012 & Sumithrin ${ }^{a}$ & SC & France (Paris) & Resistant & - & [158] \\
\hline 2013 & Deltamethrin $^{a}$ & SC & USA (CIN-1) & Resistant & 51 & [90] \\
\hline 2013 & Deltamethrin $^{a}$ & SC & USA (CIN-1 S) & Resistant & $32,700,000$ & [90] \\
\hline 2013 & Deltamethrin ${ }^{a}$ & SC & USA (NY-1) & Resistant & $>300$ & [90] \\
\hline 2013 & Deltamethrin ${ }^{a}$ & $\mathrm{~T}$ & USA (Richmond, VA) & Resistant & $>200,000$ & [94] \\
\hline
\end{tabular}


Table 4 Published reports of insecticide resistance and product efficacy in modern bed bugs (Cimex spp.), post 2000 (Continued)

\begin{tabular}{|c|c|c|c|c|c|c|}
\hline 2013 & $\beta$-cyfuthrin ${ }^{a}$ & T & USA (Richmond, VA) & Resistant & $>160,000$ & [94] \\
\hline 2014 & Deltamethrin $^{a}$ & SC & Germany (Berlin) & Resistant & $3.8-5.1$ & [159] \\
\hline 2014 & Deltamethrin $^{a}$ & SC & USA: New York (Brooklyn) & Susceptible & - & [284] \\
\hline 2015 & $\begin{array}{l}\text { Imidacloprid/ } \beta \text { - } \\
\text { cyfluthrin }^{c}\end{array}$ & SC & USA (Richmond and Epic Center strains) & Resistant & $\begin{array}{l}\text { E: } 3-5 ; \\
\text { Fl: } 121- \\
493\end{array}$ & {$[285]$} \\
\hline 2015 & $\begin{array}{l}\text { Acetamiprid }{ }^{c} / \\
\text { bifenthrin }^{\mathrm{a}}\end{array}$ & SC & USA (Richmond and Epic Center strains) & Resistant & $\begin{array}{l}\text { E: } 39- \\
1080 \\
\text { Fl: } 99- \\
1943\end{array}$ & [285] \\
\hline 2015 & Deltamethrin $^{a}$ & SC & USA (Epic Center strain) & Resistant & 392 & [285] \\
\hline 2015 & d-allethrin ${ }^{a}$ & SC & $\begin{array}{l}\text { Australia [NSW: Sydney (Abbotsford, Darlinghurst, North Parramatta, } \\
\text { Northbridge, Redfern), Newcastle (Maryland); VIC: Melbourne } \\
\text { (Ripponlea, South Yarra, Moonee Ponds), West Melbourne; WA: } \\
\text { Perth (Cottesloe); NT: Alice springs; SA: Adelaide (Semaphore Park)] }\end{array}$ & Resistant & - & {$[16,54]$} \\
\hline 2016 & Imidacloprid $^{c}$ & T & USA (Jersey City, NJ) & Susceptible & 2.0 & [64] \\
\hline 2016 & Imidacloprid $^{c}$ & T & USA (Troy, MI) & Resistant & 462.6 & [64] \\
\hline 2016 & Imidacloprid $^{c}$ & T & USA (Cincinnati, OH) & Resistant & 163.3 & [64] \\
\hline 2016 & Acetamiprid $^{c}$ & T & USA (Jersey City, NJ) & Resistant & 31.7 & [64] \\
\hline 2016 & Acetamiprid $^{c}$ & T & USA (Troy, MI) & Resistant & $>33,333$ & [64] \\
\hline 2016 & Acetamiprid $^{c}$ & T & USA (Cincinnati, OH) & Resistant & $>33,333$ & [64] \\
\hline 2016 & Thiamethoxam ${ }^{c}$ & $\mathrm{~T}$ & USA (Jersey City, NJ) & Susceptible & 2.4 & [64] \\
\hline 2016 & Thiamethoxam $^{c}$ & T & USA (Troy, MI) & Resistant & 546 & [64] \\
\hline 2016 & Thiamethoxam ${ }^{c}$ & T & USA (Cincinnati, OH) & Resistant & 226.2 & [64] \\
\hline 2016 & Dinotefuran ${ }^{c}$ & T & USA (Jersey City, NJ) & Resistant & 46.8 & [64] \\
\hline 2016 & Dinotefuran $^{c}$ & T & USA (Troy, MI) & Resistant & 198 & [64] \\
\hline 2016 & Dinotefuran ${ }^{c}$ & T & USA (Cincinnati, OH) & Resistant & 358.6 & [64] \\
\hline 2016 & Deltamethrin ${ }^{a}$ & T & Australia: Parramatta(NSW), Alice Springs(NT) and Melbourne(VIC) & Resistant & - & [127] \\
\hline 2016 & Deltamethrin $^{a}$ & SC & Australia (Parramatta[NSW]) & Resistant & - & [95] \\
\hline \multicolumn{7}{|c|}{ C. hemipterus } \\
\hline 2002 & a-cypermethrin ${ }^{a}$ & SC & Tanzania & Resistant & - & [55] \\
\hline 2002 & Permethrin $^{a}$ & SC & Tanzania & Resistant & - & [55] \\
\hline 2007 & $\mathrm{DDT}^{\mathrm{h}}$ & SC & Sri Lanka & Resistant & - & [56] \\
\hline 2007 & Malathion ${ }^{e}$ & SC & Sri Lanka & Resistant & - & [56] \\
\hline 2007 & Propoxur ${ }^{b}$ & SC & Sri Lanka & Resistant & - & [56] \\
\hline 2007 & Deltamethrin $^{e}$ & SC & Sri Lanka & Resistant & - & [56] \\
\hline 2007 & Permethrin $^{e}$ & SC & Sri Lanka & Resistant & - & [56] \\
\hline 2011 & $\lambda$-cyhalothrin ${ }^{a}$ & SC & Malaysia (Kmelayu14); Singapore (Serangoon) & Effective & - & [129] \\
\hline 2011 & Bifentrin $^{a}$ & SC & Malaysia (Kmelayu14); Singapore (Serangoon) & Effective & - & [129] \\
\hline 2011 & Fenitrothion $^{\mathrm{e}}$ & SC & Malaysia (Kmelayu14); Singapore (Serangoon) & Effective & - & [129] \\
\hline 2011 & Fipronil $^{d}$ & SC & Malaysia (Kmelayu14); Singapore (Serangoon) & Effective & - & [129] \\
\hline 2011 & Imidacloprid & SC & Malaysia (Kmelayu14); Singapore (Serangoon) & Effective & - & [129] \\
\hline 2011 & $\mathrm{DDT}^{\mathrm{h}}$ & SC & Malaysia (Kmelayu14); Singapore (Serangoon) & Resistant & - & [129] \\
\hline 2011 & $\mathrm{DDT}^{\mathrm{h}}$ & SC & Thailand (Bangkok, Chonburi, Phuket, Krabi) & Resistant & - & [12] \\
\hline 2011 & Dieldrin $^{\mathrm{h}}$ & SC & Thailand (Bangkok, Chonburi, Phuket, Krabi) & Resistant & - & [12] \\
\hline 2011 & Bendiocarb ${ }^{b}$ & SC & Thailand (Bangkok, Chonburi, Phuket, Krabi) & Resistant & - & [12] \\
\hline 2011 & Propoxur & SC & Thailand (Bangkok, Chonburi, Phuket, Krabi) & Resistant & - & [12] \\
\hline 2011 & Malathion ${ }^{\mathrm{e}}$ & SC & Thailand (Bangkok, Chonburi, Phuket, Krabi) & Resistant & - & [12] \\
\hline
\end{tabular}


Table 4 Published reports of insecticide resistance and product efficacy in modern bed bugs (Cimex spp.), post 2000 (Continued)

\begin{tabular}{|c|c|c|c|}
\hline 2011 & Fenitrothion ${ }^{e}$ & SC & Thailand (Bangkok, Chonburi, Phuket, Krabi) \\
\hline 2011 & Cyfluthrin $^{a}$ & SC & Thailand (Bangkok, Chonburi, Phuket, Krabi) \\
\hline 2011 & Deltamethrin $^{a}$ & SC & Thailand (Bangkok, Chonburi, Phuket, Krabi) \\
\hline 2011 & Permethrin $^{a}$ & SC & Thailand (Bangkok, Chonburi, Phuket, Krabi) \\
\hline 2011 & $\lambda$-cyhalothrin ${ }^{a}$ & SC & Thailand (Bangkok, Chonburi, Phuket, Krabi) \\
\hline 2011 & Etofenprox ${ }^{\mathrm{a}}$ & SC & Thailand (Bangkok, Chonburi, Phuket, Krabi) \\
\hline 2011 & Diazinon $^{e}$ & Spray & Thailand (Bangkok, Chonburi, Phuket, Krabi) \\
\hline 2011 & Fenobucarb ${ }^{b}$ & Spray & Thailand (Bangkok, Chonburi, Phuket, Krabi) \\
\hline 2011 & Esfenvalerate $^{a}$ & Spray & Thailand (Bangkok, Chonburi, Phuket, Krabi) \\
\hline 2011 & Cypermethrin $^{a}$ & Spray & Thailand (Bangkok, Chonburi, Phuket, Krabi) \\
\hline 2011 & Bifenthrin $^{a}$ & Spray & Thailand (Bangkok, Chonburi, Phuket, Krabi) \\
\hline 2011 & Chlorfenapyr ${ }^{9}$ & Spray & Thailand (Bangkok, Chonburi, Phuket, Krabi) \\
\hline 2011 & Fipronil $^{d}$ & Spray & Thailand (Bangkok, Chonburi, Phuket, Krabi) \\
\hline 2011 & Imidacloprid $^{c}$ & Spray & Thailand (Bangkok, Chonburi, Phuket, Krabi) \\
\hline 2015 & d-allethrin ${ }^{a}$ & SC & Australia (North Queensland) \\
\hline 2015 & d-allethrin ${ }^{a}$ & SC & Australia (Sydney, [NSW]: Auburn) \\
\hline 2015 & d-allethrin ${ }^{a}$ & SC & Malaysia (Kuala Lumpur) \\
\hline 2015 & d-allethrin ${ }^{a}$ & SC & Thailand (Bangkok, Chiang Mai) \\
\hline 2015 & d-allethrin ${ }^{a}$ & SC & Africa (Kenya) \\
\hline
\end{tabular}

$\begin{array}{lll}\text { Resistant } & - & {[12]} \\ \text { Resistant } & - & {[12]} \\ \text { Resistant } & - & {[12]} \\ \text { Resistant } & - & {[12]} \\ \text { Resistant } & - & {[12]} \\ \text { Resistant } & - & {[12]} \\ \text { Less effective } & - & {[12]} \\ \text { Less effective } & - & {[12]} \\ \text { Less effective } & - & {[12]} \\ \text { Less effective } & - & {[12]} \\ \text { Less effective } & - & {[12]} \\ \text { Less effective } & - & {[12]} \\ \text { Less effective } & - & {[12]} \\ \text { Effective } & - & {[12]} \\ \text { Resistant } & >130 & {[17]} \\ \text { Resistant } & 37 & {[17]} \\ \text { Resistant } & >130 & {[17]} \\ \text { Resistant } & >130 & {[17]} \\ \text { Resistant } & 30 & {[17]} \\ & & \end{array}$

\section{Abbreviation: SC Surface contact, $T$ Topical application, IT Injection topical application [112]}

${ }^{\text {a Pyrethroids }}$

${ }^{\text {b} C a r b a m a t e s ~}$

cNeonicotinoids

${ }^{\mathrm{d} P h e n y l p y r a z o l e s}$

eOPs

fSpinosyn

9Pyrrole

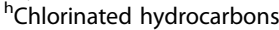

Table 5 Resistance mechanisms (verified and candidate mechanisms) in bed bugs (Cimex spp.)

\begin{tabular}{|c|c|c|c|c|c|}
\hline \multicolumn{3}{|l|}{ Mechanism } & \multirow{2}{*}{$\begin{array}{l}\text { C. lectularius } \\
\text { Candidate mechanism }\end{array}$} & \multirow{2}{*}{$\begin{array}{l}\text { C. hemipterus } \\
\text { Candidate mechanism }\end{array}$} & Insecticide \\
\hline \multicolumn{3}{|c|}{ Behavioral resistance } & & & Pyrethroids \\
\hline \multirow[t]{9}{*}{$\begin{array}{l}\text { Physiological } \\
\text { resistance }\end{array}$} & $\begin{array}{l}\text { Penetration } \\
\text { resistance }\end{array}$ & Cuticle & $\begin{array}{l}\text { Verified by morphological } \\
\text { study }[95,103]\end{array}$ & Candidate mechanism & A broad spectrum of insecticide classes \\
\hline & $\begin{array}{l}\text { Metabolic } \\
\text { resistance }\end{array}$ & P450s & $\begin{array}{l}\text { Verified by RNAi [90] and } \\
\text { synergism studies [127] }\end{array}$ & $\begin{array}{l}\text { Verified by synergism } \\
\text { studies [129] }\end{array}$ & $\begin{array}{l}\text { Pyrethroids, OCs, OPs, carbamates, } \\
\text { neonicotinoids and pyrroles }\end{array}$ \\
\hline & & Esterases & $\begin{array}{l}\text { Verified by synergism } \\
\text { studies [127] }\end{array}$ & Candidate mechanism & $\begin{array}{l}\text { Carbamates, OPs, pyrroles, neonicotinoids } \\
\text { and pyrethroids }\end{array}$ \\
\hline & & GSTs & Candidate mechanism & Candidate mechanism & OCs, OPs and pyrethroids \\
\hline & & ABC-transporters & Verified by RNAi [90] & Candidate mechanism & $\begin{array}{l}\text { Pyrethroids, OCs, OPs, carbamates, } \\
\text { and neonicotinoids }\end{array}$ \\
\hline & $\begin{array}{l}\text { Target site } \\
\text { insensitivity }\end{array}$ & $K d r$ & $\begin{array}{l}\text { Verified by QS combined } \\
\text { with FCVB [162] }\end{array}$ & Candidate mechanism & Pyrethroids and DDT \\
\hline & & Altered AChEs & Candidate mechanism & Candidate mechanism & OPs and carbamates \\
\hline & & $\begin{array}{l}\text { Insensitive GABA } \\
\text { receptors }\end{array}$ & Candidate mechanism & Candidate mechanism & Cyclodienes (OCs) and phenylpyrazoles \\
\hline & & Altered nAChRs & Candidate mechanism & Candidate mechanism & Neonicotinoids \\
\hline \multicolumn{3}{|c|}{ Symbiont-mediated resistance } & Candidate mechanism & Candidate mechanism & OPs \\
\hline
\end{tabular}




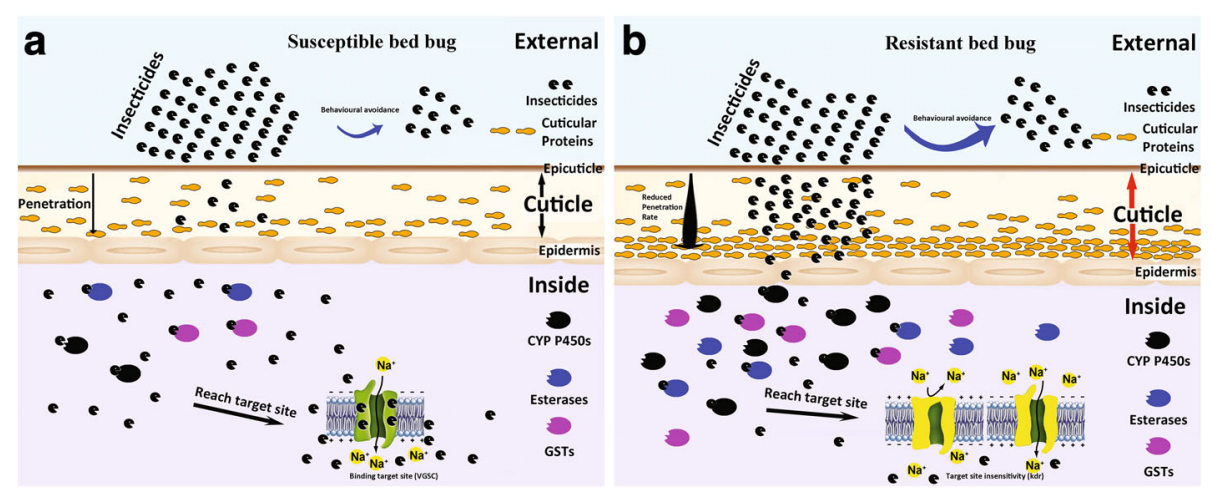

Fig. 1 Schematic of potential behavioral and physiological changes involved in insecticide resistance in bed bugs. a Susceptible bed bug. b Resistant bed bug. The various forms of resistance act in compounding layers to counteract the effect of the insecticide. For example, direct application of an insecticide such as a pyrethroid may kill the bed bugs; however due to the 'excito-repellency' nature of this class of compounds, some bed bugs may avoid insecticide exposure (potential behavioral resistance). If the bed bugs come into contact with an insecticide, the cuticle may be thickened or remodelled by over-expression of cuticular proteins, which will reduce the rate of insecticide penetration (penetration resistance) beyond the cuticular layer. If the insecticides enter the insect, bed bugs can enhance metabolic detoxification (e.g. P450s, esterases, GSTs) to inhibit the insecticidal effect (metabolic resistance). Finally, if the insecticides reach the neurological system to act on the target sites (such as the VGSC), point mutations (e.g. kdr mutations) can reduce the sensitivity of the insecticide target site to the insecticide (target site insensitivity)

pests, including the house fly Musca domestica (L.) [98-100], the German cockroach B. germanica [2, 101], the dengue mosquito Aedes aegypti (L.) [102], and the common bed bug, C. lectularius [94, 95, 103].

Penetration resistance plays a crucial role in insecticide resistance in bed bugs. Koganemaru et al. [94] demonstrated that the resistance ratio in the resistant Richmond C. lectularius strain that was topically applied with deltamethrin or beta-cyfluthrin onto the cuticle was $10^{5}$ greater than that when applied subcuticularly, in comparison to the insecticide-susceptible Harlan strain. However, compared with other physiological resistance mechanisms, penetration resistance remains the least understood for many insect pests. Nevertheless recently, various RNA and genomic sequencing efforts have been made to identify the putative genes associated with cuticular penetration resistance in bed bugs [90, 92-94, 104]. Bai et al. [104] analysed using the 454-pyrosequencing technique the transcriptomic sequences of $C$. lectularius from the susceptible Harlan strain and one field-collected resistant strain and identified 45 putative cuticular protein genes that were possibly associated with insecticide resistance in bed bugs. Mamidala et al. [92] detected 46 cuticular protein genes that were upregulated in the deltamethrin-resistant strains of $C$. lectularius. Five cuticular protein genes [larval cuticle protein (LCP), pupal cuticle protein (PCP), chitin synthase (CHS), chitin deacetylase (CDA), and cuticular protein analogous to peritrophin (CPAP)] were further confirmed by quantitative real-time PCR (qRT-PCR) to be possibly associated with insecticide resistance in $C$. lectularius; these genes displayed higher transcript levels in resistant strains compared to those in susceptible strains [92]. Another 19 cuticular protein genes were similarly reported to be associated with insecticide resistance in C. lectularius, especially pyrethroid resistance [90, 94]. Overexpression of these genes were inferred to thicken or remodel the bed bug cuticle to reduce the insecticide penetration rate [94], which could prevent or slow the insecticide from reaching the target sites on nerve cells (Fig. 1b). These results suggested that penetration resistance significantly contributes to bed bug resistance to insecticides. Unfortunately, no study on penetration resistance in $C$. hemipterus has been reported so far.

Molecular assays such as dsRNA-mediated interference (RNAi) technique may not be able to verify the association between over-expression of culticular genes and penetration resistance since the cuticle has been thickened or remodelled [90]. Nevertheless, more recently, a study examining the relationship between cuticular thickness of C. lectularius and insecticide residual bioassays, revealed a positive correlation between the thickened cuticle and insecticide resistance level [95]. The authors found that highly pyrethroid-resistant individuals of the Parramatta strain of $C$. lectularius possessed a significantly thicker cuticle compared with that of an insecticide susceptible strain. Also, the cuticle thickness of this resistant strain was positively correlated to time-to-knockdown in insecticide bioassays [95]. Future studies should be performed to provide direct evidence on penetration resistance in bed bugs through in vivo assay using radio-labelled insecticide [105].

\section{Metabolic resistance}

Metabolic resistance is considered a key resistance mechanism and has been well reviewed in past literature [4-7]. Mamidala et al. [91] also provided a review of metabolic resistance in bed bugs. Based on these reports, three 
major groups of enzymes, namely P450s, esterases, and GSTs, as well as ABC transporters [90], are involved (Table 5) and may have a broad spectrum of activity against different insecticide classes [97]. Unfortunately, most of metabolic resistance research has been undertaken in C. lectularius; the studies on metabolic resistance in C. hemipterus are limited (Table 5).

\section{P450s}

P450s, the most important subset of the monooxygenase system, constitute one of the largest superfamilies of proteins found in all living organisms [106-108] and plays a significant role in the detoxification of insecticides $[100,109,110]$. Recently, more than 1700 genes of P450s were characterized from various insects [7, 111, 112], and 386 contigs of P450s associated with insecticide resistance were found in hematophagus insects [91].

There are two possible mechanisms attributed to up-regulation of P450 genes [112]: (i) constitutive transcriptional overexpression (mRNA levels), in which the gene is continually transcribed, and (ii) induced transcriptional overexpression, in which the expression of the gene is induced as needed. However, the factors regulating the overexpression of P450s in these two mechanisms are less known. The first mechanism is common in many insect pests, including bed bugs. Currently, the link between insecticide resistance and constitutive overexpression of $\mathrm{P} 450$ genes has been shown in C. lectularius [90, 92, 113]. Adelman et al. [113] found that the resistance ratios to deltamethrin and $\beta$-cyfluthrin in C. lectularius (Richmond strain, compared with susceptible Harlan strain) were 5167 and 111, respectively. Biochemical assays revealed that the P450 activities of the Richmond strain were significantly enhanced by $41 \%$ compared to that of the Harlan strain. In addition, genetic studies revealed that three P450 genes, namely CYP397A1 (>36-fold), CYP6DM2 (>29-fold) and CYP400A1 (>18-fold), were all significantly overexpressed in the Richmond strain [113]. The Richmond strain showed high resistance to pyrethroids due to overexpressed P450 genes (and possible other mechanisms as well). In addition, four P450 genes (CYP9 [104], CYP397A1V2, CYP6A2 and CYP6A13 [92]) were found to be putatively responsible for $C$. lectularius resistance to pyrethroids. The dsRNA-mediated interference (RNAi) technique confirmed that another four P450 genes (CYP397A1, CYP398A1, CYP6DN1 and CYP4CM1) were involved in $C$. lectularius pyrethroid resistance, as these genes were up-regulated in resistant strain(s) [90]. Molecular docking studies revealed that the $\mathrm{P} 450$ genes may confer cross-resistance to the major classes of insecticides (e.g. OCs, pyrethroids and neonicotinoids) used to control bed bugs [92]. All these findings suggest that P450mediated detoxification plays a key role in metabolic resistance to insecticides, especially the pyrethroids.
In the second mechanism, the expression of some P450 genes can be induced by exogenous and endogenous compounds which include insecticides [110] which led to increased resistance to insecticides $[114,115]$. This phenomenon had been reported in several insect pests, including $M$. domestica $[116,117]$ and the mosquito Culex quinquefasciatus (Say) [118]. Additionally, both mechanisms (constitutive and induced overexpression) can be exhibited in same insect population within an area, such as M. domestica [117]. However, in comparison with the constitutive overexpression, the induction associated with insecticide resistance is less well known and not described in bed bugs to date. Further studies should be conducted to better understand the mechanism of induction in bed bugs.

Currently, the mixture insecticide products which contain a neonicotinoid and a pyrethroid, are used to control bed bugs, particularly in the USA and other parts of the world [119]. Constitutive or both constitutive and induced overpression of P450 genes have been associated with neonicotinoid resistance in other insects $[117,120]$. In the wake of neonicotinoid resistance in $C$. lectularius [64], further studies are warranted to determine the role of P450s, as well as potential crossresistance in both species of bed bugs.

The reaction of the $\mathrm{P} 450$ system requires an electron transferred from nicotinamide adenine dinucleotide phosphate (NADPH) to the 4450 heme centre by a cytochrome P450 partner enzyme, NADPH-cytochrome P450 reductase (CPR), and/or cytochrome $b_{5}$ reductase in microsomal systems, and by an adrenodoxin-like ferredoxin coupled to an adrenodoxin reductase in mitochondrial systems [121-124]. Recently, Zhu et al. [122] sequenced and characterized the gene of CPR from $C$. lectularius $(C l C P R)$ and found that RNAi suppressed the expression of ClCPR, which led to the resistant CIN-1 strain (a field-collected C. lectularius strain collected in 2005 in Cincinnati, OH) showing increased susceptibility to deltamethrin. This finding verified at least a partial role of CPR in P450-mediated detoxification and indicated that P450-mediated metabolic resistance to pyrethroids occurred in the CIN-1 strain.

Piperonyl butoxide (PBO), a primary inhibitor of some cytochrome $\mathrm{P} 450$ monooxygenases, is used to characterize the possible involvement of P450-mediated detoxification as a resistance mechanism [125-127]. PBO could be included in formulations as a synergist of pyrethroid-based insecticides $[128,129]$ to enhance their efficacy. Romero et al. [128] used PBO to determine the role of P450s in deltamethrin resistance in two highly resistant $C$. lectularius strains (CIN-1: Cincinnati, OH, USA; WOR-1, collected in 2007 in Worcester, MA, USA). The results showed that the resistance level of CIN-1 and WOR-1 reduced from $>2588$ fold to 174-fold and from $>2588$-fold to 39-fold after treatment with $\mathrm{PBO}$, respectively, when compared to the 
corresponding results obtained with the Fort Dix (= Harlan) susceptible strain [128]. These results indicated that P450s contribute in part to the deltamethrin resistance in these strains of $C$. lectularius. Similar synergism studies were performed by How \& Lee [129] and Lilly et al. [127] for two Southeast Asian C. hemipterus strains and four Australian C. lectularius strains, respectively. Both studies supported that P450-mediated metabolic resistance to pyrethroids occurred in bed bugs.

\section{Esterases}

Esterases confer resistance to carbamates and OPs in many insect species $[2,4,5,7,130-132]$ as well as to pyrethroids [127, 133], mainly due to the activity of carboxylesterases $[134,135]$ and only in a few rare cases by arylesterases (aromatic esterases) [2].

Esterases (especially carboxylesterases) mediate metabolic resistance by two main mechanisms: (i) increased level of gene expression (quantitative change), and (ii) mutations in coding gene sequences (qualitative changes) [4, 7]. In the first mechanism (quantitative change), resistant insects overproduce non-specific esterases or carboxylesterases by gene up-regulation to quickly sequester the insecticides (e.g. carbamates and OPs) [133]. This mechanism has been documented in numerous insect species including mosquitoes, cattle ticks, aphids, cockroaches [4], and both C. hemipterus [56] and C. lectularius [64, 90, 113]. Adelman et al. [113] recently reported a significant increase in the general esterase activity (at least by $35 \%$ ) based on the biochemical assays in a highly resistant Richmond C. lectularius strain, when compared to that of the susceptible Harlan strain. Their subsequent findings based on genetic studies (via RNA sequencing and relative gene expression based on qRT-PCR) identified that two esterase-encoding genes, CE3959 and CE21331, were significantly overexpressed in the Richmond strain. These findings suggest that CE3959 and CE21331 may be candidate genes contributing to esterase-mediated resistance in C. lectularius. Zhu et al. [90] also found that the gene CLCE21331 (also known as CE21331) was associated with C. lectularius pyrethroid resistance, due to overexpression in resistant strains. They subsequently determined that the gene CLCE21331 showed maximum up-regulation ( $>50$-fold) in most field populations (76.2\% of 21 populations) compared with the susceptible LA-1 C. lectularius strain (collected in 2006 in Los Angeles, CA, USA [30]), that strongly suggests the importance of esterase-mediated metabolic resistance in bed bugs. Karunaratne et al. [56] found that elevated esterase mechanisms were present in C. hemipterus populations based on biochemical assays, and elevated levels of general esterases were similarly found to be associated with resistance to the neonicotinoids in C. lectularius [64]. However, further studies including the use of metabolism studies [105], should be attempted to experimentally validate the specific gene(s) encoding esterase mediated mechanism in bed bugs. Besides the biochemical assays and genetic studies on esterase-mediated resistance, researchers also have used bioassays in combination with synergists to investigate the activity levels of general esterases in resistant bed bug populations. Hardstone et al. [136] selected PBH (3-phenoxybenzyl hexanoate, a surrogate substrate for carboxylesterases and oxidases) as a metabolic synergist to suppress resistance to pyrethroids in C. lectularius. The authors found that PBH synergized the action of deltamethrin 6-fold on an insecticide-susceptible $C$. lectularius strain (FL-BB, collected from Gainesville, FL, USA, more than 20 years ago), and was 2.8 -fold more synergistic than $\mathrm{PBO}$. These findings suggested that esterases were involved in $C$. lectularius metabolic detoxification of deltamethrin. Similarly, Lilly et al. [127] employed a novel synergist, EN16/5-1 (6-[2-(2-butoxyethoxy) ethoxymethyl]-5-propyl2, 3-dihydrobenzofuranby), which mainly inhibits the activity of esterases, to determine if esterase-mediated pyrethroid resistance exists in C. lectularius. They found that the resistance in three of four $C$. lectularius strains to deltamethrin was significantly suppressed by EN16/5-1, which strongly suggested that esterases conferred metabolic resistance to C. lectularius in Australia.

In the second mechanism (qualitative changes), resistant insects can increase esterase-mediated metabolism due to a single point mutation or substitution in the structural genes. For example, the $L c a E 7$ gene of the sheep blowfly Lucilia cuprina (Wiedemann) encodes a carboxylesterase. A single point mutation on the $L c a E 7$ gene changes glycine at residue site 137 to an aspartic acid and then converts the carboxylesterase to an organophosphorus hydrolase that confers organophosphorus resistance [137, 138]. However, limited reports about this mechanism are available worldwide [7]. This mechanism still is a candidate mechanism and yet to be reported in bed bugs.

\section{GSTs (candidate resistance mechanism)}

GSTs mediate metabolic resistance to organophosphates, chlorinated hydrocarbons, and pyrethroids through catalyzing the conjugation of electrophilic compounds by reduced glutathione (GSH) [7, 139-141]. On the other hand, some insect GSTs catalyse a dehydrochlorination reaction by using GSH as a cofactor rather than as a conjugate $[7,141,142]$. GSTs are also involved in detoxification via xenobiotic binding, intracellular transport of endogenous lipophilic compounds, or sequestration [7].

Using biochemical assays, Karunaratne et al. [56] found that DDT resistance in a Sri Lankan $C$. hemipterus strain was associated with high GST levels, as dehydrochlorination of DDT by GSTs is a major route of detoxification in insects [141]. Adelman et al. [113] found that one GST gene (gsts1) was putatively associated with pyrethroid resistance in the Richmond C. lectularius strain due to up- 
regulated transcription, and three other GST genes were similarly identified by Mamidala et al. [92]. However, further studies on transgenic expression (such as those in Drosophila flies [143]) and metabolism studies [105], are urgently warranted to empirically confirm this mechanism in bed bugs.

\section{$A B C$ transporters}

ATP-binding cassette transporters ( $\mathrm{ABC}$ transporters) are one of the largest classes of transporters that are responsible for the ATP-powered translocation of many substrates across membranes. The function of $\mathrm{ABC}$ transporters is as either importers, which bring nutrients and other molecules into cells, or as exporters, which pump toxins, drugs and lipids across membranes [144-146]. In addition, ABC transporters were found to increase the efficiency of toxin removal from the targeted site. Hence, $\mathrm{ABC}$ transporters have been associated with resistance to major insecticide classes (Table 5) although not directly related to the detoxification of the compounds. In bed bugs, Mamidala et al. [92] suspected that $A B C$ transporters were involved in metabolic resistance in C. lectularius due to overexpression of the genes encoding $\mathrm{ABC}$ transporters. Zhu et al. [90] confirmed the role of $\mathrm{ABC}$ transporters (e.g. $A b c 8$ and $A b c$ 9) mediated metabolic resistance to pyrethroids ( $\beta$-cyfluthrin) in C. lectularius, via RNAi. In addition, the authors also identified this mechanism was widespread in the field populations (20/21) [90].

Biochemical and molecular assays have identified that P450s, esterases, and GSTs are associated with bed bug insecticide resisance. Synergism studies [95] and molecular assays based on RNAi [90] have confirmed that P450s and esterases as well as $\mathrm{ABC}$ transporters mediated resistance mechanisms exist to pyrethroids in C. lectularius. However, most of these mechanisms have yet to be demonstrated in C. hemipterus. In addition, further studies specifically involving metabolism experiments to empirically demonstrate the disappearance of the parent compound and an increase of metabolites in resistant strains would be helpful in clarifying the role of these mechanisms in bed bugs.

\section{Target site insensitivity}

Insecticides such as OPs, carbamates, DDT, and pyrethroids affect specific target sites (e.g. AChEs, VGSC, GABA receptor) (Table 5) that typically are associated with the insect nervous system [147]. Insecticide-resistant insects have evolved modifications at these target sites that allows for normal neurological function to occur, despite the presence of the toxicant. The four main types of target site insensitivity mechanisms in resistant insects are: (i) knockdown resistance ( $k d r$-type), which causes resistance to pyrethroids and DDT; (ii) altered AChEs, which confer resistance to OPs and carbamates; (iii) insensitive GABA receptors (also known as $\mathrm{rdl}$-mutation), which provide resistance to cyclodienes and phenylpyrazoles; and (iv) altered nAChRs, which confer resistance to neonicotinoids $[6,147,148]$.

\section{$K d r$}

VGSCs are essential for normal transmission of nerve impulses [149]. DDT and pyrethroids act on or bind to the VGSC proteins to disrupt the process, which is followed by knockdown, paralysis, and eventually death of the insect. Many insect pests have evolved moderate to high levels of resistance to DDT and pyrethroids by reducing target site sensitivity (so-called $k d r$ ) [150]. The first case of reduced neuronal sensitivity to DDT was reported in the 1950s in $M$. domestica [151]. The $k d r$-resistance is a recessive trait that confers cross-resistance to most pyrethroids as well as DDT and its analogues $[46,152]$.

The VGSC gene from D. melanogaster was originally cloned and sequenced in the late 1980s [153]. This study revealed how to sequence the VGSC gene of both resistant and susceptible insects. Several studies showed that $k d r-$ type resistance to DDT and pyrethroids results from a single or multiple point mutations (also known as $k d r$ mutations) in coding sequences of VGSC in various insect pests (Fig. 2) [46, 150, 154, 155], including bed bugs $[17,54,156,157]$. Yoon et al. [156] first cloned and sequenced the coding gene of $C$. lectularius VGSC from both insecticide resistant and susceptible strains in the USA. Two $k d r$ mutations (V419L: valine 419 to leucine, and L925I: leucine 925 to isoleucine) were linked to confer pyrethroid resistance in C. lectularius [156]. These two $k d r$ mutations (either one or both) were found to be widely distributed across the USA in C. lectularius (88\% of 117 strains [157] and $85.7 \%$ of 21 strains [90] in different studies). One hundred percent of the tested $C$. lectularius collected from Paris, France [158] and Berlin, Germany [159] only contained L925I. Of C. lectularius collected from various locations in Australia (25 strains), 96\% possessed L925I [55], while from Israel (12 strains), 100\% had L925I, of which, a few specimens from both countries had additional V419L $[54,160]$. Based on the various genotypes of V419L and L925I mutations of 110 field-collected strains of C. lectularius in the USA, Zhu et al. [157] identified four haplotypes; haplotype A (without V419L and L925I mutations; 15.5\% [17/110]), haplotype B (only L925I; 40.9\% [45/110]), haplotype C (V419L and L925I; 40.9\% [45/110]) and haplotype D (V419L; 2.7\% [3/110]).

Recently, a novel mutation, I936F (isoleucine 936 to phenylalanine), was identified in the VGSC gene of one field-collected C. lectularius strain (from Adelaide in Australia) that was linked to low levels of resistance to $\mathrm{d}$-allethrin [54]. This novel mutation was also found in museum preserved $C$. lectularius specimens collected over 1994-2002 from four disparate locations (4/7) and one 


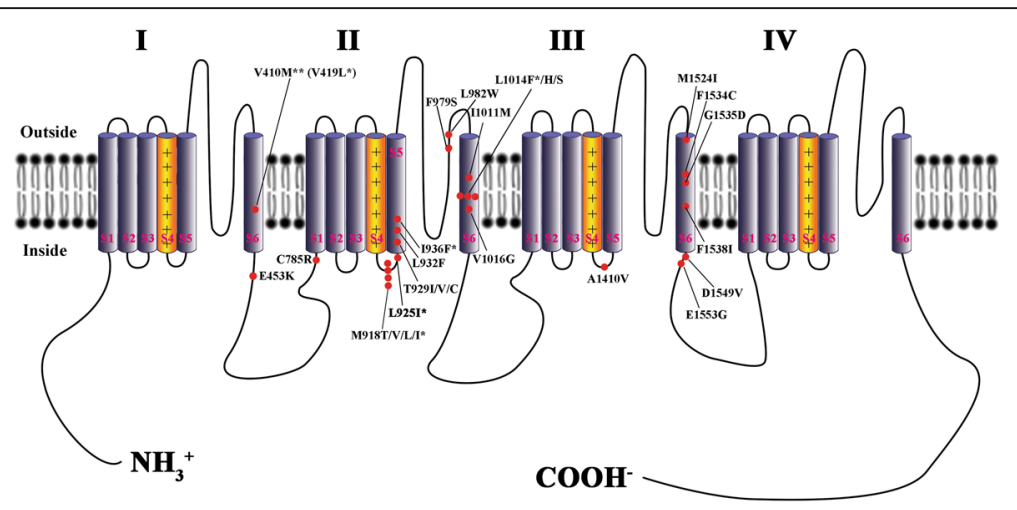

Fig. $2 \mathrm{kdr}$ mutations in insect voltage-gated sodium channels implicated in pyrethroid/DDT resistance. All information of $k d r$ mutation sites came from Davies \& Williamson [150], Zhu et al. [157] and Dang et al. [17, 54]. I, II, III and IV, four homologous repeat transmembrane domains. One asterisk indicates $k d r$ mutations (or putative $k d r$ mutations) identified from both the common bed bug C. lectularius (V419L, valine to leucine; L925I, leucine to isoleucine; putative 1936F, isoleucine to phenylalanime) and the tropical bed bug C. hemipterus (putative M918l, methionine to isoleucine; putative L1014F, leucine to phenylalanime). Two asterisks: V410 found in the tobacco budworm Heliothis virescens (F.) and V419 found in C. lectularius are the same residue

field-collected Perth C. lectularius strain (collected in 2007), all from Australia [54]. Interestingly, the museum preserved specimens and the Adelaide strain did not have the $k d r$ V419L and L925I mutations (haplotype A). Only the Perth strain had the L925I mutation (haplotype B). The novel I936F mutation was probably once relatively prevalent in preserved Australian C. lectularius specimens (without V419 L and L925I) but largely disappeared after 2004, when the knowledge of bed bug control practices was improved $[15,54]$. It is possible that I936F only conferred low levels of resistance and the populations with the mutation did not survive, as the Adelaide strain showed relatively higher susceptibility to d-allethrin than that in other strains with L925I or both V419L and L925I [54]. Although I936F mutation confers low levels of resistance, it may help other mutation(s) or other resistance mechanism(s) to evolve. The findings that the Australian Perth C. lectularius strain had L925I and both L925I and I936F mutations [54] may support this scenario.

Another recent study has identified four novel mutations in the VGSC genes of C. hemipterus collected from multiple countries, including Australia [L899V (leucine 899 to valine), M918I (methionine 918 to isoleucine), D953G (aspartic acid 953 to glycine) and L1014F (leucine 1014 to phenylalanine)], Thailand (M918I, D953G and L1014F), India (M918I and L1014F), Malaysia (L1014F) and Kenya (L1014F), of which, two mutations (M918I and L1014F) were associated with high resistance to pyrethroids in C. hemipterus [17]; however the presence of other resistance mechanisms were not excluded. These two sites are known to confer pyrethroid resistance in a wide range of insect pests (Fig. 2) [150, 157]. The I936F, M918I and L1014F mutations could be verified as $k d r$ mutations in bed bugs by functional expression of each mutation individually and in combination using the
Xenopus oocyte expression system with two-electrode voltage-clamp electrophysiology [161], although this has yet to be undertaken.

The reports of the various mutations in the VGSC genes suggest that $k d r$-resistance in $C$. lectularius and $C$. hemipterus is widespread. Seong et al. [162] found that deltamethrin resistance levels increased in C. lectularius with increasing frequency of the resistance allele (e.g. L925I mutation). The M918I mutation, which was always found together with the L1014F mutation, probably plays a synergistic role in enhancing pyrethroid resistance in $C$. hemipterus [17]. These findings may suggest that multiple $k d r$ mutations play a significant role in bed bug resistance to pyrethroids and DDT.

It is noteworthy that the $k d r$ mutations found in the two sympatric species (C. hemipterus and C. lectularius) have occurred at different regions in the genome and not identical between the two species. In contrast to $C$. lectularius, $k d r$ mutations in $C$. hemipterus may likely have occurred from the malaria control programs (e.g. the widespread use of pyrethroid-treated bed-nets and indoor residual wall sprays of DDT/pyrethroid) in the tropics [12, 28, 55, 56]. Cimex hemipterus from Kenya (with L1014F), Malaysia (L1014F), India (M918I and L1014F) had similar mutations, in which, these mutations were also found in malaria vectors of Anopheles spp. [46, 163]. The presence of $k d r$ mutations in Anopheles spp. could have severe consequences for the sustainable use of pyrethroids, especially when pyrethroids are presently used for treating bed nets [164]. On the other hand, mutations may be completely random, and the different $k d r$ mutations occurring between $C$. lectularius and $C$. hemipterus may be a function of this randomness and completely unrelated to the use of a particular insecticide. 


\section{Altered AChEs (candidate resistance mechanism)}

The first report of insensitivity of AChE to OPs and carbamates was reported in the spider mite Tetranychus urticae (Koch), and subsequently reduced sensitivity of AChE was reported as a common OP/carbamate resistance mechanism in many insect species [4, 165-168].

The genetic study of the gene sequence and genomic structure encoding for AChE (symbol: Ace) in different insects revealed that sensitivity of AChE to inhibition was reduced by altered amino acids caused by point mutations on the Ace gene [169, 170], which is referred to as 'altered AChE'. For example, the malathion-resistant MH19 strain of $D$. melanogaster was found to contain a single amino acid substitution, F368Y (phenylalanine 368 to tyrosine), caused by a point mutation in the Ace gene. This point mutation was found to confer resistance to malathion by Pelement transformation experiments [165]. Subsequently, three other point mutations [phenylalanine 115 to serine (F115S), isoleucine 199 to threonine/valine (I199T/V), and glycine 303 to alanine (G303A)] in the Ace gene sequence of $D$. melanogaster were identified [171]. These four mutations in D. melanogaster associated with resistance to OPs and carbamates were verified using the Xenopus laevis oocyte expression system [171]. Furthermore, other mutations in the gene encoding $\mathrm{AChE}$ have been found in other insects $[4,170]$ which reduce the degree of AChE inhibition by insecticides. Additionally, like the $k d r$-type resistance, insecticide resistance due to altered AChE may produce a broad range of cross-resistance among OPs and carbamates $[172,173]$.

Several studies had identified resistance to OPs and carbamates in both $C$. lectularius $[11,44,47,53]$ and $C$. hemipterus [12, 56, 129]. Karunaratne et al. [56] reported that $29-44 \%$ of Sri Lankan C. hemipterus populations showed target site AChE insensitivity, and this may be responsible for resistance to both OPs and carbamates.

Recently, Seong et al. [168] identified and characterized the full-length-cDNA sequences encoding two AChEs (CAChE1 and CAChE2) from C. lectularius. Hwang et al. [174] examined the molecular and enzymatic properties of these two AChEs. The relatively higher correlation between in vitro ClAChE1 inhibition and in vivo toxicity suggested that ClAChE1 is the more relevant toxicological target for OPs and carbamates in C. lectularius. These findings offer valuable insights into altered $\mathrm{AChE}$-mediated resistance in bed bugs, although most of these AChE-inhibitor insecticides have been prohibited for usage indoor against bed bugs in many parts of the world.

\section{Insensitive GABA receptor (candidate resistance mechanism)}

The GABA-gated chlorine channel, which is also known as the GABA receptor, is the validated target for cyclodiene (e.g. dieldrin) and phenylpyrazole (e.g. fipronil) [175-178].
Resistance to cyclodienes in several insect pests is caused by a single mutation [A302S/G: alanine 302 to serine/glycine (residue 302 in D. melanogaster, and residue 296 in An. gambiae are the same residue)] in the GABA receptor $[147,179,180]$. The replacement of alanine 302 affects the binding site and destabilizes the preferred conformation of the receptor [181]. Furthermore, an additional mutation (V327I: valine to isoleucine) was detected in the same gene, and it was consistently associated with the mutation A296S (alanine 296 to serine) in resistant anophelines [182].

Several studies had identified resistance to dieldrin in both $C$. lectularius and C. hemipterus [38], but both cyclodienes and phenylpyrazoles are currently not legally allowed to be used against bed bugs in most countries. Recently, the genome sequencing of $C$. lectularius was completed, and the resistance to dieldrin $(R d l)$ gene encoding the GABA receptor was identified [93]. This cyclodiene target site is a target site for phenylpyrazoles (e.g. fipronil) as well. Therefore, these data may provide an important clue to reveal the resistance mechanism of insensitive GABA receptor to both cyclodienes and phenylpyrazoles in bed bugs in the future.

\section{Altered nAChRs (candidate resistance mechanism)}

Neonicotinoids are widely used to control a broad range of sucking insect pests in plants [58, 120]. Neonicotinoids act selectively on the insect central nervous system as agonists of the nAChRs, opening the channel and causing continuous depolarisation and firing of postsynaptic neurons resulting in paralysis and death [183]. With the increase of neonicotinoid usage, resistance to these insecticides has increasingly been reported, not only due to metabolic detoxification mechanism, such as P450s, but also due to the target-site mutation(s) on nAChRs [120, 184]. For example, the mutation R81T (arginine 81 to threonine) present in the $\beta 1 \mathrm{nAChR}$ subunit confers high levels of resistance to imidacloprid in cotton-melon aphid, Aphis gossypii (Glover) [185] and green peach aphid, Myzus persicae (Sulzer) [186]. More recently, Romero \& Anderson [64] reported high levels of neonicotinoid resistance in $C$. lectularius. Although metabolic resistance including general esterases may be involved [64], the role of altered $\mathrm{nAChR}$ has never been confirmed in the bed bug.

\section{Symbiont-mediated insecticide resistance (candidate resistance mechanism)}

Symbiotic relationships between animals and microorganisms are common in nature. Various microorganisms have established associations with animal hosts through parasitism, mutualism and commensalism, or by ectosymbiosis and endosymbiosis [187]. In insects, bacterial symbionts, such as Wolbachia, commonly associated with hosts, can manipulate insect host reproduction and nutritional mutualism [188]. Interestingly, bacterial symbionts have been 
identified to be involved in insecticide resistance in some insect pests, which is termed 'symbiont-mediated' insecticide resistance [189, 190]. Kikuchi et al. [189] found that fenitrothion-degrading Burkholderia endosymbiont strains established a specific and beneficial symbiosis with the soybean bug Riptortus pedestris (F.) and conferred fenitrothion resistance. Apart from Burkholderia, a variety of organophosphorus degraders have been isolated and characterized from many bacterial genera [191]. In addition, bacterial symbionts can be involved in insect resistance to biological agent such as Bacillus thuringiensis Berliner [192] and the parasitoid wasp Aphidius ervi Haliday [193]. A recent study suggested a correlation between the high bacterial densities (e.g. Arsenophonus, Rickettsia, and Wolbachia) in whitefly Bemisia tabaci (Gennadius) and the insect's ability to detoxify toxic compounds such as insecticides (e.g. thiamethoxam, imidacloprid, pyriproxyfen and spiromesifen) [194].

Recently, molecular studies identified various symbionts, especially the bacterial symbionts, in bed bugs [104, 188, 195-197], although the first endosymbiont, Rickettsia lectularia Arkwright et al. (= Symbiotes lectularius), was documented by light microscopy in C. lectularius almost 90 years ago [198]. Hypsa \& Aksoy [195] first isolated two symbionts, Wolbachia (an alpha-proteobacterium) and a BEV-like symbiont (an unnamed gamma-proteobacterium) from ovary tissue of $C$. lectularius, which were later found to be responsible for manipulating reproduction of bed bugs [196]. Subsequently, Wolbachia was found to play an essential role in nutritional mutualism in C. lectularius [188]. A transcriptomic study by Bai et al. [104] identified a total of $14.24 \%$ of non-insect transcriptomic sequences (e.g. non-insect eukaryotes, $11.16 \%$, fungi, $1.78 \%$, bacteria, $1.21 \%$, viruses, $0.04 \%$, Archaea, $0.02 \%$, and artificial sequences, $0.03 \%$ ) in C. lectularius that probably belongs to various symbionts or pathogens in bed bugs. In fact, a genomic study by Benoit et al. [197] further demonstrated various sequences from multiple bacterial symbionts and/ or possible pathogens, or opportunists in C. lectularius, for instance, Arsenophous, Wolbachia, Sodalis, Hamiltonella, Peptoclostridium, Methanococcus, Serratia, Shewanella, and 81 other genera. Despite the presence of multiple functional symbionts in bed bugs, their potential role in mediating insecticide resistance in bed bugs is still undocumented and should be considered in future studies.

\section{Monitoring insecticide resistance}

Over the last few years, there have been many reports of insecticide resistance in bed bugs worldwide. Monitoring insecticide resistance status and resistance mechanisms in bed bugs is a proactive and essential approach to determine proper insecticide usage and to provide early warning for the need to modify chemical control strategies. Numerous studies on the methods of detecting and documenting insecticide resistance in pest populations have been evaluated. The three major methods of monitoring insecticide resistance are (i) conventional toxicity bioassays, (ii) biochemical assays, and (iii) molecular assays (Table 6).

\section{Conventional toxicity bioassays}

The standard bioassay that is routinely used to detect insecticide resistance involves collecting insects from the field and rearing them until sufficient numbers are available for testing. Mortality of nymphs or adults is then assessed after exposure to a range of doses of an insecticide. Subsequently, the $\mathrm{LD}_{50}, \mathrm{LC}_{50}$ or $\mathrm{LT}_{50}$ values are determined using probit analysis. The results from field populations are then compared with those from a susceptible population, and a resistance ratio is calculated to estimate the susceptibility of field populations. The susceptibility of recent collected bed bugs to major insecticide classes (such as pyrethroids, OPs, carbamates, and neonicotinoids) have been evaluated using bioassays (Table 7) [30, 44, 48, 53, 64].

However, bioassays can be difficult to undertake. Normally this method requires a relatively large number of live bed bugs for the test, and obtaining such numbers is not always possible, especially when the number of bed bugs collected from field infestations can be relatively small $[17,162]$. In addition, a standard susceptible strain is required for comparison, but many organisations do not have access to such a strain. A few susceptible $C$. lectularius strains are maintained in laboratories around the world, such as the Ft. Dix strain (= Harlan strain, established in 1973) [30, 113], FL-BB strain (early 1990s) $[30,136]$, LA-1 strain (2006) [30, 90], UBA strain of the Federal Environment Agency (since 1947) [159], and Monheim (Germany) strain (late 1960s) [53], but to date, no susceptible $C$. hemipterus strain is available. Other traditional bioassays, such as the use of discriminating concentrations which are based on previous studies on the dose-response curves of susceptible strains, could be an alternative option [16, 39], if there is no susceptible strain or sufficient number of live bed bugs available for testing. However, a single discriminating dose could only indicate whether resistance is present, but not the degree of resistance.

Most insecticide resistance monitoring depends on traditional bioassays, which use a fixed insecticide concentration (e.g. discriminating/diagnostic concentration) for a pre-determined exposure time in a chamber or on a filter paper impregnated with insecticides. The results are reported as percentage mortality and/or knockdown effect. For example, the diagnostic concentration (or WHO susceptibility test kit) defined by the World Health Organization (WHO) (e.g. twice the concentration/dosage that kills $100 \%$ of the susceptible insect strain) is widely 
Table 6 Methods used to monitor for insecticide resistance in bed bugs (Cimex spp.)

\begin{tabular}{|c|c|c|}
\hline Method $^{a}$ & Advantages & Disadvantages \\
\hline $\begin{array}{l}\text { Bioassays via dose/ } \\
\text { concentration-response } \\
\text { assays }\end{array}$ & Provide levels of resistance & $\begin{array}{l}\text { Require a susceptible strain, need large numbers of live bed } \\
\text { bugs; regardless of mechanism(s) }\end{array}$ \\
\hline $\begin{array}{l}\text { Bioassays via } \\
\text { discriminating } \\
\text { concentration/dose } \\
\text { assays }\end{array}$ & $\begin{array}{l}\text { Standardized (e. g. WHO susceptibility test kits); } \\
\text { simple to perform }\end{array}$ & $\begin{array}{l}\text { Provide no information about levels of resistance and type of } \\
\text { resistance mechanism(s) (except when using synergists); lack } \\
\text { sensitivity }\end{array}$ \\
\hline Biochemical assays & $\begin{array}{l}\text { Require a small sample size; sensitive; provide indirect } \\
\text { evidence on specific resistance mechanism(s) }\end{array}$ & $\begin{array}{l}\text { Require sophisticated and costly equipment and the } \\
\text { technology which pest managers do not have ready access } \\
\text { to; require materials to be kept frozen }\end{array}$ \\
\hline Molecular assays & $\begin{array}{l}\text { Require a small sample size; very sensitive; provide } \\
\text { informations on specific resistance mechanism(s); can detect } \\
\text { resistance alleles (e. g. } k d r \text { mutations), even from dead body; } \\
\text { could develop specific molecular markers to detect specific } \\
\text { mechanism(s) }\end{array}$ & $\begin{array}{l}\text { Require specific and costly equipment, high ongoing costs } \\
\text { and the technology which pest managers may not have } \\
\text { access to; costly reagents, require materials to be kept frozen }\end{array}$ \\
\hline
\end{tabular}

Information from Ranson et al. [163], Seong et al. [162] and Dang et al. [16]

used to determine the susceptibility or resistance to major classes of insecticides in mosquito vectors [38, 39]. Several studies have investigated bed bug resistance using this method (Table 7). Myamba et al. [55] adapted the WHO mosquito test kit [199] to detect pyrethroid resistance in $C$. hemipterus in Tanzania. Karunaratne et al. [56] also adapted the WHO method [39] to determine resistance to several insecticides in C. hemipterus in Sri Lanka. Tawatsin et al. [12] examined the insecticide resistance of both $C$. lectularius and C. hemipterus in Thailand using the WHO test kit [200].

Similar to the WHO methods, many studies established the baseline susceptibility data (e.g. $\mathrm{LC}_{99} / \mathrm{LD}_{99}$ ) for insecticides that results in $99 \%$ or more mortality of susceptible bed bug strain(s) (Table 7) [30, 47, 53, 201, 202]. These data can serve as guidelines for selecting discriminating concentrations to screen for bed bug resistance to insecticides, even in the absence of a susceptible strain. For example, Boase et al. [47] established two different discriminating concentrations that produced $99 \%$ mortality in three susceptible C. lectularius strains in the United Kingdom to detect resistance to bendiocarb (carbamates) and alphacypermethrin (pyrethroids), respectively. Romero et al. [30] used a discriminating concentration (10-fold greater than the labelled rate of active ingredient in the commercial product and nearly 30-fold the dose required to kill $100 \%$ of the susceptible Ft. Dix C. lectularius strain) to evaluate resistance to deltamethrin in third-to-fifth instar C. $l$ ectularius of 10 field-collected populations. Zhu et al. [157] also used this discriminating concentration to assess resistance to pyrethroids in $17 \mathrm{C}$. lectularius populations. Kilpinen et al. [53] determined the $C$. lectularius resistance to permethrin by the discriminating concentration of 1.6fold $\mathrm{LD}_{99}$ and chlorpyrifos by the concentration of 2-fold $\mathrm{LD}_{99}$, respectively. However, if the discriminating concentrations used are excessively high, this could potentially mask the detection of resistance, especially when the resistance level is still relatively low. Early detection of resistance is only possible if the diagnostic concentration is low enough (or a dose response curve undertaken). Otherwise, resistance could only be discovered after widespread field control failures are reported.

Once the resistance status is determined, the resistance mechanisms should next be characterized. A rapid and simple bioassay in combination with synergists could be used to detect some metabolic resistance mechanisms. Synergists serve as enzyme inhibitors of metabolic detoxification enzymes such as esterases, P450s, and GSTs (Table 8). Bioassays incorporating synergists have been used widely to detect the role of different resistance mechanisms in many insect pests. For example, synergists, such as $\mathrm{PBO}$, have been incorporated in the control of bed bugs, and to detect potential resistance mechanisms [127-129, 136]. However, not all resistance mechanisms could be characterized using synergists. Therefore, biochemical assays and molecular assays must be employed along with insecticide bioassays to detect the specific resistance mechanisms (Tables 6, and 9).

\section{Biochemical assays}

Biochemical assays use model substrates to detect elevated activity of metabolic enzymes involved in insecticide resistance in individual insects. Over the last two decades, biochemical assays have been used successfully to detect and monitor insecticide resistance in numerous insects [203] especially in combination with insecticide bioassay. Karunaratne et al. [56] surveyed insecticide resistance and potential resistance mechanisms in Sri Lankan C. hemipterus based on toxicity bioassays [36, 39] and biochemical assays [203]. They found that C. hemipterus showed high levels of resistance to DDT and malathion, and detected elevated levels of GSTs and esterases as well. Yoon et al. [156] used biochemical assays to identify resistance mechanisms responsible for deltamethrin 
Table 7 Published discriminating doses and susceptibility baselines used to detect insecticide resistance in bed bugs (Cimex spp.)

\begin{tabular}{|c|c|c|c|c|c|}
\hline \multirow[t]{2}{*}{ Insecticide } & \multirow{2}{*}{$\begin{array}{l}\text { Discriminating } \\
\text { concentration }\end{array}$} & \multirow[t]{2}{*}{ Assessment } & \multicolumn{2}{|c|}{ Susceptibility baseline } & \multirow[t]{2}{*}{ Reference } \\
\hline & & & $\mathrm{LC}_{50} / \mathrm{LD}_{50}$ & $\mathrm{LC}_{90(99)} / \mathrm{LD}_{90(99)}$ & \\
\hline \multicolumn{6}{|l|}{ C. lectularius } \\
\hline $\mathrm{DDT}^{\mathrm{a}}$ & $4 \%$ & $5 d^{f}$ & - & - & [39] \\
\hline Dieldrin $^{a}$ & $0.8 \%$ & $2 d^{f}$ & - & - & [39] \\
\hline Fenitrothion $^{\mathrm{b}}$ & $1 \%$ & $5 h^{f}$ & - & - & [39] \\
\hline Malathion ${ }^{\mathrm{b}}$ & $5 \%$ & $16 h^{f}$ & - & - & [39] \\
\hline Trichlorfon $^{b}$ & $1 \%$ & $5 h^{f}$ & - & - & [39] \\
\hline Propoxur ${ }^{c}$ & $0.8 \%$ & $24 h^{f}$ & - & - & [39] \\
\hline Permethrin ${ }^{d}$ & $0.25 \%$ & $C^{f}$ & - & - & [39] \\
\hline Deltamethrin $^{d}$ & $0.025 \%$ & $C^{f}$ & - & - & [39] \\
\hline Dichlorvos $^{\mathrm{b}}$ & - & $24 h^{f}$ & 2.9 ppm & 5.7 ppm & [202] \\
\hline Pirimiphos-methyl ${ }^{\mathrm{b}}$ & - & $24 h^{f}$ & 13.5 ppm & 29.8 ppm & [202] \\
\hline$\lambda$-cyhalothrin ${ }^{d}$ & - & $24 h^{f}$ & 22.2 ppm & $357.7 \mathrm{ppm}$ & [202] \\
\hline Permethrin ${ }^{d}$ & - & $24 h^{f}$ & 71.4 ppm & 201.7 ppm & {$[202]$} \\
\hline Bendiocarb $^{c}$ & - & $24 h^{f}$ & 47.1 ppm & 95.9 ppm & [202] \\
\hline Malathion ${ }^{\mathrm{b}}$ & - & $24 h^{f}$ & 92 ppm & 245 ppm & [202] \\
\hline Carbaryl $^{c}$ & - & $24 h^{f}$ & 166.3 ppm & 245 ppm & [202] \\
\hline Tetrachlorvinphos ${ }^{\mathrm{b}}$ & - & $24 h^{f}$ & 252 ppm & $472.7 \mathrm{ppm}$ & [202] \\
\hline Bendiocarb ${ }^{c}$ & $35.3 \mathrm{M}$ & $48 h^{f}$ & - & $35.3 \mathrm{M}$ & {$[47]$} \\
\hline a-cypermethrin ${ }^{d}$ & $23.1 \mathrm{M}$ & $48 h^{f}$ & - & $23.1 \mathrm{M}$ & {$[47]$} \\
\hline Deltamethrin $^{d}$ & $0.06 \%$ & $C^{g}$ & - & - & {$[48]$} \\
\hline Deltamethrin $^{d}$ & $1300 \mathrm{M}\left(30 \times \mathrm{LC}_{99}\right)$ & $24 h^{f}$ & $3.1 \mathrm{M}$ & $44 \mathrm{M}$ & {$[30]$} \\
\hline$\lambda$-cyhalothrin ${ }^{d}$ & - & $24 h^{f}$ & $2.16 \mathrm{M}$ & $66 M$ & [30] \\
\hline Deltamethrin $^{d}$ & $1 \%$ & $C^{f}$ & - & - & [156] \\
\hline Deltamethrin $^{\mathrm{d}}$ & - & $24 h^{f}$ & $1.4 \mathrm{M}$ & $19.2 \mathrm{M}$ & [201] \\
\hline Bendiocarb ${ }^{c}$ & - & $24 h^{f}$ & $6.5 \mathrm{M}$ & $38.1 \mathrm{M}$ & {$[201]$} \\
\hline Pirimphos-methyl ${ }^{\mathrm{b}}$ & - & $\mathrm{T}, 24 \mathrm{~h}$ & $0.11 \mathrm{U}$ & - & {$[49,52]$} \\
\hline Imidacloprid $^{e}$ & - & $\mathrm{T}, 24 \mathrm{~h}$ & $0.0057 \mathrm{U}$ & - & {$[49,52]$} \\
\hline Bendiocarb ${ }^{c}$ & - & $\mathrm{T}, 24 \mathrm{~h}$ & $0.027 \mathrm{U}$ & - & {$[49,52]$} \\
\hline Permethrin $^{d}$ & - & $\mathrm{T}, 24 \mathrm{~h}$ & $0.00044 \cup$ & - & {$[49,52]$} \\
\hline Deltamethrin $^{d}$ & - & $\mathrm{T}, 24 \mathrm{~h}$ & $0.00057 \cup$ & - & {$[49,52]$} \\
\hline Deltamethrin $^{d}$ & - & $1 \mathrm{~h}^{\mathrm{f}}$ & 18.1 ppm & 81.8 ppm & [162] \\
\hline Deltamethrin $^{d}$ & & $12 h^{f}$ & $3.2 \mathrm{ppm}$ & 26 ppm & [162] \\
\hline$\lambda$-cyhalothrin ${ }^{d}$ & & $1 \mathrm{~h}^{\mathrm{f}}$ & 17.7 ppm & 87 ppm & {$[162]$} \\
\hline$\lambda$-cyhalothrin ${ }^{d}$ & & $12 h^{f}$ & 3.4 ppm & 30 ppm & [162] \\
\hline Deltamethrin $^{d}$ & $1300 \mathrm{M}\left(30 \times \mathrm{LC}_{99}\right)$ & $24 \mathrm{~h}^{f}$ & - & - & [157] \\
\hline Deltamethrin $^{d}$ & - & $\mathrm{IT}, 24 \mathrm{~h}$ & $0.00003 \cup$ & - & [113] \\
\hline$\beta$-cyfluthrin ${ }^{d}$ & - & $\mathrm{IT}, 24 \mathrm{~h}$ & $0.00004 \mathrm{U}$ & - & [113] \\
\hline $\mathrm{DDT}^{\mathrm{a}}$ & $4 \%$ & $C^{f}$ & - & - & {$[12]$} \\
\hline Dieldrin $^{a}$ & $0.8 \%$ & $C^{f}$ & - & - & [12] \\
\hline Bendiocarb ${ }^{c}$ & $0.1 \%$ & $C^{f}$ & - & - & [12] \\
\hline Propoxur ${ }^{c}$ & $0.1 \%$ & $C^{f}$ & - & - & [12] \\
\hline Malathion ${ }^{\mathrm{b}}$ & $5 \%$ & $C^{f}$ & - & - & [12] \\
\hline Fenitrothion $^{\mathrm{b}}$ & $1 \%$ & $C^{f}$ & - & - & [12] \\
\hline
\end{tabular}


Table 7 Published discriminating doses and susceptibility baselines used to detect insecticide resistance in bed bugs (Cimex spp.) (Continued)

\begin{tabular}{|c|c|c|c|c|c|}
\hline Cyfluthrin $^{d}$ & $0.15 \%$ & $C^{f}$ & - & - & [12] \\
\hline Deltamethrin $^{d}$ & $0.05 \%$ & $C^{f}$ & - & - & [12] \\
\hline Permethrin $^{d}$ & $0.75 \%$ & $C^{f}$ & - & - & [12] \\
\hline$\lambda$-cyhalothrin ${ }^{d}$ & $0.05 \%$ & $C^{f}$ & - & - & [12] \\
\hline Etofenprox $^{d}$ & $0.5 \%$ & $C^{f}$ & - & - & [12] \\
\hline Permethrin $^{d}$ & $2.56 \cup\left(1.6 \times L^{2} C_{99}\right)$ & T, 24/48 h & $0.159 \mathrm{U}$ & $1.65 \mathrm{U}$ & [53] \\
\hline Permethrin $^{d}$ & $57.6 \mathrm{M}$ & $40 \min ^{\mathrm{h}}$ & - & - & [53] \\
\hline Deltamethrin $^{d}$ & $19.6 \mathrm{M}$ & $40 \min ^{\mathrm{h}}$ & - & - & [53] \\
\hline Chlorpyrifos $^{\mathrm{b}}$ & $0.2 \cup\left(2 \times L_{99}\right)$ & T, 24/48 h & $0.03 \mathrm{U}$ & $0.1 \mathrm{U}$ & [53] \\
\hline Chlorpyrifos $^{b}$ & $53 \mathrm{M}$ & $40 \min ^{\mathrm{h}}$ & - & - & [53] \\
\hline Malathion ${ }^{b}$ & $0.007 \%\left(2 \times L_{95}\right)$ & T & - & - & [248] \\
\hline Diazinon $^{b}$ & $0.02 \%\left(2 \times \mathrm{LC}_{95}\right)$ & T & - & - & [248] \\
\hline Trichlorfon $^{\mathrm{b}}$ & $1.4 \%\left(2 \times L C_{95}\right)$ & T & - & - & [248] \\
\hline Chlorpyrifos $^{\mathrm{b}}$ & $0.014 \%\left(2 \times L C_{95}\right)$ & T & - & - & {$[248]$} \\
\hline Permethrin $^{d}$ & $0.03 \%\left(2 \times L C_{95}\right)$ & $\mathrm{T}$ & - & - & [248] \\
\hline Cypermethrin $^{d}$ & $0.00008 \%\left(2 \times L^{2} C_{95}\right)$ & T & - & - & [248] \\
\hline a-cypermethrin ${ }^{d}$ & $0.000001 \%\left(2 \times L C_{95}\right)$ & T & - & - & [248] \\
\hline Deltametrhrin $^{d}$ & $0.00008 \%\left(2 \times L^{2} C_{95}\right)$ & T & - & - & [248] \\
\hline$\lambda$-cyhalothrin ${ }^{d}$ & $0.00005 \%\left(2 \times L C_{95}\right)$ & T & - & - & {$[248]$} \\
\hline Imidacloprid $^{e}$ & $0.0015 \%\left(2 \times L_{95}\right)$ & T & - & - & {$[248]$} \\
\hline Acetamiprid $^{e}$ & $0.0044 \%\left(2 \times L^{2} C_{95}\right)$ & $\mathrm{T}$ & - & - & [248] \\
\hline Deltamethrin $^{d}$ & $1300 \mathrm{M}\left(30 \times \mathrm{LC}_{99}\right)$ & $24 h^{f}$ & - & - & [92] \\
\hline Deltamethrin $^{d}$ & $0.06 \cup\left(100 \times L D_{50}\right)$ & $\mathrm{T}, 24 \mathrm{~h}$ & $0.0006 \mathrm{U}$ & - & [122] \\
\hline Deltamethrin $^{d}$ & - & $24 h^{f}$ & $30 \mathrm{M}$ & - & {$[90]$} \\
\hline Deltamethrin $^{d}$ & - & $\mathrm{T}$ & $0.0004 U$ & - & [94] \\
\hline$\beta$-cyfuthrin ${ }^{d}$ & - & T & $0.00308 \mathrm{U}$ & - & [94] \\
\hline Deltamethrin $^{d}$ & - & $24 \mathrm{~h}^{\mathrm{f}}$ & $2.58 \mathrm{M}$ & & [159] \\
\hline d-allethrin ${ }^{d}$ & $40 \mathrm{mg} / \mathrm{mat}$ & $24 h^{i}$ & - & - & {$[16,54]$} \\
\hline Imidacloprid $^{e}$ & - & $\mathrm{T}, 72 \mathrm{~h}$ & $0.0023 \mathrm{U}$ & - & [64] \\
\hline Acetamiprid $^{e}$ & - & $\mathrm{T}, 72 \mathrm{~h}$ & $0.0003 \mathrm{U}$ & - & {$[64]$} \\
\hline Thiamethoxam ${ }^{e}$ & - & $\mathrm{T}, 72 \mathrm{~h}$ & $0.0019 \mathrm{U}$ & - & [64] \\
\hline Dinotefuran $^{e}$ & - & $\mathrm{T}, 72 \mathrm{~h}$ & $0.0145 \mathrm{U}$ & - & [64] \\
\hline \multicolumn{6}{|l|}{ C. hemipterus } \\
\hline $\mathrm{DDT}^{\mathrm{a}}$ & $2 \%$ & $1 \mathrm{~h}^{\mathrm{f}}$ & - & - & [39] \\
\hline a-cypermethrin ${ }^{d}$ & $20 \mathrm{M}$ & $72 h^{j}$ & - & - & {$[55]$} \\
\hline Permethrin $^{d}$ & $200 M$ & $72 \mathrm{~h}^{\mathrm{j}}$ & - & - & {$[55]$} \\
\hline Permethrin $^{d}$ & $0.75 \%$ & $72 \mathrm{~h}^{\mathrm{f}}$ & - & - & {$[55]$} \\
\hline $\mathrm{DDT}^{\mathrm{a}}$ & $2 \%$ & $24 h^{f}$ & - & - & {$[56]$} \\
\hline Malathion ${ }^{\mathrm{b}}$ & $5 \%$ & $16 h^{f}$ & - & - & {$[56]$} \\
\hline Propoxur ${ }^{c}$ & $0.8 \%$ & $24 h^{f}$ & - & - & {$[56]$} \\
\hline Deltamethrin $^{d}$ & $0.025 \%$ & $C^{f}$ & - & - & {$[56]$} \\
\hline Permethrin $^{d}$ & $0.25 \%$ & $C^{f}$ & - & - & {$[56]$} \\
\hline $\mathrm{DDT}^{\mathrm{a}}$ & $4 \%$ & $C^{f}$ & - & - & [12] \\
\hline Dieldrin $^{a}$ & $0.8 \%$ & $C^{f}$ & - & - & [12] \\
\hline
\end{tabular}


Table 7 Published discriminating doses and susceptibility baselines used to detect insecticide resistance in bed bugs (Cimex spp.) (Continued)

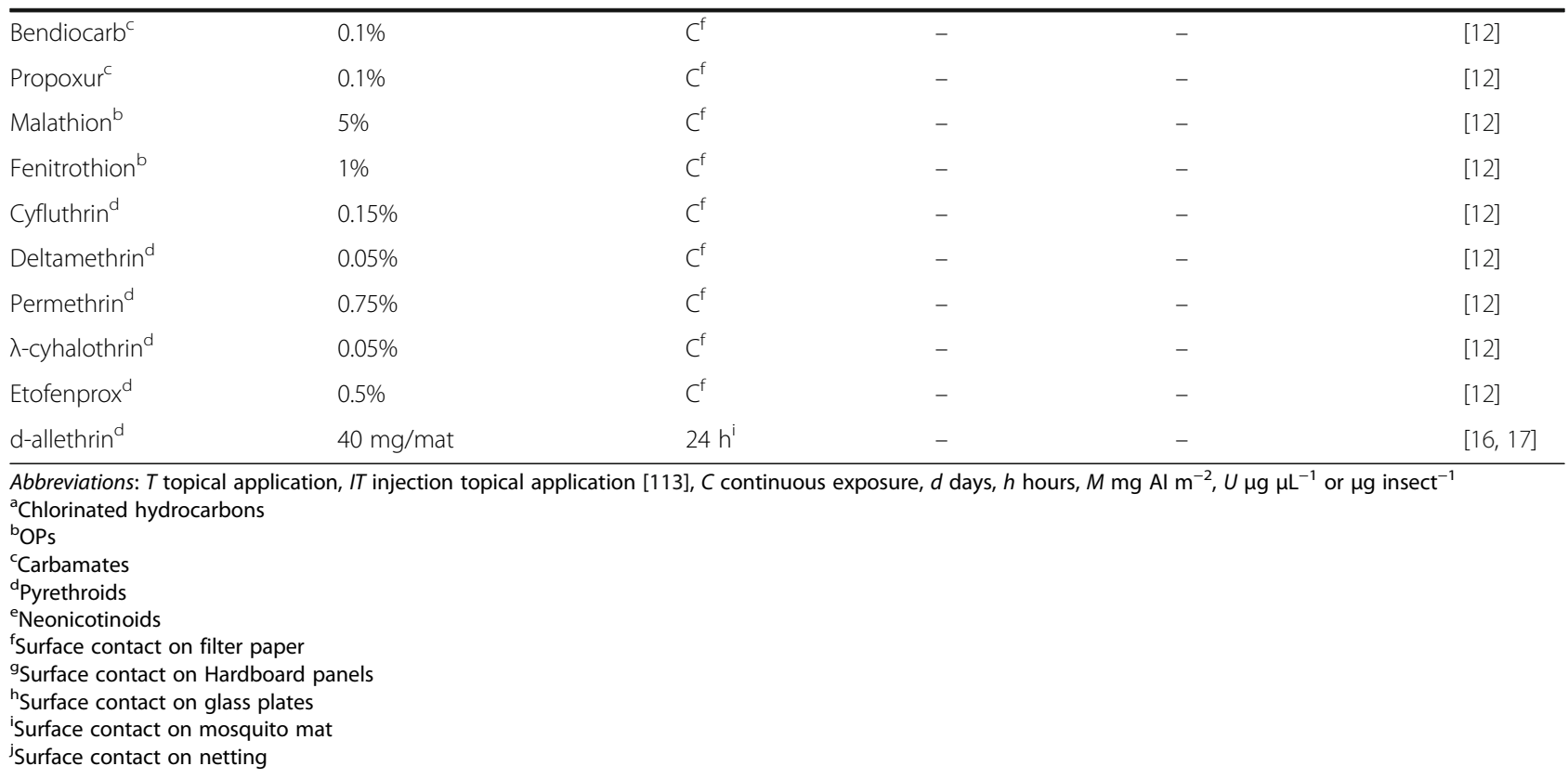

resistance in a New York C. lectularius strain, although there were no differences in the activity of the enzymes evaluated. Adelman et al. [113] also used biochemical assays to detect the differential activity of detoxification enzymes, which suggested that metabolic resistance probably was associated with pyrethroid resistance in $C$. lectularius. Romero \& Anderson [64] evaluated the activities of metabolic detoxification enzymes (P450s, GSTs, and esterases) in C. lectularius using biochemical assays. They found that metabolic resistance is probably involved in resistance to neonicotinoids. However, it is important to clarify that the presence of elevated levels of

Table 8 Synergists as inhibitors of major metabolic detoxification enzymes

\begin{tabular}{|c|c|}
\hline $\begin{array}{l}\text { Insecticide detoxification } \\
\text { enzymes }\end{array}$ & Synergists/inhibitors $^{a}$ \\
\hline $\begin{array}{l}\text { Cytochrome P450 } \\
\text { monooxygenases (P450s) }\end{array}$ & PBO, sesamex \\
\hline Esterases & $\begin{array}{l}\text { EN16/5-1, DEF, TPP, IBP, K-1, K-2, sesamex, } \\
\text { and SV-1 }\end{array}$ \\
\hline $\begin{array}{l}\text { Glutathione S-transferases } \\
\text { (GSTs) }\end{array}$ & DEM, EA and CF \\
\hline \multicolumn{2}{|c|}{$\begin{array}{l}\text { Abbreviations: DEF S.S.S-tributlyphosphorotrithioate, TPP triphenyl phosphate, } \\
\text { IBP S-benzyl diisopropyl phosphorothiolate, } K-1 \text { (2-phenyl-4H-1,3,2- } \\
\text { benzodioxaphosphorothiolate), } K-2 \text { 2-phenoxy-4H-1,3,2-benzodioxaphosphorin } \\
\text { 2-oxide, sesamex 5-[1-[2-(2-ethoxyethoxy) ethoxy]ethoxy]-1,3-benzodioxole, SV- } \\
\text { 1, O,O-diethyl-O-phenyl phosphorothiolate, DEM diethyl maleate, EA ethacrynic } \\
\text { acid, CF chlorfenethol } \\
\text { a'Data sourced from Brogdon \& Chan [286], Heong et al. [147] and Lilly et } \\
\text { al. [127] }\end{array}$} \\
\hline
\end{tabular}

enzymes alone is not a direct evidence to demonstrate their involvements as resistance mechanisms, unless it could be shown through in vivo metabolism and/or synergism studies that these enzymes were involved [105].

\section{Molecular assays}

Detection of insecticide resistance using molecular assays could provide early warning of the development of insecticide resistance and the specific resistance mechanism, which would allow the choice of insecticides to be decided more accurately. For example, $k d r$-resistance mutations could be identified in many DDT- and/or pyrethroidresistant insects. Multiple molecular assays have been developed to detect $k d r$ mutations, such as direct DNA sequencing analysis, allele-specific PCR (AS-PCR), Heated Oligonucleotide Ligation Assay (HOLA), Sequence Specific Oligonucleotide Probe Enzyme-linked ImmunoSorbent Assay (SSOP-ELISA), PCR-Dot Blot, Fluorescence Resonance Energy Transfer/Melt Curve Analysis (FRET/MCA), High Resolution Melt (HRM), and TaqMan Real-Time PCR assays, in a range of insect pests [204], including bed bugs (Table 9) [17, 54, 90, 92, 113, 156-158, 162]. Direct DNA sequencing analysis, including QS (Quantitative Sequencing) $[160,162]$ is the most common molecular assay used to identify $k d r$ mutations (e.g. V419L, L925I) in fieldcollected bed bug strains (Table 9) [54, 92, 113, 157, 158]. However, this analysis is not practical for studying largescale populations. Other assays such as AS-PCR [90, 157] can be used to detect $k d r$ mutations in field-collected strains (Table 9). As noted by Bass et al. [204], a more 
Table 9 Published molecular markers of genes putatively involved in resistance mechanisms of bed bugs (Cimex spp.)

\begin{tabular}{|c|c|c|c|c|}
\hline Resistance mechanism & Gene & Molecular assay & Primer sequence $\left(5^{\prime}-3^{\prime}\right)$ & Reference \\
\hline \multirow[t]{7}{*}{$k d r$} & V419 L & PCR and sequencing & $\begin{array}{l}\text { F: AACCTGGATATACATGCCTTCAAGG; } \\
\text { R: TGATGGAGATIITGCCACTGATG }\end{array}$ & {$[54,157]$} \\
\hline & L925; 1936F & PCR and sequencing & $\begin{array}{l}\text { F: GGAATTGAAGCTGCCATGAAGTTG; } \\
\text { R: TGCCTATTCTGTCGAAAGCCTCAG }\end{array}$ & {$[54,157]$} \\
\hline & V419L & AS-PCR & $\begin{array}{l}\text { F(V): ATTCCTGGGATCATTCTACCTCg; } \\
\text { F(L): ATTCCTGGGATCATTCTACCTCC; } \\
\text { R: TGATGGAGATITTGCCACTGATG }\end{array}$ & {$[90,157]$} \\
\hline & L925। & AS-PCR & $\begin{array}{l}\text { F(L): ATTATGGGCAGAACAGTGGGTGCCC; } \\
\text { F(I): ATTATGGGCAGAACAGTGGGTGCCa; } \\
\text { R: TGCCTATTCTGTCGAAAGCCTCAG }\end{array}$ & {$[90,157]$} \\
\hline & V419L & QS & $\begin{array}{l}\text { F: GTCCGTGGCACATGTTGTTCTTCA; } \\
\text { R: CTGATGGAGATIITGCCACTGATGC; } \\
\text { R: CCTCTTCAGCAGCTTCTTCTTCTTC (for sequencing) }\end{array}$ & {$[160,162]$} \\
\hline & L925। & QS & $\begin{array}{l}\text { F: GGTCTATCAGTTITGAGGTCATTCAG; } \\
\text { R: GGAGTTCGCCATCAGGGAATCTAT; } \\
\text { F: GTGTTAAGCTGGCTAAGTCATGGCC (For sequencing) }\end{array}$ & {$[160,162]$} \\
\hline & M918I; L1014F & PCR and sequencing & $\begin{array}{l}\text { F: GGAATTGAAGCTGCCATGAAGTTG; } \\
\text { R: TGCCTATTCTGTCGAAAGCCTCAG }\end{array}$ & [17] \\
\hline \multirow[t]{19}{*}{ Penetration resistance } & Contig_1766 (CDA) & qRT-PCR & $\begin{array}{l}\text { F: TGAATGCTATAAGAATCGTA; } \\
\text { R: ATTACCAATACACCAACAA }\end{array}$ & [92] \\
\hline & $\begin{array}{l}\text { Contig_1762 } \\
\text { (CHS) }\end{array}$ & qRT-PCR & $\begin{array}{l}\text { F: TAATGAAGCAAGGCACTA; } \\
\text { R: AATACTCCACACGATACC }\end{array}$ & [92] \\
\hline & Contig_48951 (CPAP) & qRT-PCR & $\begin{array}{l}\text { F: GTCCTCAGCACCAATCGT; } \\
\text { R: GTTGTTGGAACTGTTGTTGATG }\end{array}$ & [92] \\
\hline & Contig_17694 (LCP) & qRT-PCR & $\begin{array}{l}\text { F: GCCACTACTATAACAGAG; } \\
\text { R: ATTACCTCCAAGATTGAAT }\end{array}$ & [92] \\
\hline & Contig_21630 (PCP) & qRT-PCR & $\begin{array}{l}\text { F: CCAGATAATTCAAGAGATG; } \\
\text { R: AGTCTAATCGGTCTATATG }\end{array}$ & [92] \\
\hline & Contig_24229 & qRT-PCR & $\begin{array}{l}\text { F: CGCCAGGGCCGAGGAGTATG; } \\
\text { R: ACGGGGTCGGCGGTGTAGTCT }\end{array}$ & [94] \\
\hline & Contig_24231 & qRT-PCR & $\begin{array}{l}\text { F: CGACGATCATCCCCAATACAGTT; } \\
\text { R: AGGGGCGGCTITAGCGACCACA }\end{array}$ & [94] \\
\hline & Contig_24227 & qRT-PCR & $\begin{array}{l}\text { F: TTCTITTGGCAGCTTTGGTTGTA; } \\
\text { R: CCTGCTITCGGTCTGGGATTTG }\end{array}$ & [94] \\
\hline & Contig_24230 & qRT-PCR & $\begin{array}{l}\text { F: GACTACTACGCCCACCCGAAATAC; } \\
\text { R: GTGAGCAGCGTGGCCAGTCTTGTG }\end{array}$ & [94] \\
\hline & Contig_24228 & qRT-PCR & $\begin{array}{l}\text { F: TCCCGCTGTTACCAAGACTCAATG; } \\
\text { R: GCCAAAGCGACTGCAGGTGTATC }\end{array}$ & [94] \\
\hline & Contig_2034 & qRT-PCR & $\begin{array}{l}\text { F: TACCGTTAATGCTGCTACACCAA; } \\
\text { R: TCCCGAGGCGACGAAACCACT }\end{array}$ & [94] \\
\hline & Contig_1629 & qRT-PCR & $\begin{array}{l}\text { F: AGGCCAGTCCAACACAACCAAC; } \\
\text { R: TGCTGCCGTCCTCATTCTCC }\end{array}$ & [94] \\
\hline & Contig_3037 & qRT-PCR & $\begin{array}{l}\text { F: ACGGCAGGATGGTCGAAGATTATG; } \\
\text { R: AGGACGAGGGGCGGGCTGTGGT }\end{array}$ & [94] \\
\hline & Contig_2322 & qRT-PCR & $\begin{array}{l}\text { F: CGAACCTGCCGGAAGTGACATAAA; } \\
\text { R: TTGCGGCTGGTAGTACTGAGGTTG }\end{array}$ & [94] \\
\hline & Contig_773 & qRT-PCR & F: GCCGTTGAGCAGCAGCGATAA; & [94] \\
\hline & & & R: CGTGGGGCGGAAGAAGGATT & \\
\hline & Contig_2220 & qRT-PCR & $\begin{array}{l}\text { F: ATGGCACCAGGAGGGGAACTTA; } \\
\text { R: GGTACTGGGGCTGGGCTCTGT }\end{array}$ & [94] \\
\hline & Contig_1833 & qRT-PCR & $\begin{array}{l}\text { F: ACAATTCGGTGGTGCCCCTITCT; } \\
\text { R: TCGGCGACGTAGCTGACCTGGAC }\end{array}$ & [94] \\
\hline & Contig_820 & qRT-PCR & $\begin{array}{l}\text { F: ATCAGCAGCCAAGTCGTAGGAAGC; } \\
\text { R: GGAGGGGTTGGGAGGTGGTCT }\end{array}$ & [94] \\
\hline
\end{tabular}


Table 9 Published molecular markers of genes putatively involved in resistance mechanisms of bed bugs (Cimex spp.) (Continued)

\begin{tabular}{|c|c|c|c|c|}
\hline & Contig_934 & qRT-PCR & $\begin{array}{l}\text { F: ACACCACTCCCGTTCCCATCGTC; } \\
\text { R: CGTTCTCGTCGGCGGTGTAAGTCA }\end{array}$ & [94] \\
\hline & Contig_2492 & qRT-PCR & $\begin{array}{l}\text { F: CGGTATCTCGGCGAAGGAACAG; } \\
\text { R: GCGGCGTAGGGAGATGAGCA }\end{array}$ & [94] \\
\hline & Contig_22513 & qRT-PCR & $\begin{array}{l}\text { F: CGACGGAACATACAACTGGGAATA; } \\
\text { R: GTCGGCGGTGTAGGTCAACTGGAT }\end{array}$ & [90] \\
\hline & Contig_15313 & qRT-PCR & $\begin{array}{l}\text { F: ACGGAACCCATCCCGATCCTTAAA; } \\
\text { R: ATGCCGTTACCGGTTTCGTATTCC }\end{array}$ & [90] \\
\hline & Contig_02621 & qRT-PCR & $\begin{array}{l}\text { F: ACTCCTGAAGTCCAAGCAGCAAGA; } \\
\text { R: TCGGAAGGGTTGTCCAAATCGTGA }\end{array}$ & {$[90]$} \\
\hline & Contig_8158 & qRT-PCR & $\begin{array}{l}\text { F: CCAAGCGGTCAAAGCAGCACATTT; } \\
\text { R: AGCCTAGCGAGAGCTTGGTTGTAA }\end{array}$ & [90] \\
\hline \multirow[t]{12}{*}{$\begin{array}{l}\text { Metabolic resistance } \\
\text { [1] P450s }\end{array}$} & $\begin{array}{l}\text { CYP9 } \\
\text { (Contig No.: N/A) }\end{array}$ & qRT-PCR & N/A & [104] \\
\hline & $\begin{array}{l}\text { CYP6DM2 } \\
\text { (Contig No.: N/A) }\end{array}$ & qRT-PCR & $\begin{array}{l}\text { F: CCCCCTTATGCTACCCGTTTGA; } \\
\text { R: TTCGTCCTITITATGTCCGTCTGC }\end{array}$ & [113] \\
\hline & $\begin{array}{l}\text { CYP397A1 } \\
\text { (Contig No.: N/A) }\end{array}$ & qRT-PCR & $\begin{array}{l}\text { F: CTCGGGCTCACCACTCTCAACA; } \\
\text { R: ACCGTCATGGCTCCCGTCAG }\end{array}$ & [113] \\
\hline & $\begin{array}{l}\text { CYP400A1 } \\
\text { (Contig No.: N/A) }\end{array}$ & qRT-PCR & $\begin{array}{l}\text { F: CCTGCGCGTTCGGAGTCAATA; } \\
\text { R: CATCGGCTAAATAGAGGAAAAAGT }\end{array}$ & [113] \\
\hline & $\begin{array}{l}\text { Contig_19601 } \\
\text { (CYP397A1V2) }\end{array}$ & qRT-PCR & $\begin{array}{l}\text { F: TCGGAGGAATGGAAGAAG; } \\
\text { R: CGTCATGGTATGGATGGT }\end{array}$ & [92] \\
\hline & $\begin{array}{l}\text { Contig_103 } \\
\text { (CYP6A2) }\end{array}$ & qRT-PCR & $\begin{array}{l}\text { F: AAGTTGTCCTAGAGTGTT; } \\
\text { R: GAGATATGCGTGAATGTC }\end{array}$ & [92] \\
\hline & $\begin{array}{l}\text { Contig_22399 } \\
\text { (CYP6A13) }\end{array}$ & qRT-PCR & $\begin{array}{l}\text { F: CGTCATGGTATGGATGGT; } \\
\text { R: TCGGAGGAATGGAAGAAG }\end{array}$ & [92] \\
\hline & $\begin{array}{l}\text { Contig_11345 } \\
\text { (CYP397A1) }\end{array}$ & qRT-PCR & $\begin{array}{l}\text { F: TATTGGAGTCGACAGGGCGTGAAA; } \\
\text { R: TGACATCGCCCAATTGCTTGTAGC }\end{array}$ & [90] \\
\hline & $\begin{array}{l}\text { Contig_03764 } \\
\text { (CYP398A1) }\end{array}$ & qRT-PCR & $\begin{array}{l}\text { F: TGTCGACCCAATGATGGCTCTGAA; } \\
\text { R: GAAATTGGAGGCCGATTTGGCGAT }\end{array}$ & [90] \\
\hline & $\begin{array}{l}\text { Contig_04490 } \\
\text { (CYP6DN1) }\end{array}$ & qRT-PCR & $\begin{array}{l}\text { F: GCGAGTCTGGGAAATTGTGCATGAAT; } \\
\text { R: AATGCCCGATTACGATGTCAGGGA }\end{array}$ & [90] \\
\hline & $\begin{array}{l}\text { Contig_04099 } \\
\text { (CYP4CM1) }\end{array}$ & qRT-PCR & $\begin{array}{l}\text { F: ATTGGTAACATTGGAGGCCCTGGA; } \\
\text { R: AGAGATTTGCCTTACCACCAGCGA }\end{array}$ & [90] \\
\hline & $\begin{array}{l}\text { CICPR } \\
\text { (Contig No. N/A) }\end{array}$ & qRT-PCR & $\begin{array}{l}\text { F: TATGCCGCAGAATACGGACAACTC; } \\
\text { R: ACCTGCAAATTCTTCACCAGTGCC }\end{array}$ & [122] \\
\hline \multirow[t]{2}{*}{ [2] Esterases } & $\begin{array}{l}\text { CE3959 } \\
\text { (Contig No. N/A) }\end{array}$ & qRT-PCR & $\begin{array}{l}\text { F: ACGTCTGGAGAAGGGCAACTGAAA; } \\
\text { R: GACGGCCGGGTAGATGAAAACAAC }\end{array}$ & {$[90,113]$} \\
\hline & $\begin{array}{l}\text { CE21331 } \\
\text { (Contig_03262) }\end{array}$ & qRT-PCR & $\begin{array}{l}\text { F: TCTCACGGGGACGAACTGCCTTAT; } \\
\text { R: CCTGGTCTTCTGGGTATTTCTTCA }\end{array}$ & {$[90,113]$} \\
\hline [3] GSTS & $\begin{array}{l}\text { gsts } 1 \\
\text { (Contig No. N/A) }\end{array}$ & qRT-PCR & $\begin{array}{l}\text { F: AGGAGAGCCAGTTAGATTTATGTT; } \\
\text { R: AAGCGATTCCCACCGATTTT }\end{array}$ & [113] \\
\hline \multirow[t]{5}{*}{ [4] ABC- Transporters } & Contig_1346 & qRT-PCR & $\begin{array}{l}\text { F: TGCTCTACATAATTCTGACAT; } \\
\text { R: GTAGGACGGTATGAGGTA }\end{array}$ & [92] \\
\hline & $\begin{array}{l}\text { Contig_08506 } \\
\text { (Abc8) }\end{array}$ & qRT-PCR & $\begin{array}{l}\text { F: ATCCTGATGGGCCGAGTAAACCAT; } \\
\text { R: TTCTGGAGGTGACCGTCAAGTTGT }\end{array}$ & [90] \\
\hline & $\begin{array}{l}\text { Contig_02154 } \\
\text { (Abc9) }\end{array}$ & qRT-PCR & $\begin{array}{l}\text { F: TTAAGCAACCGATGTGACGCAAGC; } \\
\text { R: TGACCCAGACGTTGTCAACACAGA }\end{array}$ & [90] \\
\hline & $\begin{array}{l}\text { Contig_05955 } \\
\text { (Abc10) }\end{array}$ & qRT-PCR & $\begin{array}{l}\text { F: TCACAGCGGTCTTCCTGGATTCTT; } \\
\text { R: AACTTCTGCGCGCACATTAGAACG }\end{array}$ & [90] \\
\hline & $\begin{array}{l}\text { Contig_09403 } \\
(\text { Abc11) }\end{array}$ & qRT-PCR & $\begin{array}{l}\text { F: ATGCAGCTCAGTAGGGTCGTCTIT; } \\
\text { R: CGGGCCAAAGTCAAATCAGCACAT }\end{array}$ & [90] \\
\hline
\end{tabular}


sensitive and specific molecular assay (e.g. TaqMan RealTime PCR assay) should be developed to identify $k d r$ mutations.

The recent transcriptome and genomic studies in bed bug populations have revealed that multiple candidate genes that putatively mediate resistance mechanisms may be present in bed bug populations (Table 1) [90, 92, 93, 113, 197]. In these studies, overexpression of genes that encode metabolic enzymes (e.g. P450s, esterases, and GSTs) and genes that encode cuticular proteins for thickening or remodelling cuticle to reduce the insecticide penetration rate, were used as discriminating criteria to identify genes that are likely associated with insecticide resistance, especially with pyrethroid resistance, in bed bugs [90, 92, 94, 104, 113], although they need to be further experimentally validated. Based on the quantitative RT-PCR technology, many molecular markers have been developed to monitor those putative resistance-associated genes based on these studies (Table 9) [90, 92]. Additionally, RNAi techniques also provides a promising approach to further validate the gene(s) that governs resistance in bed bugs $[90,122]$. Lastly, other approaches, such as transgenic expression [143] and metabolism studies [105], can be conducted to directly validate the gene(s) governing resistance in bed bugs.

\section{Conclusions}

Over the last two decades, bed bugs have undergone a major resurgence around the world. The widespread presence of insecticide resistance in field bed bug populations may be the single most important factor responsible for the bed bug resurgence. Transcriptomic and genomic studies have significantly revolutionized insecticide resistance research in bed bugs over recent years. Multiple physiological-based mechanisms are putatively associated with bed bug insecticide resistance. These mechanisms include reduced penetration by thickening or remodelling cuticle (e.g. upregulation of cuticularrelated protein genes), metabolic resistance (e.g. increased metabolic activities of detoxification enzymes), and target site insensitivity ( $k d r$ mutations). However, the involvement of most of the candidate genes associated with insecticide resistance found through transcriptomic and genomic approaches still need to be verified by empirical functional approaches such as RNAi, gene functional characterization, metabolism/biotransformation studies, and neurophysiological studies. The progress in understanding insecticide resistance mechanisms mentioned herein is mainly focused on the common bed bug $C$. lectularius. Little is known on insecticide resistance mechanisms in the tropical bed bug C. hemipterus, although it is likely to share similar mechanisms. Bioassay methods are relatively simple to perform and provide standardized data to monitor insecticide resistance. However, they have several practical limitations. For instance, bioassays require a susceptible strain for comparison and a large quantity of insects for testing. Ideally, biochemical, molecular assays and insecticide bioassays could be concertedly performed to detect insecticide resistance and its mechanisms. The latter two assays have advantages, such as requiring a smaller sample size, and could accurate identify the gene(s) that is/are associated with the resistance mechanisms. However, these assays require sophisticated and costly equipment and reagents to perform which may not be readily available in developing countries. In addition, it would be counter-productive to use biochemical and molecular monitoring assays as a standalone approach without empirical validation of resistance status.

\section{Abbreviations}

ABC-transporters: ATP-binding cassette transporters;

AChEs: Acetylcholinesterases; ADP: Adenosine diphosphate; ATP: Adenosine triphosphate; BHC: Benzene hexachloride; CDA: Chitin deacetylase;

CF: Chlorfenethol; CHS: Chitin synthase; CIN-1: A Cimex lectularius strain collected in 2005 in Cincinnati, OH; CPAP: Cuticular protein analogous to peritrophin; CPR: NADPH-Cytochrome P450 Reductase; CPRR: Cuticular protein with the rebers and riddiford consensus; DDT: Dichloro-diphenyl trichloroethane; DDVP: Dichlorvos; DEF: S.S.S-tributlyphosphorotrithioate; DEM: Diethyl maleate; EA: Ethacrynic acid; EN16/5-1: 6-[2-(2-butoxyethoxy) ethoxymethyl]-5-propyl-2, 3-dihydrobenzofuranby; FCVB: Filter Contact Vial Bioassay; FL-BB: A susceptible C. lectularius strain collected from Gainesville, Florida; FRET/MCA: Fluorescence Resonance Energy Transfer/Melt Curve Analysis; GABA receptor: $\gamma$-aminobutyric acid receptor; gamma-HCH: gammahexachlorocyclohexane; GSH: Reduced glutathione; GSTs: Glutathione Stransferases; HOLA: Heated Oligonucleotide Ligation Assay; HRM: High Resolution Melt; IBP: S-benzyl diisopropyl phosphorothiolate; IRAC: Insecticide Resistance Action Committee; IRM: Insecticide resistance management; $\mathrm{K}$ 1: (2-phenyl-4H-1,3,2-benzodioxaphosphorothiolate); K-2: 2-phenoxy-4H-1,3,2benzodioxaphosphorin 2-oxide; kdr: knockdown resistance; LA-1: A susceptible C. lectularius strain collected in 2006 in Los Angeles, CA; LCP: Larval cuticle protein; METI: Mitochondrial electron transport inhibitors; nAChRs: Nicotinic acetylcholine receptors;

NADPH: Nicotinamide Adenine Dinucleotide Phosphate;

OCs: Organochlorines; OPs: Organophosphates; P450s: Cytochrome P450 monooxygenases; PBH: 3-Phenoxybenzyl hexanoate, a surrogate substrate for carboxylesterases and oxidases; PBO: Piperonyl butoxide; PCP: Pupal cuticle protein; qRT-PCR: Quantitative Real-Time PCR; QS: Quantitative Sequencing; RACE: Rapid amplification of CDNA ends; RNAi: dsRNAmediated interference; SEM: Scanning electron microscope; sesame: 5-[1-[2-(2-ethoxyethoxy) ethoxy]ethoxy]-1,3-benzodioxole; SSOP-ELISA: Sequence Specific Oligonucleotide Probe Enzyme-linked Immuno Sorbent Assay; SV-1: O,O-diethyl-O-phenyl phosphorothiolate; TPP: Triphenyl phosphate; VGSC: Voltage-gated sodium channel; WOR-1: a C. lectularius strain collected in 2007 in Worcester, MA

\section{Acknowledgments}

The authors thank Universiti Sains Malaysia for the post-doctoral fellowship to Kai Dang, and Bayer Environmental Science for research support.

\section{Funding}

Not applicable.

Availability of data and materials Not applicable. 


\section{Authors' contributions}

KD and CYL wrote the manuscript, GVS and SLD further improved the content of the manuscript. All authors read and approved the final manuscript.

\section{Competing interests}

The authors declare that they have no competing interests.

\section{Consent for publication}

Not applicable.

\section{Ethics approval and consent to participate}

Not applicable.

\section{Publisher's Note}

Springer Nature remains neutral with regard to jurisdictional claims in published maps and institutional affiliations.

\begin{abstract}
Author details
${ }^{1}$ Urban Entomology Laboratory, Vector Control Research Unit, School of Biological Sciences, Universiti Sains Malaysia, 11800 Penang, Malaysia. 2Department of Medical Entomology, NSW Health Pathology, Westmead Hospital, Westmead, NSW 2145, Australia. ${ }^{3}$ Centre for Chemical Biology, Universiti Sains Malaysia, 10 Persiaran Bukit Jambul, 11900 Penang, Malaysia.
\end{abstract}

Received: 1 August 2016 Accepted: 6 June 2017

Published online: 29 June 2017

\section{References}

1. Georghiou GP. The evolution of resistance to pesticides. Annu Rev Ecol Syst. 1972:3:133-68.

2. Lee $\mathrm{CY}$. Insecticide resistance and its underlying mechanisms in the German cockroach, Blattella germanica (Linn.) (Dictyoptera: Blattellidae). J Biosci. 1997;8:156-72.

3. Hemingway J, Field L, Vontas J. An overview of insecticide resistance. Science. 2002:298:96-7.

4. Hemingway J, Hawkes NJ, McCarroll L, Ranson H. Molecular basis of insecticide resistance in mosquitoes. Insect Biochem Molec. 2004;34:653-65.

5. Liu N, Zhu F, Xu Q, Pridgeon JW, Gao X. Behavioral change, physiological modification, and metabolic detoxification: mechanisms of insecticide resistance. Acta Entomol Sin. 2006;49:671-9.

6. Liu N. Insecticide resistance in mosquitoes: impact, mechanisms, and research directions. Annu Rev Entomol. 2015;60:537-59.

7. Li X, Shuler MA, Berenbaum MR. Molecular mechanisms of metabolic resistance to synthetic and natural xenobiotics. Annu Rev Entomol. 2007;52:231-53.

8. Usinger RL. Monograph of Cimicidae (Hemiptera-Heteroptera), Thomas Say Foundation, vol. 7. College Park: Entomological Society of America; 1966.

9. Potter MF. The history of bed bug management - with lessons from the past. Am Entomol. 2011;57:14-25.

10. Koganemaru R, Miller DM. The bed bug problem: past, present, and future control methods. Pestic Biochem Physiol. 2013;106:177-89.

11. Suwannayod S, Changbang Y, Buranapanichpan S. The life cycle and effectiveness of insecticides against the bed bugs of Thailand. Southeast Asian J Trop Med Public Health. 2010;41:548-54.

12. Tawatsin A, Thavara U, Chompoosri J, Phusup Y, Jonjang N, Khumsawads C. Insecticide resistance in bedbugs in Thailand and laboratory evaluation of insecticides for the control of Cimex hemipterus and Cimex lectularius (Hemiptera: Cimicidae). J Med Entomol. 2011:48:1023-30.

13. Newberry K, Jansen EJ, Thibaud GR. The occurrence of the bedbugs Cimex hemipterus and Cimex lectularius in northern Natal and Kwazulu, South Africa. Trans R Soc Trop Med Hyg. 1987;81:431-3.

14. Gbakima AA, Terry BC, Kanja F, Kortequee S, Dukuley I, Sahr F. High prevalence of bedbugs Cimex hemipterus and Cimex lectularius in camps for internally displaced persons in Freetown, Sierra Leone: a pilot humanitarian investigation. West Afr J Med. 2002;21:268-71.

15. Doggett SL, Russell RC. The resurgence of bed bugs, Cimex spp. (Hemiptera: Cimicidae) in Australia: experiences from down under. In: Robinson WH, Bajomi D, editors. Proceedings of the 6th International Conference on Urban Pests, Budapest, Hungary, 13 to 16 July 2008. Pápai: OOK-Press; 2008. p. 407-25.
16. Dang K, Lilly DG, Bu W, Doggett SL. Simple, rapid and cost-effective technique for the detection of pyrethroid resistance in bed bugs, Cimex spp. (Hemiptera: Cimicidae). Austral Entomol. 2015;54:191-6.

17. Dang K, Toi CS, Lilly DG, Lee CY, Naylor R, Tawatsin A, et al. Identification of putative $k d r$ mutations in the tropical bed bug, Cimex hemipterus (Hemiptera: Cimicidae). Pest Manag Sci. 2015;71:1015-20.

18. Campbell BE, Koehler PG, Buss LJ, Baldwin RW. Recent documentation of the tropical bed bug (Hemiptera: Cimicidae) in Florida since the common bed bug resurgence. Fla Entomol. 2016;99:549-51.

19. Birchard K. Bed bugs biting in Britain: only rarely used pesticides effective. Med Post. 1998;34:55

20. Potter MF, Haynes KF, Connelly K, Deutsch M, Hardebeck E, Partin D, et al. The sensitivity spectrum: human reactions to bed bug bites. Pest Control Technol. 2010;38:70-4.

21. Doggett SL, Dwyer DE, Peñas PF, Russell RC. Bed bugs: clinical relevance and control options. Clin Microbiol Rev. 2012;25:164-92.

22. Minocha R, Wang C, Dang K, Webb C, Fernández-Peñas P, Doggett SL. Systemic erythrodermic reactions following repeated exposure to bites from the common bed bug Cimex lectularius (Hemiptera: Cimicidae). Austral Entomol. 2016; doi: 10.1111/aen.12250

23. Rahim AHAR, Zahran Z, Majid AHA. Human skin reactions towards bites of tropical bed bug, Cimex hemipterus F. [sic] (Hemiptera: Cimicidae): a preliminary case study. Asian Pac J Trop Dis. 2016;6:366-71.

24. Goddard J, DeShazo R. Bed bugs (Cimex lectularius) and clinical consequences of their bites. JAMA. 2009;301:1358-66.

25. Reinhardt K, Kempke D, Naylor RA, Siva-Jothy MT. Sensitivity to bites by the bed bug, Cimex lectularius. Med Vet Entomol. 2009;23:163-6.

26. Leulmi H, Bitam I, Berenger JM, Lepidi H, Rolain JM, Almeras L, et al. Competence of Cimex lectularius bed bugs for the transmission of Bartonella quintana, the agent of trench fever. PLoS Negl Trop Dis. 2015;9:e0003789.

27. Sentana-Lledo D, Barbu CM, Ngo MN, Wu Y, Sethuraman K, Levy MZ. Seasons, searches, and intentions: what the internet can tell us about the bed bug (Hemiptera: Cimicidae) epidemic. J Med Entomol. 2016;53:116-21.

28. Davies TGE, Field LM, Williamson MS. The re-emergence of the bed bug as a nuisance pest: implications of resistance to the pyrethroid insecticides. Med Vet Entomol. 2012;26:241-54.

29. Bandyopadhyay T, Kumar A, Saili A. Bed bug outbreak in a neonatal unit. Epidemiol Infect. 2015;143:2865-70.

30. Romero A, Potter MF, Potter DA, Haynes KF. Insecticide resistance in the bed bug: a factor in the pest's sudden resurgence? J Med Entomol. 2007;44: 175-8.

31. IRAC: The IRAC register. http://www.irac-online.org . Accessed 12 June 2017.

32. Zhu KY. Insecticide resistance. In: Capinera JL, editor. Encyclopedia of entomology. 2nd ed. New York: Springer; 2008. p. 1979-81.

33. WHO. Environmental health criteria for DDT and its derivatives. Geneva: World Health Organization; 1979.

34. Johnson MS, Hill AJ. Partial resistance of a strain of bed bugs to DDT residual. Med Newsl. 1948;12:26-8.

35. Busvine JR. Insecticide-resistance in bed-bugs. Bull World Health Organ. 1958;19:1041-52.

36. WHO. Insecticide resistance and vector control. Thirteenth report of the WHO expert committee on insecticides. In: WHO Technical Report Series, vol. No. 265. Geneva: World Health Organization; 1963.

37. WHO. Insecticide resistance and vector control. Seventeenth report of the WHO expert committee on insecticides, WHO Technical Report Series, vol. No. 433. Geneva: World Health Organization; 1970.

38. WHO. Resistance of vectors and reservoirs of disease to pesticides. Twentysecond report of the WHO expert committee on insecticides, WHO Technical Report Series, vol. No. 585. Geneva: World Health Organization; 1976.

39. WHO. Vector resistance to Pesticides, Fifteenth report of the WHO Expert Committee on Vector Biology and control. Geneva: World Health Organization; 1992.

40. Brown AWA, Pal R. Insecticide resistance in Arthropods. 2nd ed. Geneva: World Health Organization; 1971.

41. Newberry K, Mchunu ZM. Changes in the relative frequency of occurrence of infestations of two sympatric species of bedbug in northern Natal and Kwazulu, South Africa. Trans R Soc Trop Med Hyg. 1989;83:262-4.

42. Newberry K, Mchunu ZM, Cebkhulu SQ. Bedbug reinfestation rates in rural Africa. Med Vet Entomol. 1991;5:503-5.

43. Axtell RC, Arends JJ. Ecology and management of arthropod pests of poultry. Annu Rev Entomol. 1990;35:101-26. 
44. Steelman CD, Szalanski AL, Trout R, McKern JA, Solorzano C, Austin JW. Susceptibility of the bed bug Cimex lectularius L. (Heteroptera: Cimicidae) collected in poultry production facilities to selected insecticides. J Agr Urban Entomol. 2008:25:41-51.

45. Elliott M, Janes NF. Synthetic pyrethroids - a new class of insecticide. Chem Soc Rev. 1978;7:473-505.

46. Davies TGE, Field LM, Usherwood PNR, Williamson MS. DDT, pyrethrins, pyrethroids and insect sodium channels. IUBMB Life. 2007;59:151-62.

47. Boase C, Small G, Naylor R. Interim report on insecticide susceptibility status of UK bedbugs. Professional Pest Controller; 2006. p. 6-7.

48. Moore DJ, Miller DM. Laboratory evaluations of insecticide product efficacy for control of Cimex lectularius. J Econ Entomol. 2006;99:2080-6.

49. Lilly DG, Doggett SL, Zalucki MP, Orton C, Russell RC. Bed bugs that bite back, confirmation of insecticide resistance in the common bed bug, Cimex lectularius. Prof Pest Manag. 2009;13:22-4.

50. Lilly DG, Doggett SL, Orton C, Russell RC. Bed bug product efficacy under the spotlight, part 1. Prof Pest Manag. 2009;13-14:19-20.

51. Lilly DG, Doggett SL, Orton C, Russell RC. Bed bug product efficacy under the spotlight, part 2. Prof Pest Manag. 2009;13-14(15):18.

52. Lilly DG, Zalucki MP, Orton C, Russell RC, Webb CE, Doggett SL. Confirmation of insecticide resistance in Cimex lectularius Linnaeus (Hemiptera: Cimicidae) in Australia. Austral Entomol. 2015;54:96-9.

53. Kilpinen $\mathrm{O}$, Kristensen $\mathrm{M}$, Jensen KMV. Resistance differences between chlorpyrifos and synthetic pyrethroids in Cimex lectularius population from Denmark. Parasitol Res. 2011;109:1461-4.

54. Dang K, Toi CS, Lilly DG, Bu W, Doggett SL. Detection of knockdown resistance mutations in the common bed bug, Cimex lectularius (Hemiptera: Cimicidae), in Australia. Pest Manag Sci. 2015;71:914-22.

55. Myamba J, Maxwel CA, Asidi A, Curtis CF. Pyrethroid resistance in tropical bed bugs, Cimex hemipterus, associated with use of treated bednets. Med Vet Entomol. 2002;16:448-51.

56. Karunaratne SHPP, Damayanthi BT, Fareena MHJ, Imbuldeniya V, Hemingway J. Insecticide resistance in the tropical bedbug Cimex hemipterus. Pestic Biochem Physiol. 2007;88:102-7.

57. Jeschke $P$, Nauen R. Neonicotinoids-from zero to hero in insecticide chemistry. Pest Manag Sci. 2008;64:1084-98.

58. Jeschke P, Nauen $R$, Shindler M, Elbert A. Overview of the status and global strategy for neonicotinoids. J Agric Food Chem. 2010;59:2897-908.

59. Potter MF, Haynes KF, Gordon JR, Hardebeck E, Wickemeyer W. Dual-action bed bug killers. Pest Control Technol. 2012;40:62-8. 75-6

60. Gordon JR, Goodman MH, Potter MF, Haynes KF. Population variation in and selection for resistance to pyrethroid-neonicotinoid insecticides in the bed bug. Sci Rep. 2014;4:3836.

61. Gordon JR, Potter MF, Haynes KF. Insecticide resistance in the bed bug comes with a cost. Sci Rep. 2015;5:10807.

62. Wang C, Singh N, Cooper R, Liu C, Buczkowski G. Evaluation of an insecticide dust band treatment method for controlling bed bugs. J Econ Entomol. 2013;106:347-52.

63. Wang C, Singh N, Cooper R. Field study of the comparative efficacy of three pyrethroid/neonicotinoid mixture products for the control of the common bed bug, Cimex lectularius. Insects. 2015:6:197-205.

64. Romero A, Anderson TD. High levels of resistance in the common bed bug, Cimex lectularius (Hemiptera: Cimicidae), to neonicotinoid Insecticides. J Med Entomol. 2016:53:727-31.

65. Romero A, Potter MF, Haynes KF. Evaluation of chlorfenapyr for control of the bed bug, Cimex lectularius L. Pest Manag Sci. 2010;66:1243-8.

66. Doggett SL, Orton CJ, Lilly DG, Russell RC. Bed bugs - a growing problem worldwide, Australian and international trends update and causes for concern, session 2A. Australian Environmental Pest Managers Association, NSW Conference 2011 Sydney, Australia. 2011. http://medent.usyd.edu.au/ bedbug/papers/aepma_2011_doggett.pdf. Accessed 1 Mar 2017

67. Black BC, Hollingsworth RM, Ahammadsahib KI, Kukel CD, Donovan S. Insecticidal action and mitochondrial uncoupling activity of AC-303, 630 and related halogenated pyrroles. Pestic Biochem Physiol. 1994;50:115-28.

68. Raghavendra K, Barik TK, Bhatt RM, Srivastava HC, Sreehari U, Dash AP. Evaluation of the pyrrole insecticide chlorfenapyr for the control of Culex quinquefasciatus Say. Acta Trop. 2011;118:50-5.

69. Potter MF, Haynes KF, Romero A, Hardebeck E, Wickenmeyer W. Is there a new bed bug answer? Pest Control Technol. 2008;36(116):118-24.

70. Wang C, Gibb T, Bennett GW. Evaluation of two least toxic integrated pest management programs for managing bed bugs (Heteroptera: Cimicidae) with discussion of a bed bug intercepting device. J Med Entomol. 2009:46:566-71.

71. Perumalsamy H, Chang KS, Park C, Ahn YJ. Larvicidal activity of Asarum heterotropoides root constituents against insecticide-susceptible and -resistant Culex pipiens pallens and Aedes aegypti and Ochlerotatus togoi. J Agric Food Chem. 2010;58:10001-6.

72. Nicastro RL, Sato ME, Arthur V, Silva MZ. Chlorfenapyr resistance in the spider mite Tetranychus urticae: stability, cross-resistance and monitoring of resistance. Phytoparasitica. 2013;41:503-13.

73. Jiang T, Wu S, Yang T, Zhu C, Gao C. Monitoring field populations of Plutella xylostella (Lepidoptera: Plutellidae) for resistance to eight insecticides in China. Fla Entomol. 2015;98:65-73.

74. Silva TBM, Silva WM, Campos MR, Silva JE, Ribeiro LMS, Siqueira HAA. Susceptibility levels of Tuta absoluta (Meyrick) (Lepidoptera: Gelechiidae) to minor classes of insecticides in Brazil. Crop Prot. 2016;79:80-6.

75. Van Leeuwen T, Van Pottelberge S, Tirry L. Biochemical analysis of a chlorfenapyr-selected resistant strain of Tetranychus urticae Koch. Pest Manag Sci. 2006;62:425-33.

76. Moore DJ, Miller DM. Field evaluations of insecticide treatment regimens for control of the common bed bug, Cimex lectularius (L.) [sic]. Pest Manag Sci. 2009:65:332-8.

77. Feroz M. Biochemistry of malathion resistance in a strain of Cimex lectularius resistant to organophosphorus compounds. Bull World Hlth Org. 1971;45:795-804.

78. Radwan WA, Guneidy AM, Soliman AA. On the susceptibility of the bed bug, Cimex lectularius L. to insecticides. Bull Soc Entomol Egypt. 1972:56:235-43.

79. Lockwood JA, Sparks TC, Sory RN. Evolution of insect resistance to insecticides: a reevaluation of the roles of physiology and behavior. Bull Entomol Soc Am. 1984:30:41-51.

80. Sparks T, Lockwood JA, Byford RL, Graves JB, Leonard BR. The role of behavior in insecticide resistance. Pestic Sci. 1989;26:383-99.

81. Chareonviriyaphap T, Bangs MJ, Suwonkerd W, Kongmee M, Corbel V, Ngoen-Klan R. Review of insecticide resistance and behavioural avoidance of vectors of human diseases in Thailand. Parasit Vectors. 2013;6:280.

82. Silverman J, Bieman DN. Glucose aversion in the German cockroach, Blattella germanica. J Insect Physiol. 1993;39:925-33.

83. Silverman J, Ross MH. Behavioral resistance of field-collected German cockroaches (Blattodea: Blattellidae) to baits containing glucose. Environ Entomol. 1994;23:425-30.

84. Ross MH. Evolution of behavioral resistance in German cockroach (Dictyoptera: Blattellidae) selected with a toxic bait. J Econ Entomol. 1997:90:1482-5.

85. Wada-Katsumata A, Silverman J. Changes in taste neurons support the emergence of an adaptive behaviour in cockroaches. Science. 2013;340: 972-5.

86. Gillies MT, Chir B. The problem of exophily in Anopheles gambiae. Bull World Hlth Organ. 1956;15:437-49.

87. Mbogo CNM, Baya NM, Ofulla AVO, Githure Jl, Snow RW. The impact of permethrin-impregnated bednets on malaria vectors of the Kenyan coast. Med Vet Entomol. 1996;10:251-9.

88. Mathenge EM, Giming JE, Kolczak M, Ombok M, Irungu LW, Hawley WA. Effect of permethrin-impregnated nets on exiting behavior, blood feeding success, and time of feeding of malaria mosquitoes (Diptera: Culicidae) in western Kenya. J Med Entomol. 2001;38:531-6.

89. Romero A, Potter MF, Haynes KF. Behavioral responses of the bed bug to insecticide residues. J Med Entomol. 2009;46:51-7.

90. Zhu F, Gujar H, Gordon JR, Haynes KF, Potter MF, Palli SR. Bed bugs evolved unique adaptive strategy to resist pyrethroid insecticides. Sci Rep. 2013;3:1456.

91. Mamidala P, Jones SC, Mittapalli O. Metabolic resistance in bed bugs. Insects. 2011;2:36-48.

92. Mamidala P, Wijeratne AJ, Wijeratne S, Kornacker K, Sudhamalla B, RiveraVega $L$, et al. RNA-Seq and molecular docking reveal multi-level pesticide resistance in the bed bug. BMC Genomics. 2012;13:6.

93. Rosenfeld JA, Reeves D, Brugler MR, Narechania A, Simon S, Durrett R, et al. Genome assembly and geospatial phylogenomics of the bed bug Cimex lectularius. Nat Commun. 2016;7:10164.

94. Koganemaru R, Miller DM, Adelman ZN. Robust cuticular penetration resistance in the common bed bug (Cimex lectularius L.) correlates with increased steady-state transcript levels of CPR-type cuticle protein genes. Pestic Biochem Physiol. 2013;106:190-7. 
95. Lilly DG, Latham SL, Webb CE, Doggett SL. Cuticle thickening in a pyrethroid-resistant strain of the common bed bug, Cimex lectularius L. (Hemiptera: Cimicidae). PLoS One. 2016;11:e0153302.

96. Karaağaç SU. Insecticide resistance. In: Perveen F, editor. Insecticides advances in integrated pest management. Rijeka: InTech; 2012. p. 469-78.

97. Nkya TE, Akhouayri I, Poupardin R, Batengana B, Mosha F, Magesa S, et al. Insecticide resistance mechanisms associated with different environments in the malaria vector Anopheles gambiae: a case study in Tanzania. Malar J. 2014;13:28.

98. Plapp FW, Hoyer RF. Insecticide resistance in the house fly: decreased rate of absorption as the mechanism of action of a gene that acts as an intensifier of resistance. J Econ Entomol. 1968;61:1298-303.

99. Wen Z, Scott JG. Genetic and biochemical mechanisms limiting fipronil toxicity in the LPR strain of house fly, Musca domestica. Pestic Sci. 1999;55: 988-92.

100. Scott JG, Georghiou GP. Mechanisms responsible for high levels of permethrin resistance in the house fly. Pestic Sci. 1986;17:195-206.

101. Valles SM, Dong K, Brenner RJ. Mechanisms responsible for cypermethrin resistance in a strain of German cockroach, Blattella germanica (L.). Pestic Biochem Physiol. 2000;66:195-205.

102. Kasai S, Komagata O, Itokawa K, Shono T, Ng LC, Kobayashi M, et al. Mechanisms of pyrethroid resistance in the dengue mosquito vector, Aedes aegypti: target site insensitivity, penetration, and metabolism. PLoS Negl Trop Dis. 2014;8:e2948.

103. Lilly DG, Webb CE, Doggett SL. Evidence of tolerance to silica-based desiccant dusts in a pyrethroid-resistant strain of Cimex lectularius (Hemiptera: Cimicidae). Insects. 2016;7:74.

104. Bai X, Mamidala P, Rajarapu SP, Jones SC, Mittapalli O. Transcriptomics of the bed bug (Cimex lectularius). PLoS One. 2011;6:e16336.

105. Scott JG. Investigating mechanisms of insecticide resistance: methods, strategies, and pitfalls. In: Roush RT, Tabashnik BE, editors. Pesticide resistance in arthropods. New York and London: Chapman and Hall; 1991. p. 39-57.

106. Scott JG. Cytochromes P450 and insecticide resistance. Insect Biochem Molec. 1999;29:757-77

107. Agosin M, Perry AS. Microsomal mixed-function oxidases. In: Rockstein M, editor. Physiology of Insecta. New York: Academic Press; 1974. p. 539-96.

108. Hodgson E. The significance of cytochrome P-450 in insects. Insect Biochem. 1983;13:237-46.

109. Berge JB, Feyereisen R, Amichot M. Cytochromes P450 monooxygenases and insecticide resistance in insects. Philos Trans $\mathrm{R}$ Soc B Biol Sci. 1998;353:1701-5.

110. Feyereisen R. Insect cytochrome P450. In: Gilbert LI, latrou K, Gill SS, editors. Comprehensive molecular insect science, vol. 4. Oxford: Elsevier; 2005. p. 1-77.

111. Nelson DR. The cytochrome p450 homepage. Hum Genomics. 2009;4:59-65. http://drnelson.uthsc.edu/CytochromeP450.html. Accessed 1 Mar 2017

112. Liu N. Pyrethroid resistance in insects: genes, mechanisms, and regulation. In: Perveen F, editor. Insecticides - advances in integrated pest management. Rijeka: InTech; 2012. p. 457-68.

113. Adelman ZN, Kilcullen KA, Koganemaru R, Anderson MAE, Anderson TD, Miller DM. Deep sequencing of pyrethroid-resistant bed bugs reveals multiple mechanisms of resistance within a single population. PLoS One. 2011;6:e26228.

114. Okey AB. Enzyme induction in the cytochrome P450 system. In: Kalow W, editor. Pharmacogenetics of drug metabolism. New York: Pergamon Press; 1992. p. 549-608.

115. Brattsten LB, Wilkinson CF. Induction of microsomal enzymes in the southern armyworm (Prodenia eridania). Pestic Biochem Physiol. 1973;3:393-407.

116. Zhu F, Li T, Zhang L, Liu N. Co-up-regulation of three P450 genes in response to permethrin exposure in permethrin-resistant house flies, Musca domestica. BMC Physiol. 2008:8:18.

117. Markussen MDK, Kristensen M. Cytochrome P450 monooxygenase-mediated neonicotinoid resistance in the house fly Musca domestica L. Pestic Biochem Physiol. 2010;98:50-8.

118. Liu N, Li T, Reid WR, Yang T, Zhang L. Multiple cytochrome P450 genes: their constitutive overexpression and permethrin induction in insecticide resistant mosquitoes, Culex quinquefasciatus. PLoS One. 2011;6:e23403.

119. Potter MF, Haynes KF, Fredericks J. Bed bugs across America. Pestworld; 2015. p. 4-14.

120. Bass C, Denholm I, Williamson MS, Nauen R. The global status of insect resistance to neonicotinoid insecticides. Pestic Biochem Physiol. 2015;121:78-87.
121. Hubbard PA, Shen AL, Paschke R, Kasper CB, Kim JJP. NADPH-cytochrome P450 oxidoreductase - Structural basis for hydride and electron transfer. J Biol Chem. 2001;276:29163-70.

122. Zhu F, Sams S, Moural T, Haynes KF, Potter MF, Palli SR. RNA interference of $\mathrm{NADPH}$-cytochrome $\mathrm{P} 450$ reductase results in reduced insecticide resistance in the bed bug, Cimex lectularius. PLoS One. 2012;7(2):e31037.

123. Hanukoglu I. Electron transfer proteins of cytochrome P450 systems. Adv Mol Cell Biol. 1996;14:29-56.

124. Feyereisen R. Insect P450 enzymes. Annu Rev Entomol. 1999:44:407-33.

125. Scott JG. Investigating mechanisms of insecticide resistance: methods, strategies, and pitfalls. In: Roush RT, Tabashnik BE, editors. Pesticide resistance in arthropods. New York and London: Chapman and Hall; 1990. p. 39-57.

126. Hodgson E, Levi PE. Interactions of piperonyl butoxide with cytochrome P450. In: Jones DG, editor. Piperonyl butoxide: the insecticide synergist. London: Academic Press; 1998. p. 41-53.

127. Lilly DG, Dang K, Webb CE, Doggett SL. Evidence for metabolic pyrethroid resistance in the common bed bug (Hemiptera: Cimicidae). J Econ Entomol. 2016;109:1364-68.

128. Romero A, Potter MF, Haynes KF. Evaluation of piperonyl butoxide as a deltamethrin synergist for pyrethroid-resistant bed bugs. J Econ Entomol. 2009;102:2310-5.

129. How YF, Lee CY. Surface contact toxicity and synergism of several insecticides against different stages of the tropical bed bug, Cimex hemipterus (Hemiptera: Cimicidae). Pest Manag Sci. 2011;67:734-40.

130. Achaleke J, Martin T, Ghogomu RT, Vaissayre M, Brevault T. Esterasemediated resistance to pyrethroids in field populations of Helicoverpa armigera (Lepidoptera: Noctuidae) from Central Africa. Pest Manag Sci. 2009;65:1147-54.

131. Hotelier $T$, Nègre $V$, Marchot $P$, Chatonnet $A$. Insecticide resistance through mutations in cholinesterases or carboxylesterases: data mining in the ESTHER database. J Pestic Sci. 2010;35:315-20.

132. Bass C, Field LM. Gene amplification and insecticide resistance. Pest Manag Sci. 2011;67:886-90.

133. Bass C, Puinean AM, Zimmer CT, Denholm I, Field LM, Foster SP, et al. The evolution of insecticide resistance in the peach potato aphid, Myzus persicae. Insect Biochem Mol Biol. 2014;51:41-51.

134. Punta M, Coggill PC, Eberhardt RY, Mistry J, Tate J, Boursnell C, et al. The Pfam protein families databases. Nucleic Acids Res. 2012:40:D290-301.

135. Montella IR, Schama R, Valle D. The classification of esterases: an important gene family involved in insecticide resistance - A review. Mem Inst Oswaldo Cruz. 2012;107:437-49.

136. Hardstone MC, Strycharz JP, Kim J, Park I, Yoon KS, Ahn YJ, et al. Development of multifunctional metabolic synergists to suppress the evolution of resistance against pyrethroids in insects that blood feed on humans. Pest Manag Sci. 2015;76:842-9.

137. Newcomb RD, Campbell PM, Ollis DL, Cheah E, Russell RJ, Oakeshott JG. A single amino acid substitution converts a carboxylesterase to an organophosphorus hydrolase and confers insecticide resistance on a blowfly. Proc Natl Acad Sci U S A. 1997;94:7464-8.

138. Claudianos C, Russell RJ, Oakeshott JG. The same amino acid substitution in orthologous esterases confers organophosphate resistance on the house fly and a blowfly. Insect Biochem Mol Biol. 1999;29:675-86.

139. Soderlund DM, Bloomquist JR. Molecular mechanisms of insecticide resistance. In: Roush RT, Tabashnik BE, editors. Pesticide resistance in arthropods. New York and London: Chapman and Hall; 1991. p. 58-96.

140. Habig WH, Pabst MJ, Jakoby WB. Glutathione S-transferases. The first enzymatic step in mercapturic acid formation. J Biol Chem. 1974;249:7130-9.

141. Enayati AA, Ranson H, Hemingway J. Insect glutathione transferases and insecticide resistance. Insect Mol Biol. 2005;14:3-8.

142. Clark AG, Shamaan NA. Evidence that DDT-dehydrochlorinase from the house fly is a glutathione S-transferase. Pestic Biochem Physiol. 1984;22:249-61.

143. Riveron JM, Yunta C, Ibrahim SS, Djouaka R, Irving H, Menze BD, et al. A single mutation in the GSTe2 gene allows tracking of metabolically based insecticide in a major malaria vector. Genome Biol. 2014;15:R27.

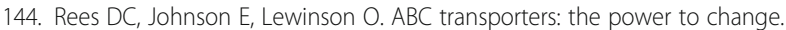
Nat Rev Mol Cell Biol. 2009;10:218-27.

145. Labbe R, Caveney S, Donly C. Genetic analysis of the xenobiotic resistance associated ABC gene subfamilies of the Lepidoptera. Insect Mol Biol. $2011 ; 20: 243-56$ 
146. Dermauw W, Leeuwen TV. The ABC gene family in arthropods: comparative genomics and role in insecticide transport and resistance. Insect Biochem Mol Biol. 2014;45:89-110.

147. Heong KL, Tan KH, Garcia CPF, Liu Z, Lu Z. Research methods in toxicology and insecticide resistance monitoring of rice planthoppers. 2nd ed. International Rice Research Institute: Los Banos; 2013.

148. Gorbel V, N'Guessan R. Distribution, mechanisms, impact and management of insecticide resistance in malaria vectors: a pragmatic review. In: Manguin S, editor. Anopheles mosquitoes - new insights into malaria vectors. Rijeka: InTech; 2013. doi:10.5772/56117.

149. Catterall WA. From ionic currents to molecular mechanisms: the structure and function of voltage-gated sodium channels. Neuron. 2000;26:13-25.

150. Davies TGE, Williamson MS. Interactions of pyrethroids with the voltagegated sodium channel. Bayer CropScience Journal. 2009;62:159-78.

151. Busvine JR. Mechanism of resistance to insecticide in houseflies. Nature. 1951;168:193-5.

152. Davies TGE, O'Reilly AO, Field LM, Wallace BA, Williamson MS. Knockdown resistance to DDT and pyrethroids: from target-site mutations to molecular modelling. Pest Manag Sci. 2008;64:1126-30.

153. Loughney K, Kreber R, Ganetzky B. Molecular analysis of the para locus, a sodium channel gene in Drosophila. Cell. 1989;58:1143-54.

154. Williamson MS, Martinez-Torres D, Hick CA, Devonshire AL. Identification of mutations in the housefly para-type sodium channel gene associated with knockdown resistance ( $k d r$ ) to pyrethroid insecticides. Mol Gen Genet. 1996;252:51-60

155. Vais H, Williamson MS, Goodson SJ, Devonshire AL, Warmke JW, Usherwood PN, et al. Activation of Drosophila sodium channels promotes modification by deltamethrin reductions in affinity caused by knock-down resistance mutations. J Gen Physiol. 2000;115:305-18.

156. Yoon KS, Kwon DH, Strycharz JP, Hollingsworth CS, Lee SH, Clark JM. Biochemical and molecular analysis of deltamethrin resistance in the common bed bug (Hemiptera: Cimicidae). J Med Entomol. 2008:45:1092-101.

157. Zhu F, Wigginton J, Romero A, Moore A, Ferguson K, Palli R, et al. Widespread distribution of knockdown resistance mutations in the bed bug, Cimex lectularius (Hemiptera: Cimicidae), populations in the United States. Arch Insect Biochem Physiol. 2010;73:245-57.

158. Durand R, Cannet A, Berdjane Z, Bruel C, Haouchine D, Delaunay P, et al. Infestation by pyrethroids resistant bed bugs in the suburb of Paris, France. Parasite. 2012;19:381-7.

159. Vander Pan A, Kuhn C, Schmolz E, Klasen J, Krucken J, Samon-Himmelstjerna GV. Studies on pyrethroid resistance in Cimex lectularius (Hemiptera: Cimicidae), in Berlin, Germany. In: Muller G, Pospischil R, Robinson WH, editors. Proceedings of the 8th International Conference on Urban Pests, Zurich, Switzerland, 20 to 23 July 2014. Pápai: OOK-Press; 2014. p. 89-95.

160. Palenchar DJ, Gellatly KJ, Yoon KS, Mumcuoglu KY, Shalom U, Clark JM. Quantitative sequencing for the determination of $k d r$-type resistance allele (V419L, L925I, 1936F) frequencies in common bed bug (Hemiptera: Cimicidae) populations collected from Israel. J Med Entomol. 2015;52:1018-27.

161. Usherwood PNR, Davies TGE, Mellor IR, O'Reilly AO, Peng F, Vais $H$, et al. Mutations in DII5 and the DIIS4-S5 linker of Drosophila melanogaster sodium channel define binding domains for pyrethroids and DDT. FEBS Lett. 2007;581:5485-92.

162. Seong KM, Lee DY, Yoon KS, Kwon DH, Kim HC, Klein TA, et al. Establishment of quantitative sequencing and filter contact vial bioassay for monitoring pyrethroid resistance in the common bed bug, Cimex lectularius. J Med Entomol. 2010;47:592-9.

163. Ranson H, N'guessan R, Lines J, Moiroux N, Nkuni VZ, Corbel V. Pyrethroid resistance in African anopheline mosquitoes: what are the implications for malaria control? Trends Parasitol. 2011;27:91-8.

164. Schapira A. DDT: a polluted debate in malaria control. Lancet. 2006;368:2111-3.

165. Fournier D, Bride JM, Hoffmann F, Karch F. Acetylcholinesterase, two types of modification confer resistance to insecticides. J Biol Chem. 1992;267:14270-4

166. Corbett JR. The biochemical mode of action of pesticides. London: Academic Press; 1974.

167. Hemingway J, Georghiou GP. Studies on the acetylcholinesterase of Anopheles albimanus resistant and susceptible to organophosphate and carbamate insecticides. Pestic Biochem Physiol. 1983;19:167-71.

168. Seong KM, Kim YH, Kwon DH, Lee SH. Identification and characterization of three cholinesterases from the common bed bug, Cimex lectularius. Insect Mol Biol. 2012;21:149-59
169. Hall JC, Kankel DR. Genetics of acetylcholinesterase in Drosophila melanogaster. Genetics. 1976;83:517-35.

170. Fournier D. Mutations of acetylcholinesterase which confer insecticide resistance in insect populations. Chem Biol Interact. 2005;157-1588:257-61.

171. Mutero A, Pralavorio M, Bride JM, Fournier D. Resistance-associated point mutations in insecticide-insensitive actylcholinesterase. Proc Natl Acad Sci U S A. 1994;91:5922-6.

172. Fournier D, Mutero A. Modification of acetylcholinesterase as a mechanism of resistance to insecticides. Comp Biochem Physiol C Pharmacol Toxicol Endocrinol. 1994;108:19-31.

173. Russell RJ, Claudianos C, Campbell PM, Horne I, Sutherland TD, Oakeshotta JG. Two major classes of target site insensitivity mutations confer resistance to organophosphate and carbamate insecticides. Pestic Biochem Physiol. 2004;79:84-93.

174. Hwang CE, Kim YH, Kwon DH, Seong KM, Choi JY, Je YH, et al. Biochemical and toxicological properties of two acetylcholinesterases from the common bed bug, Cimex lectularius. Pestic Biochem Physiol. 2014;110:20-6.

175. Cole LM, Nicholson RA, Casida J. Action of phenylpyrazole insecticides at the GABA-Gated chloride channel. Pestic Biochem Physiol. 1993;46:47-54.

176. Bloomquist JR. Cyclodiene resistance at the insect GABA receptor/chloride channel complex confers broad cross resistance to convulsants and experimental phenylpyrazole insecticides. Arch Insect Biochem Physiol. 1994;26:69-79.

177. Buckingham SD, Biggin PC, Sattelle BM, Brown LA, Sattelle DB. Insect GABA receptors: splicing, editing, and targeting by antiparasitics and insecticides. Mol Pharmacol. 2005;68:942-51.

178. Ang LH, Nazni WA, Kuah MK, Shu-Chien AC, Lee CY. Detection of the A302S Rdl Mutation in fipronil bait-selected strains of the German cockroach (Dictyoptera: Blattellidae). J Econ Entomol. 2013;106:2167-76.

179. Ffrench-Constant RH, Rocheleau TA, Steichen JC, Chalmers AE. A point mutation in a Drosophila GABA receptor confers insecticide resistance. Nature. 1993;363:449-51.

180. Du W, Awolola TS, Howell P, Koekemoer LL, Brooke BD, Benedict MQ, et al. Independent mutations in the $R d$ locus confer dieldrin resistance to Anopheles gambiae and An. arabiensis. Insect Mol Biol. 2005;14:179-83.

181. Ffrench-Constant RH, Anthony N, Aronstein K, Rocheleau T, Stilwell G. Cyclodiene insecticide resistance: from molecular to population genetics. Annu Rev Entomol. 2000;45:449-66

182. Wondji CS, Dabire RK, Tukur Z, Irving H, Djouaka R, Morgan JC. Identification and distribution of a GABA receptor mutation conferring dieldrin resistance in the malaria vector Anopheles funestus in Africa. Insect Biochem Mol Biol. 2011:41:484-91.

183. Bai D, Lummis SCR, Leicht W, Breer H, Satelle DB. Actions of imidacloprid and related nitromethylene on cholinergic receptors of an identified insect motor neuron. Pestic Sci. 1991;33:197-204.

184. Crossthwaite A, Rendine S, Stenta M, Slater R. Target-site resistance to neonicotinoids. J Chem Biol. 2014;7:125-8.

185. Koo HN, An JJ, Park SE, Kim Jl, Kim GH. Regional susceptibilities to 12 insecticides of melon and cotton aphid, Aphis gossypii (Hemiptera: Aphididae) and a point mutation associated with imidacloprid resistance. Crop Prot. 2014;55:91-7.

186. Bass C, Puinean AM, Andrews MC, et al. Mutation of a nicotinic acetylcholine receptor $\beta$ subunit is associated with resistance to neonicotinoid insecticides in the aphid Myzus persicae. BMC Neurosci. 2011;12:51.

187. Moya A, Peretó J, Gil R, Latorre A. Learning how to live together: genomic insights into prokaryote-animal symbioses. Nat Rev Genet. 2008:9:218-29.

188. Hosokawa T, Koga R, Kikuchi Y, Meng XY, Fukatsu T. Wolbachia as a bacteriocyte-associated nutritional mutualist. Proc Natl Acad Sci U S A. 2009;107:769-74.

189. Kikuchi Y, Hayatsu M, Hosokawa T, Nagayama A, Tago K, Fukatsu T. Symbiont-mediated insecticide resistance. Proc Natl Acad Sci U S A. 2012; 109:8618-22.

190. Tago K, Kikuchi Y, Nakaoka S, Katsuyama C, Hayatsu M. Insecticide applications to soil contribute to the development of Burkholderia mediating insecticide resistance in stinkbugs. Mol Ecol. 2015;24:3766-78.

191. Singh BK. Organophosphorus-degrading bacteria: ecology and industrial applications. Nat Rev Microbiol. 2009;7:156-64.

192. Broderick NA, Raffa KF, Handelsman J. Midgut bacteria required for Bacillus thuringiensis insecticidal activity. Proc Natl Acad Sci U S A. 2006;103:15196-9. 
193. Oliver KM, Russell JA, Moran NA, Hunter MS. Facultative bacterial symbionts in aphids confer resistance to parasitic wasps. Proc Natl Acad Sci U S A. 2003;100:1803-7.

194. Ghanim M, Kontsedalov S. Susceptibility to insecticides in the Q biotype of Bemisia tabaci is correlated with bacterial symbiont densities. Pest Manag Sci. 2009;65:939-42.

195. Hypsa V, Aksoy S. Phylogenetic characterization of two transovarially transmitted endosymbionts of the bedbug Cimex lectularius (Heteroptera: Cimicidae). Insect Mol Biol. 1997;6:301-4.

196. Sakamoto JM, Rasgon JL. Endosymbiotic bacteria of bed bugs: evolution, ecology and genetics. Am Entomol. 2006:52:119-22.

197. Benoit JB, Adelman ZN, Reinhardt K, et al. Unique features of a global human ectoparasite identified through sequencing of the bed bug genome. Nat Commun. 2016;7:10165

198. Arkwright JA, Atkin EE, Bacot A. An hereditary Rickettsia-like parasite of the bed bug (Cimex lectularius). Parasitology. 1921;13:27-36.

199. WHO. Manual on Practical Entomology in Malaria, part II, Methods and Techniques. Geneva: World Health Organization; 1975.

200. WHO. Instructions for determining the susceptibility or resistance of adult bedbugs to insecticides, WHO/NBC/81.809. 1981.

201. Barile J, Nauen R, Nentwig G, Pospischil R, Reid B. Laboratory and field evaluation of deltamethrin and bendiocarb to control Cimex lectularius (Heteroptera: Cimicidae). In: Robinson WH, Bajomi D, editors. Proceedings of the 6th International Conference on Urban Pests, Budapest, Hungary, 13 to 16 July 2008. Pápai: OOK-Press; 2008. p. 105-11.

202. Fletcher MG, Axtell RC. Susceptibility of the bedbug, Cimex lectularius, to selected insecticides and various treated surfaces. Med Vet Entomol. 1993;7:69-72.

203. WHO. Techniques to detect insecticide resistance mechanisms (field and laboratory manual), WHO/CDS/CPC/MAL/98.6. 1998.

204. Bass C, Nikou D, Donnelly MJ, Williamson MS, Ranson H, Ball A, et al. Detection of knockdown resistance ( $k d r)$ mutations in Anopheles gambiae: a comparison of two new high-throughput assays with existing methods. Malar J. 2007;6:111.

205. Boase C. Bedbugs - back from the brink. Pestic Outlook. 2001;12:159-62.

206. Khan HR, Rahman MM. Morphology and biology of the bed bug, Cimex hemipterus (Hemiptera: Cimicidae) in the laboratory. Dhaka Univ J Biol Sci. 2012;21:125-30.

207. Wang $L, X u Y$, Zeng $L$. Resurgence of bed bugs (Hemiptera: Cimicidae) in Mainland China. Fla Entomol. 2013;96:131-6.

208. Wang $L$, Cai $X, X u$ Y. Status of urban bed bug infestations in Southern China: an analysis of pest control service records in Shenzhen in 2012 and Dongguan in 2013. J Med Entomol. 2015;52:76-80.

209. Miller D. Bed bugs (Hemiptera: Cimicidae). In: Capinera JL, editor. Encyclopedia of entomology. 2nd ed. New York: Springer; 2008. p. 405-17.

210. Haghi SFM, Behbodi M, Hajati H, Shafaroudi MM. Prevalence of bed bug (Cimex lectularius) in human settlement area of Bahnamir, Iran. Asian Pac J Trop Dis. 2014;4(Suppl 2):786-9.

211. Mumcuoglu KY. A case of imported bed bug (Cimex lectularius) infestation in Israel. Isr Med Assoc J. 2008;10:388-9.

212. Mumcuoglu KY, Shalom U. Questionnaire survey of common bedbug (Cimex lectularius) infestations in Israel. Isr J Entomol. 2010;40:1-10.

213. Hirao M. Recent resurgence of bedbug and its management. Med Entomol Zool. 2010;61:211-21.

214. El-Azazy OME, AL-Behbehani B, Abdou NMI. Increasing bedbug, Cimex lectularius, infestations in Kuwait. J Egypt Soc Parasitol. 2013;43:415-8.

215. How YF, Lee CY. Survey of bed bugs in infested premises in Malaysia and Singapore. J Vector Ecol. 2010;35:89-94.

216. Majid AHA, Zahran Z. Resurgence of tropical bed bug, Cimex hemipterus (Hemiptera: Cimicidae) infestation in Malaysia: control strategies and challenges faced by urban pest control operator (PCO). J Entomol Zool Stud. 2015;3:419-22.

217. Zulaikha Z, Hafiz AMA, Hafis ARA, Hassan AA. A survey on the infestation levels of tropical bed bugs in Peninsular Malaysia: current updates and status on resurgence of Cimex hemipterus (Hemiptera Cimicidae). Asian Pac J Trop Dis. 2016:6:40-5.

218. Nisar M, Shah SMM, Khan I, Sheema, Sadiq A, Khan S, et al. Larvicidal, insecticidal, brine shrimp cytotoxicity and anti-oxidant activities of Diospyros kaki (L.) reported from Pakistan. Pak J Pharm Sci. 2015;28:1239-43.

219. Lee IY, Ree H, An SJ, Linton JA, Yong TS. Reemergence of the bedbug Cimex lectularius in Seoul, Korea. Korean J Parasitol. 2008;46:269-71.
220. Nanoudon S, Chanbang Y. Use of solid carbon dioxide for controlling bed bugs Cimex hemipterus (Fabricius) under laboratory conditions, Bangkok. Bangkok: Joint International Tropical Medicine Meeting; 2014. p. 55-61

221. Karunamoorthi K, Beyene B, Ambelu A. Prevalence, knowledge and selfreported containment practices about bedbugs in the resource-limited setting of Ethiopia: a descriptive cross-sectional survey. Health. 2015;7:1142-57.

222. Omudu EA, Kuse CN. Bedbug infestation and its control practices in Gbajimba: a rural settlement in Benue state, Nigeria. J Vector Borne Dis. 2010;47:222-7.

223. Emmanuel Ol, Cyrian A, Agbo OE. A survey of bedbug (Cimex lectularius) infestation in some homes and hostels in Gboko, Benue State, Nigeria. Psyche. 2014:Article ID 762704, 5 pages. doi:10.1155/2014/762704.

224. Angelakis E, Socolovschi C. Short report: Bartonella quintana in Cimex hemipterus, Rwanda. Am J Trop Med Hyg. 2013;89:986-7.

225. Kweka EJ, Mwang'onde BJ, Kimaro EE, Msangi S, Tenu F, Mahande AM. Insecticides susceptibility status of the bedbugs (Cimex lectularius) in a rural area of Magugu, Northern Tanzania. J Global Infect Dis. 2009:1:102-6.

226. Nalwanga E, Ssempebwa JC. Knowledge and practices of in-home pesticide use: a community survey in Uganda. J Environ Public Health. 2011;2011:230894.

227. Faundez El, Carvajal MA. Bed bugs are back and also arriving is the southernmost record of Cimex lectularius (Heteroptera: Cimicidae) in South America. J Med Entomol. 2014;51:1073-6.

228. Nascimento L. Investigation of occurrence of infestation by Cimicidae (Heteroptera: Cimicomorpha) in the metropolitan region of São Paulo, in the period 2004-2009 (Masters dissertation). São Paulo: Universidade de São Paulo; 2010. (In Portuguese)

229. Criado PR, Belda W, Criado RFJ, Silva RVE, Vasconcellos C. Bed bugs (Cimicidae infestation): the worldwide renaissance of an old partner of human kind. Braz J Infect Dis. 2011;15:74-80.

230. Bernardes Filho F, Quaresma MV, Avelleira JCR, Azulay DR, Azulay-Abulafia L, Bastos $A Q$, et al. Bed bug dermatitis, description of two cases in Rio de Janeiro, Brazil. An Bras Dermatol. 2015;90:240-3.

231. Myles T, Brown B, Bedard B, Bhooi R, Bruyere K, Chua AL, et al. Bed bugs in Toronto. University of Toronto, Centre for Urban and Community Studies Research Bulletin. 2003;19:1-4.

232. Hwang SW, Svoboda TJ, Jong IJD, Kabasele KJ, Gogosis E. Bed bug infestations in an urban environment. Emerg Infect Dis. 2005;11:533-8.

233. Posso CE, Wolff Ml, de Ulloa PC. The bed bugs Cimex lectularius: urban problem in the Andean region of Colombia. In: Robinson WH, Carvalho Campos $A E$, editors. Proceedings of the 7 th International Conference on Urban Pests, Ouro Preto, Brazil, 7 to 10 July 2011, vol. 2011. São Paulo: Instituto Biológico. p. 371.

234. Salazar R, Castillo-Neyra R, TustinAW B-MK, Náquira C, Levy MZ. Bed bugs (Cimex lectularius) as vectors of Trypanosoma cruzi. Am J Trop Med Hyg. 2015:92:331-5.

235. Potter MF. The perfect storm: an extension view on bed bugs. Am Entomol. 2006:52:102-4

236. Alalawi AH. Bed bugs epidemic in the United States. Entomol Ornithol Herpetol. 2015;4:143.

237. Reyes-Lugo M, Rodríguez-Acosta A. Is the infestation by bedbug (Cimex lectularius Linnaeus, 1758) extinct in Venezuela? Rev Científ FCV-LUZ. 2002;12:182-5.

238. Sadílek D, Štáhlavský F, Vilímová J, Zima J. Extensive fragmentation of the $X$ chromosome in the bed bug Cimex lectularius Linnaeus, 1758 (Heteroptera, Cimicidae): a survey across Europe. Comp Cytogenet. 2013;7:253-69.

239. Kilpinen O, Jensen KMV, Kristensen M. Bed bug problems in Denmark, with a European perspective. In: Robinson WH, Bajomi D, editors. Proceedings of the 6th International Conference on Urban Pests, Budapest, Hungary, 13 to 16 July 2008. Pápai: OOK-Press; 2008. p. 395-9.

240. Levy Bencheton A, Berenger JM, Del Giudice P, Delaunay P, Pages F, Morand JJ. Resurgence of bedbugs in southern France: a local problem or the tip of the iceberg? J Eur Acad Dermatol Venereol. 2011;25:599-602.

241. Akhoundi M, Kengne P, Cannet A, Brengues C, Berenger J, Izri A, et al. Spatial genetic structure and restricted gene flow in bed bugs (Cimex lectularius) populations in France. Infect Genet Evol. 2015;34:236-43.

242. Seidel C, Reinhardt K. Bugging forecast: Unknown, disliked, occasionally intimate. Bed bugs in Germany meet unprepared people. PLoS One. 2013;8:e51083.

243. Kuhn C, Vander PA. The worldwide expansion of bed bugs also constitutes a problem in Germany. Bundesgesundheitsblatt Gesundheitsforschung Gesundheitsschutz. 2014;57:524-30. 
244. Vander PA. Studies on the pyrethroid resistance in the bed bug, Cimex lectularius in Berlin, Germany (PhD Dissertation). Berlin: Free University Berlin; 2015.

245. Papp G, Madaczki L, Bajomi D. Occurrence of bed bug in Budapest, Hungary. In: Muller G, Pospischil R, Robinson WH, editors. Proceedings of the 8th International Conference on Urban Pests, Zurich, Switzerland, 20 to 23 July 2014. Pápai: OOK-Press; 2014. p. 81-8.

246. Masetti M, Bruschi F. Bedbug infestations recorded in Central Italy. Parasitol Int. 2007:56:81-3.

247. Giorda F, Guardone L, Mancini M, Accorsi A, Macchioni F, Mignone W. Cases of bed bug (Cimex lectularius) infestations in northwest Italy. Vet Ital. 2013:49:335-40

248. Roslavtseva SA. Bed bugs - the problem in Russia, In: Robinson WH, Carvalho Campos AE, editors. Proceedings of the 7th International Conference on Urban Pests, Ouro Preto, Brazil, 7 to 10 July 2011. São Paulo: Instituto Biológico; 2011. p. 372.

249. Roslavtseva SA, Alekseev MA, Polupanov DA. The problem of increasing the number of bed bugs in the world and their resistance to insecticides. Proceeding of the International Conference in Memoriam of Prof. Yuri S. Balashov, a Corresponding Member of the RAS: "Fundamental and Applied Aspects of the Study of Parasitic Arthropods in the XXI Century", St. Petersburg, Russia, 21 to 25 October, 2013. 2013. p. 135-137.

250. Mueller G, Luescher IL, Schmidt M. Temporal changes in the incidence of household arthropod pests in Zurich, Switzerland. In: Robinson WH, Bajomi D, editors. Proceedings of the 6th International Conference on Urban Pests, Budapest, Hungary, 13 to 16 July 2008. Pápai: OOK-Press; 2008. p. 15-21.

251. Boase C. Bed bug (Hemiptera: Cimicidae): an evidence-based analysis of the current situation. In: Robinson WH, Bajomi D, editors. Proceedings of the 6th International Conference on Urban Pests, Budapest, Hungary, 13 to 16 July 2008. Pápai: OOK-Press; 2008. p. 8-14.

252. Doggett SL, Geary MJ, Crowe WJ, Wilson P, Russell RC. Has the tropical bed bug, Cimex hemipterus (Hemiptera: Cimicidae), invaded Australia? Environ Health. 2003;3:80-2.

253. Doggett SL, Geary MJ, Russell RC. The resurgence of bed bugs in Australia, with notes on their ecology and control. Environ Health. 2004:4:30-8.

254. Norah L. Dealing with bed bugs when travelling. 2012. http://www. findingtheuniverse.com/2012/03/dealing-with-bed-bugs-as-traveller.html. Accessed 1 Mar 2017.

255. Livadas GA. Do anophelines acquire resistance to DDT? 1951. (unpublished working document WHO/Mal/74)

256. Livadas GA, Georgopoulos G. Development of resistance to DDT by Anopheles sacharovi in Greece. Bull World Health Organ. 1953;8:497-511.

257. Hess AD. Current status of insecticide resistance in insects of public health importance. Am J Trop Med Hyg. 1953;2:311-8.

258. Simmons SW. Public health significance of insect resistance to insecticides and future orientation of vector control programmes. Document EUR/ Insects/6 of WHO Symposium on the Control of Insect Vectors of Disease, October 26-31, Rome; 1953. p. 33.

259. Levinson $\mathrm{HZ}$. The control of bed bugs (Cimex lectularius L.) with DDT and GBH in Israel. Riv Parassitol. 1953;14:233-4.

260. Gratz NG. A survey of bed-bug resistance to insecticides in Israel. Bull World Health Organ. 1959;20:835-40.

261. Floch H. Dédétérésistances. Archives de l'Institut Pasteur de la Guyane et du Territoire de l'Inini. 1956:365:152-3.

262. Mofidi C, Samimi B. Preliminary experiments on the susceptibility of Cimex lectularius to insecticides in Tehran. Institute of Parasitology and Malariology, Tehran. Mimeograph document. 1956; May: 5 pp.

263. Cwilich R, Mer GG, Meron AV. Bedbugs resistant to gamma-BHC (Lindane) in Israel. Nature. 1957;179:636-7.

264. Busvine JR. Recent progress in the eradication of bed bugs. Sanitarian. 1957; 65:365-9.

265. Quarterman KD, Schoof HF. The status of insecticide resistance in arthropods of public health importance in 1956. Am J Trop Med Hyg. 1958;7:74-83.

266. Lofgren CS, Keller JC, Burden GS. Resistance tests with bed bug and evaluation of insecticides for its control. J Econ Entomol. 1958;51:241-4.

267. Brown AWA. Report on a visit to eastern European countries. World Health Organization. 1959;WHO/Insecticides/99. (Mimeographed document).

268. Reid ET. Insecticide resistance. Cent Afr J Med. 1960;6:528-34.

269. Sharma MID, Mohan BN, Singh NN. Further observations on the technique for quantitative estimation of susceptibility of bed-bugs to contact insecticides. Indian J Malariol. 1962;16:1-16.
270. Whitehead GB. A study of insecticide resistance in a population of bed bugs, Cimex lectularius L., and a method of assessing effectiveness of contro measures in houses. J Entomol Soc S Afr. 1962;25:121-7.

271. Sharma MID. Studies on the susceptibility of bed-bugs to DDT, Dieldrin and Diazinon in Gaza. World Health Organization. 1963;WHONector Control/48.

272. Radwan WA, Guneidy AM, Soliman AA. On the susceptibility of the bed bug, Cimex lectularius L. to insecticides. Bull Entomol Soc Egypt Econ Ser. 1972;6:73-7.

273. Ewers WH. Parasites of man in Papua-New Guinea. Southeast Asian J Trop Med Public Health. 1972;3:79-86.

274. Chen HH, Tseng PT, Pletsch DJ. DDT resistant bedbugs (Cimex hemipterus Fabr.) found in an army camp in southern Taiwan, China. J Formos Med Assoc. 1956;55:143-8.

275. Rao TR, Halgari AV. A note on resistance of bed bugs to DDT in Bombay State. Indian J Malariol. 1956:10:149-54.

276. Smith A. Dieldrin-resistance in Cimex hemipterus Fabricius in the Pare Area of North-East Tanganyika. Bull World Health Organ. 1958;19:1124-5.

277. Gratz NG. Insecticide resistance in bed-bugs and flies in Zanzibar. Bull World Health Organ. 1961;24:668-70.

278. Armstrong JA, Bransby-Williams WR, Huddleston JA. Resistance to dieldrin of Cimex hemipterus (Fabricius). Nature. 1962;193:499-501.

279. Bourke TV. Some aspects of insecticide application in malaria control programmes other than the effect on the insect vectors. Papua New Guinea Agric J. 1973;24:33-40.

280. Watanabe M. Insecticide susceptibility and effect of heat treatment on bedbug, Cimex lectularius. Med Entomol Zool. 2010;61:239-44.

281. Polanco AM, Miller DN, Brewster CC. Survivorship during starvation for Cimex lectularius L. Insects. 2011:2:232-42.

282. Polanco AM, Brewster CC, Miller DN. Population growth potential of the bed bug Cimex lectularius L.: a life table analysis. Insects. 2011;2:173-85.

283. Anderson JF, Cowles RS. Suceptibility of Cimex lectularius (Hemiptera: Cimicidae) to pyrethroid insecticides and to insecticidal dusts with or without pyrethroid insecticides. J Econ Entomol. 2012;105:1789-95.

284. Tahir HM, Malik HT. Susceptibility of Cimex lectularius L. (Heteroptera: Cimicidae) to Deltamethin. Pak J Zool. 2014;46:288-90.

285. Campbell BE, Miller DM. Insecticide resistance in eggs and first instars of the bed bug, Cimex lectularius (Hemiptera: Cimicidae). Insects. 2015;6:122-32.

286. Brogdon WG, Chan A. Guidelines for evaluating insecticide resistance in vectors using the CDC bottle bioassay. Ctr Dis Control Prev. 2010; https:// www.cdc.gov/malaria/resources/pdf/fsp/ir_manual/ir_cdc_bioassay_en.pdf. Accessed 30 Jun 2016

\section{Submit your next manuscript to BioMed Central and we will help you at every step:}

- We accept pre-submission inquiries

- Our selector tool helps you to find the most relevant journal

- We provide round the clock customer support

- Convenient online submission

- Thorough peer review

- Inclusion in PubMed and all major indexing services

- Maximum visibility for your research

Submit your manuscript at www.biomedcentral.com/submit 